\title{
تصور مقترح لتفعيل التعليم من أجل عالم متصل في منهج رياض الأطفال (·,
}

A suggested Framework for Activating Education for a Connected World in the Kindergarten

Curriculum (2.0)

$$
\text { أستاذ مناهج الطفل المسيم أحمد المنير }
$$

كلية التربية بالإسماعيلية-جامعة قناة السويس

\section{Randa Abdelaleem Ahmed Elmonayer}

Assistant Professor of Child Curriculum

Ismailia Faculty of Education

Suez Canal University

$$
\text { الاستشهاد المرجعى: }
$$

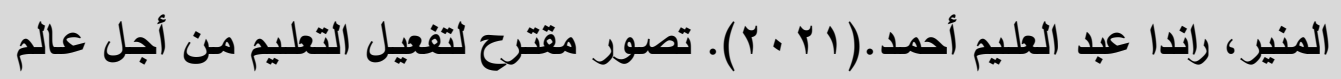

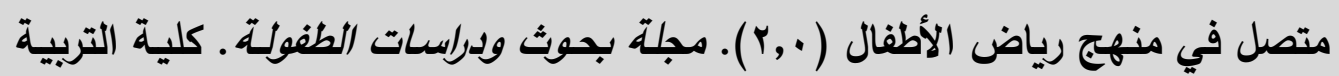

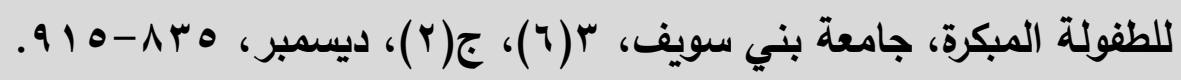


هدفت هذه الدراسة إلى إعداد تصور مقترح لتفعيل التعليم من أجل عالم متصل في منهج رياض

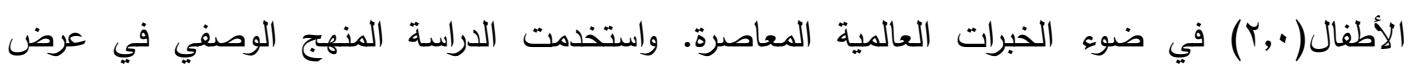

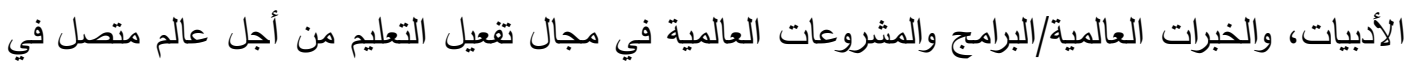

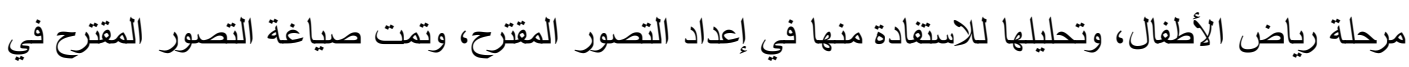

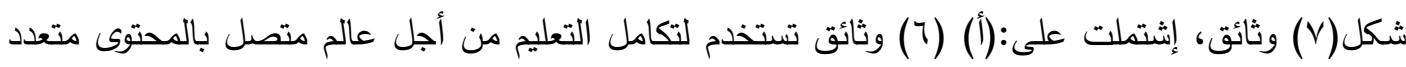

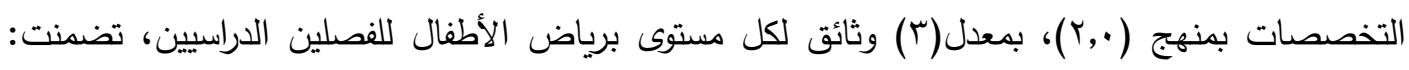

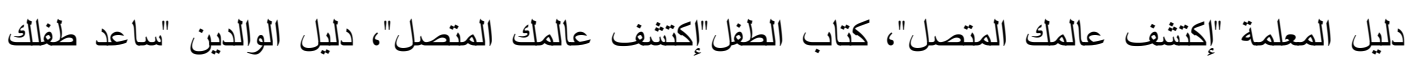

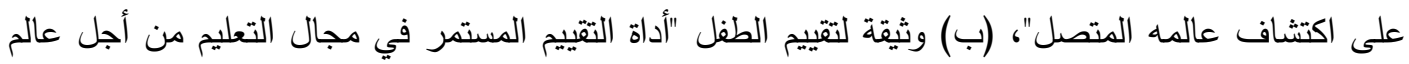

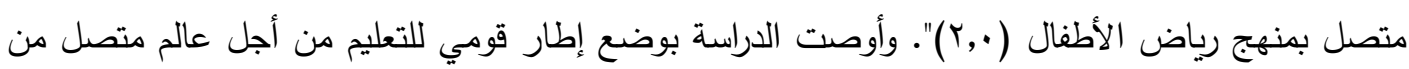

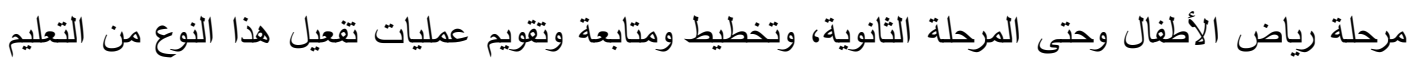

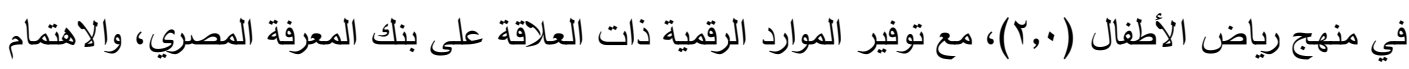

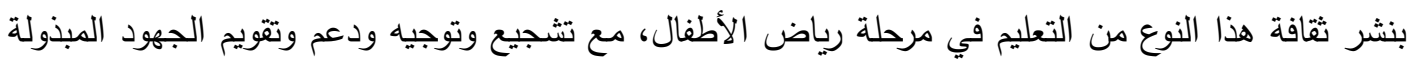

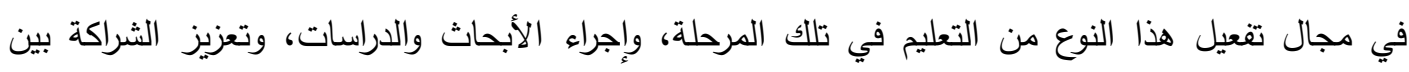

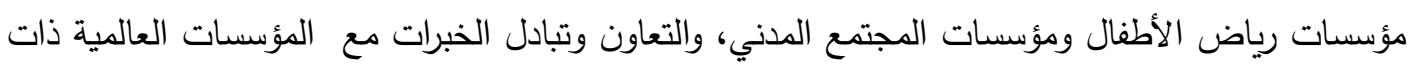
العلاقة، وتدريب معلمات الروضة قبل وأثناء الخدمة في مجال تفعيل هذا النوع من التعليم، مع الاهتمام بتفعيل هذا النوع من التعليم في المنهج ضمن معايير ضمان جودة واعتماد مؤسسات رياض ولثاء الأطفال.

الكلمات المفتاحية: تصور مقترح، التعليم من أجل عالم متصل، منهج رياض الأطفال (·,r). 


\section{Abstract:}

This study aimed to prepare a suggested framework for activating Education for a Connected World in the Kindergarten curriculum (2.0) in light of contemporary international experiences. The study used the descriptive approach in presenting the literature, international experiences /international programs and projects in the field of activating Education for a Connected World in the kindergarten stage, and analyzing them to benefit from them in preparing the suggested framework, the suggested framework was formulated in form of (7) documents include (a) (6) documents used for integrating Education for a Connected World into multidisciplinary content in the (2.0) curriculum, at a rate of (3) documents for each level in kindergarten for both semesters, which include: the teacher's guide "Discover your Connected World", the child's book "Discover your Connected World" and Parent's Guide" Help your Child Discover his Connected World ", and (b) A document for child assessment "Ongoing Assessment Tool for Education for a Connected World" in the Kindergarten curriculum (2.0). The study recommended setting up a national framework for Education for a Connected World from kindergarten to secondary education stage, planning, following up and evaluating the processes of activating this type of education in the Kindergarten curriculum (2.0), with providing relevant digital resources in the Egyptian Knowledge Bank, attention to spreading the culture of this type of education In the kindergarten stage, encouraging, directing, supporting and evaluating the efforts exerted in activating this type of education in this stage, conducting research and studies, strengthening the partnership between kindergarten institutions and civil society institutions, cooperating and exchanging experiences with relevant international institutions, and training pre-service and in-service kindergarten teachers in the field of activating this type of education, with attention to activating this type of education in the curriculum within the standards for quality assurance and accreditation of kindergarten institutions.

Keywords: Suggested framework, Education for a Connected World, Kindergarten curriculum (2.0). 
يشهذ العالم تطوراً متسارعاً في نظم الاتصالات، والتي جعلت العالم عالماً رقمياً

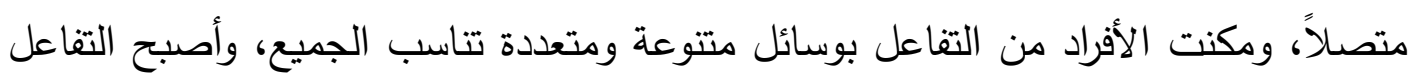

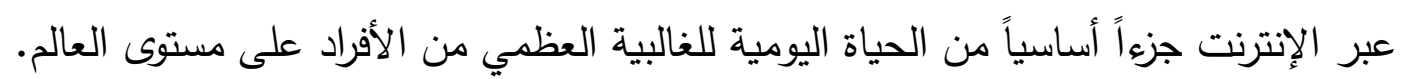
وظهرت الحاجة ملحة لحوار مهنى عالمي أوسع حول السلوك عبر الإنترنت

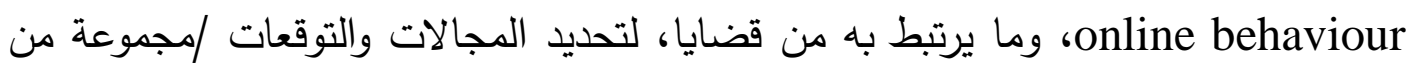

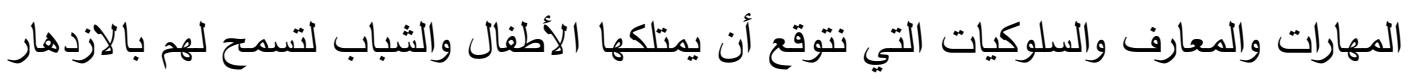

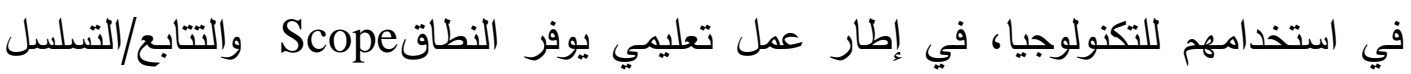
(UK Safer Internet Centre, Sequence (1) 2018 , pp.1-3)

وكنتاج لحوار مهني عالمي بمشاركة (T) منظمة عالمية حكومية وغير حكومية،

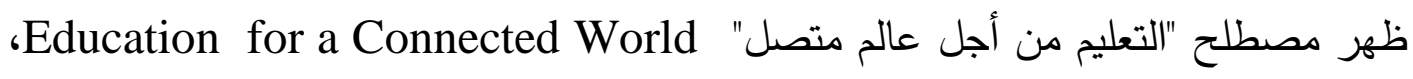

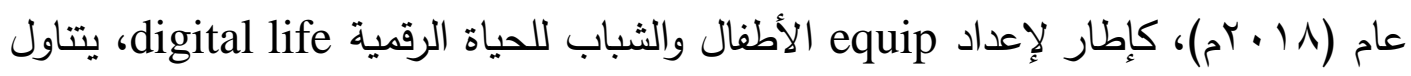

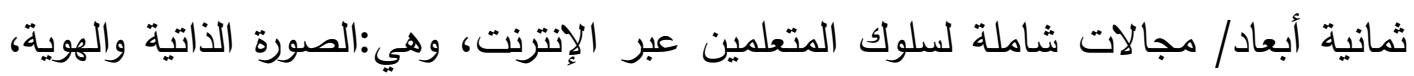

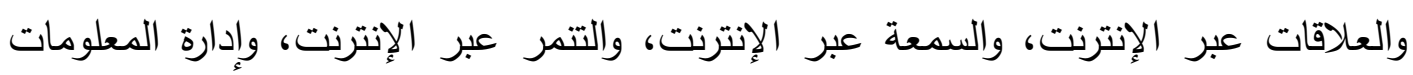

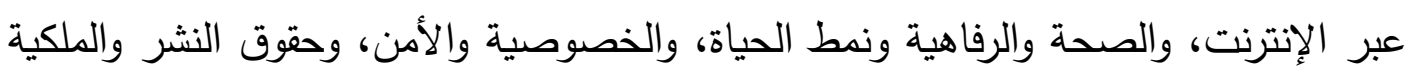
(UKCCIS, 2018, pp.1-3)

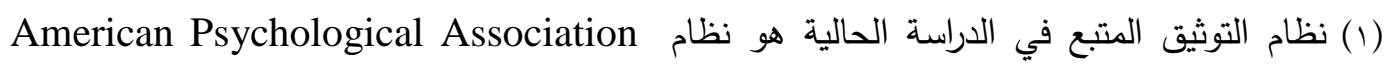

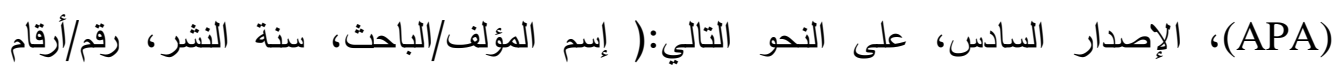
الصفحات)، وفقاً للدليل التالي: التصار: American Psychological Association (2010).Publication manual of the American Psychological Association 6 edition. Washington. DC 


\section{كلية التربية للطفولة المبكرة- جامعة بني سويف}

وعلى المستوى العالمي تشهد الفترة الحالية اهتماماً متزايداً بتفعيل "التعليم من أجل عالم متصل" Education for a Connected World في مرحلة الطفولة المبكرة بصفة خاصة، خاصة مع ظهور جائحة فيروس كورونا المستجد (COVID-19) العالمية، والتي شهدت زيادة في عدد الأطفال الملتحقين بعالم الإنترنت لأول مرة، لدعم دراساتهم والحفاظ

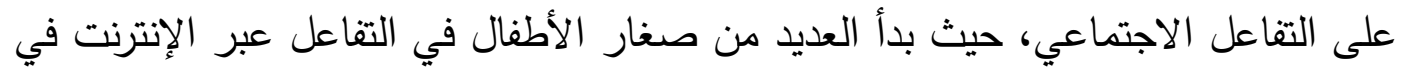
وقت أبكر بكثير مما كان يُخطط له (ITU, 2020, p.7) .

وفي ظل اهتمام الدولة المصرية بتطوير التعليم في مرحلة الطفولة المبكرة، وهو ما

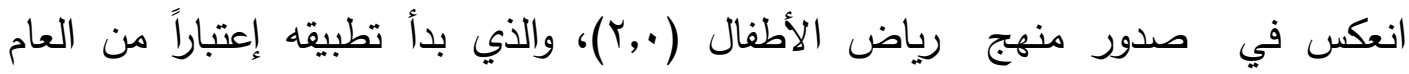

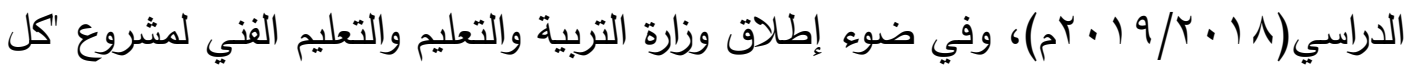

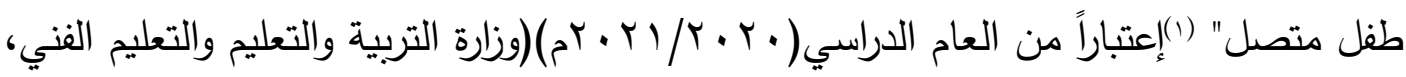

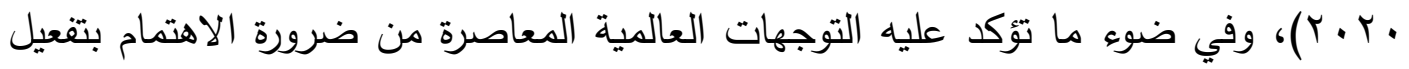

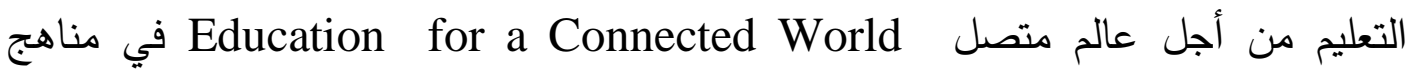

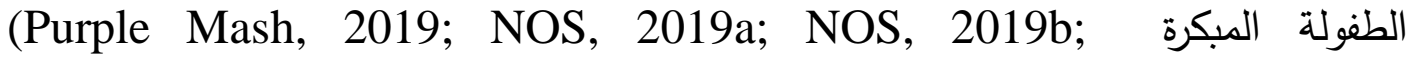
( SWGfL,2020) $\cdot(r, \cdot)$

ومن خلال دراسة استطلاعية قامت بها الباحثة للتعرف على واقع التعليم من أجل

عالم متصل Education for a Connected World في منهج رياض الأطفال (·, (Y)، تبين أن هذا النوع من التعليم مفهوم غائب في منهج رياض الأطفال (•,r(ب)، نظراً لحداثة

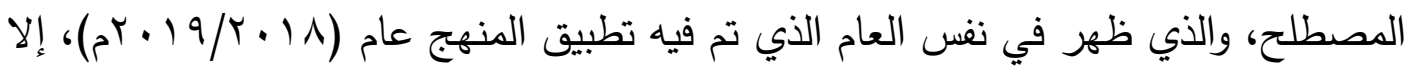

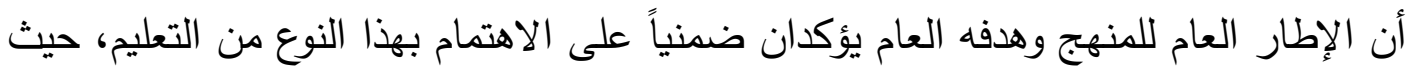

(1) مشروع يهدف إلى إتاحة الأجهزة الإلكترونية لمساعدة الأطفال على التعلم، بوجود تسهيلات لأولياء

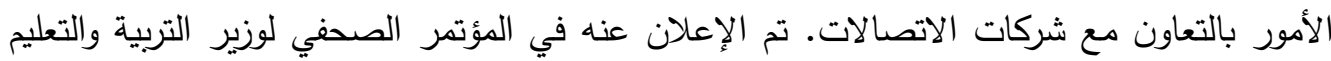

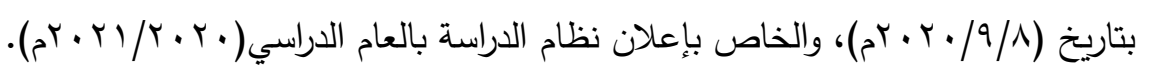

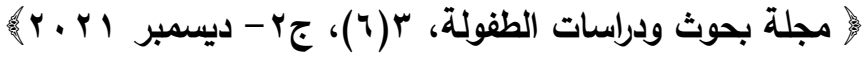


يعتمد الإطار العام للمنهج على المهارات الحياتية(')، والتحديات التي تواجه المجتمع المصري والعربي والعالمي(ז)، والاتجاهات التربوية الحديثة، وذلك بهدف الارتقاء بشخصية الطفل

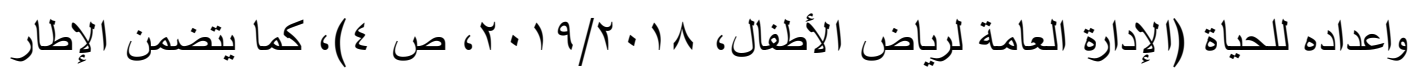

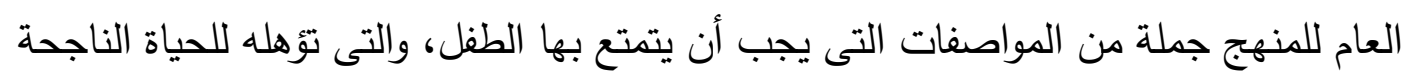
والعمل الكفه فى القرن الحادى والعشرين، ومنها أن يكون الطفل مستمراً فى التعليم والتعلم،

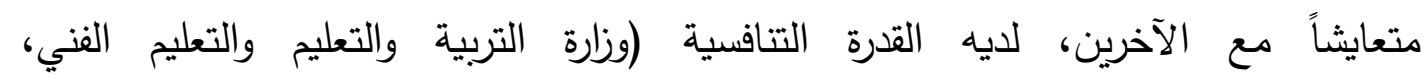

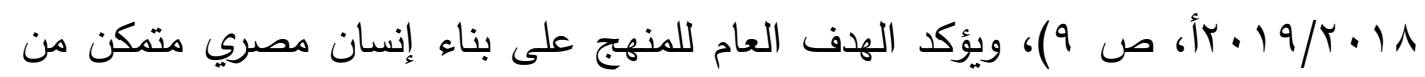
المعرفة والمهارات الحياتية، قادر على التعلم مدى الحياة، وقادر على المنافسة العالمية

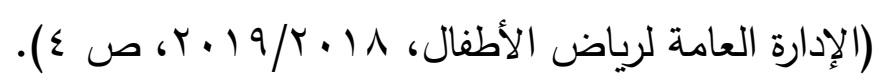

وقد تبين من خلال تحليل محتوى مؤشرات ونواتج تعلم منهج رياض الأطفال

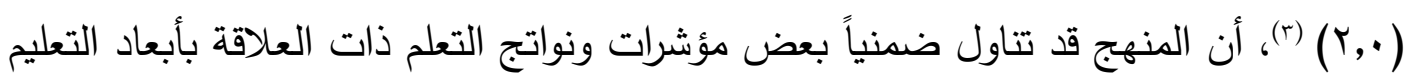
من أجل عالم متصل Education for a Connected World، وذلك في مجال تكنولوجيا

(1) تتحدد في أربع عشرة مهارة حياتية، مصنفة وفق أبعاد التعلم الأربعة: تعلَّم لتعرف-المهارات العلمية

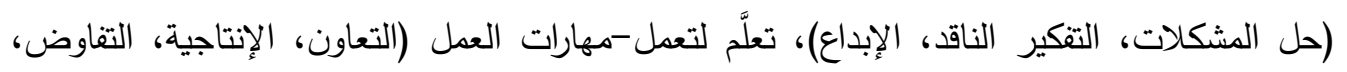

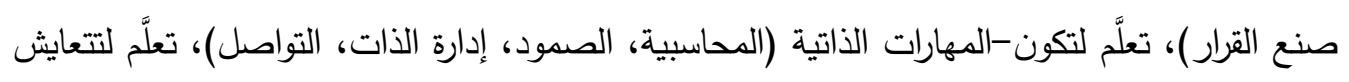
مع الآخرين-مهارات التعايش (المشاركة، التعاطف، احترام التتوع)، وترتبط جميع المهارات السابقة

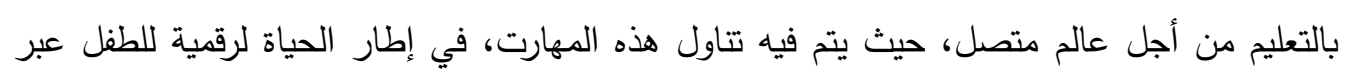
الإنترنت.

(r) التحديات مصنفة وفقاً لخمس قضايا رئيسة: البيئة والتتمية، الصحة والسكان، عدم التمييز ، المواطنة،

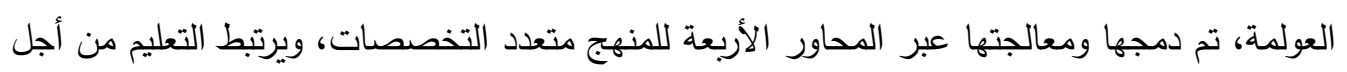
عالم متصل بشكل كبير بقضية العولمة، بلإضافة إلى أنه يتتاول عدداً من القضايا عبر الإنترنت، كما لإنها سيتم التوضيح في الجزء الخاص بخصائصها. (r) تم التحليل في ضوء قائمة مبئية بأبعاد ومؤشرات ونواتج تعلم التعليم من أجل عالم متصل في منهج رياض الأطفال. 


\section{كلية التربية للطفولة المبكرة- جامعة بني سويف}

المعلومات والاتصالات، بالمحتوى متعدد التخصصات، للمستويين الأول والثاني. ويوضح

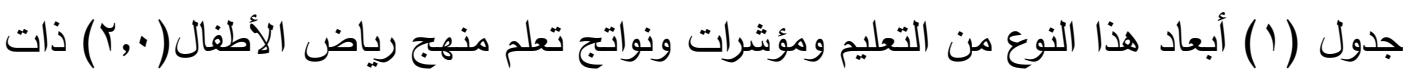
العلاقة (المحتوى متعدد التخصصات -مجال تكنولوجيا المعلومات والاتصالات) ومدي تلاتي

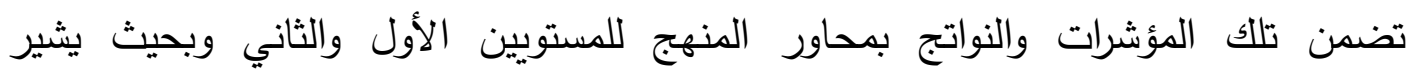

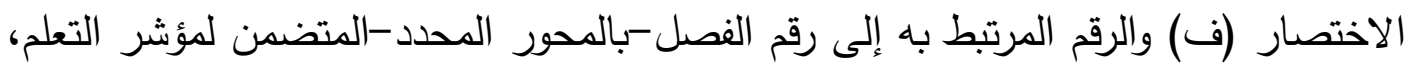
ويشير الاختصار (د) والرقم المرتبط به إلى رقم الدرس الدتضمن لنواتج التعلم. ويتضح من التصن

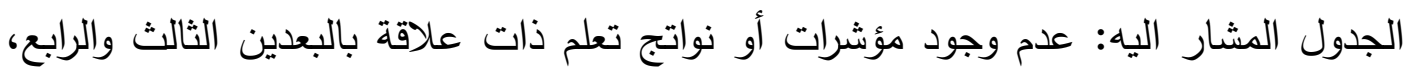

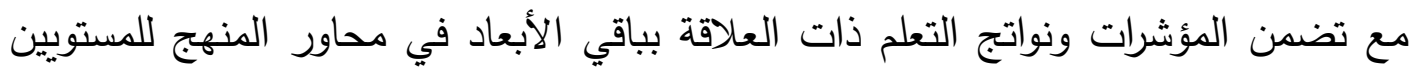

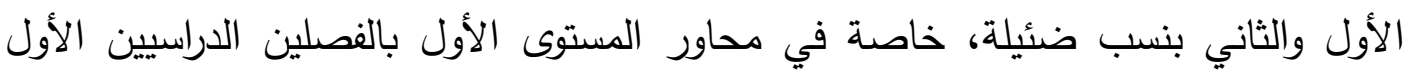

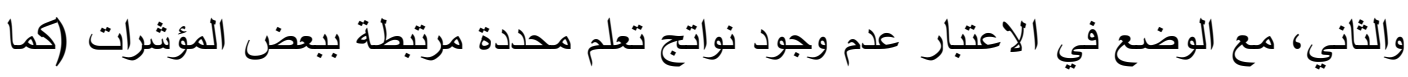

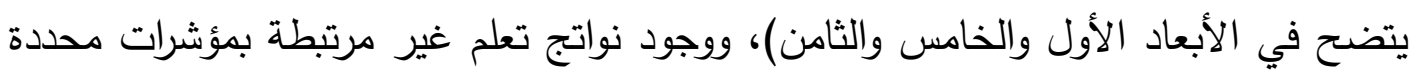

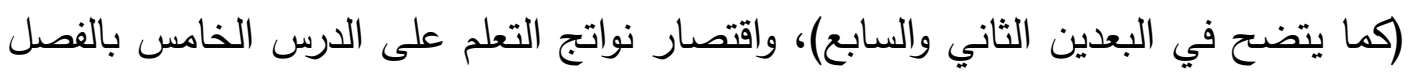
الثالث بمحور التواصل للمستوى الثاني فقط.

كما تبين من خلال تحليل أحدث الدراسات ذات العلاقة-في حدود علم الباحثة-

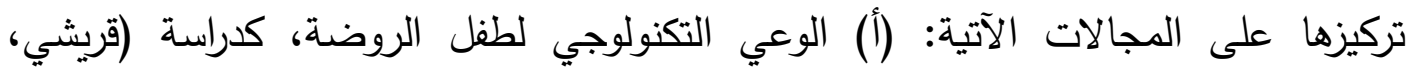

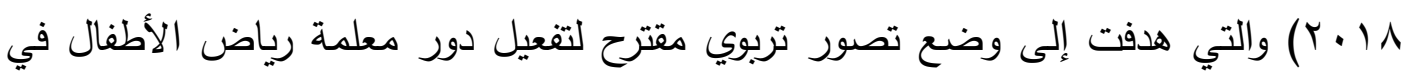

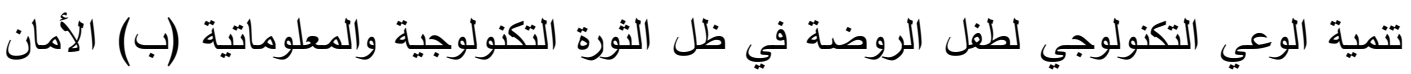
والسلامة عبر الإنترنت في سياق التربية الأمانية لطفل الروضة، كدراسة (عبد السيد،

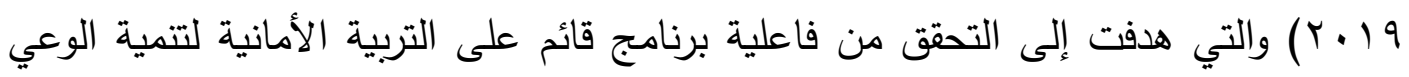

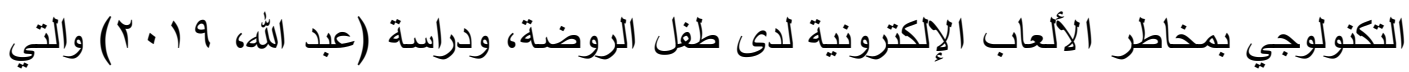

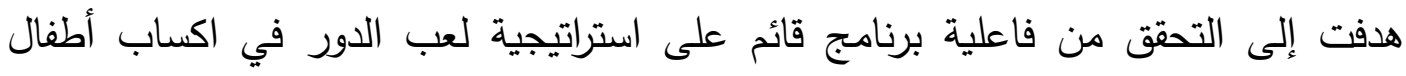

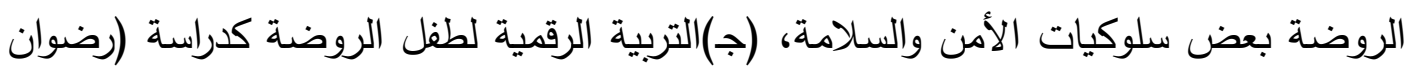

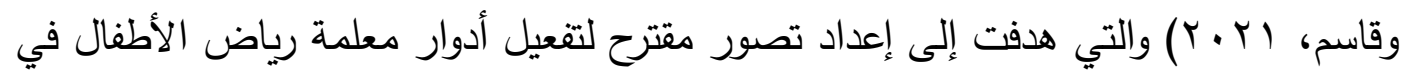

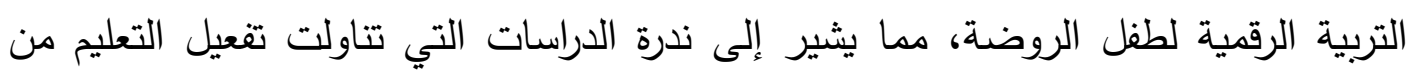


أجل عالم متصل Education for a Connected World في منهج رياض الأطفال

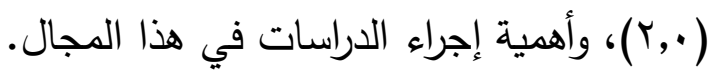

\section{جدول (1)}

أبعاد التعليم من أجل عالم متصل ومؤشرات ونواتج تعلم منهج رياض الأطفال(·,_r) ذات العلاقة (المحتوى

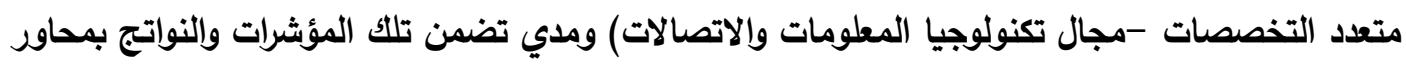
المنهج للمستويين الأول والثاني

\begin{tabular}{|c|c|c|c|c|c|c|c|c|c|}
\hline \multicolumn{8}{|c|}{ مدي تضمن تلك المؤشرات بمحاور المنهج } & \multirow{4}{*}{ 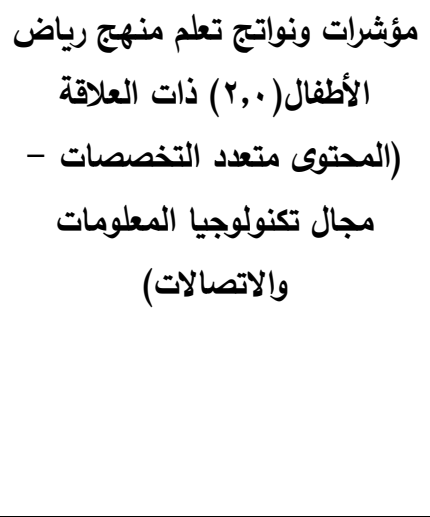 } & \multirow{4}{*}{ أبعاد التعليم من أجل } \\
\hline \multicolumn{4}{|c|}{ محاور المستوى الثاني } & \multicolumn{4}{|c|}{ محاور المستوى الأول } & & \\
\hline \multicolumn{2}{|c|}{ فصل دراسي } & \multicolumn{2}{|c|}{ فصل دراسي } & \multicolumn{2}{|c|}{ فصل دراسي } & \multicolumn{2}{|c|}{ فصل دراسي } & & \\
\hline 昰 & 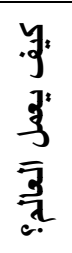 & $\begin{array}{l}\overline{3} \\
\frac{1}{2} \\
3 \\
3 \\
3\end{array}$ & $\begin{array}{l}.3 \\
. \bar{y} \\
. ?\end{array}$ & $\frac{\overline{9}}{3}$ & 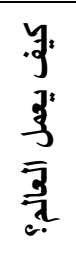 & $\begin{array}{l}\overline{3} \\
\frac{1}{3} \\
3 \\
3 \\
3 .\end{array}$ & .3. & & \\
\hline ف فץ & - & - & - & - & - & - & - & 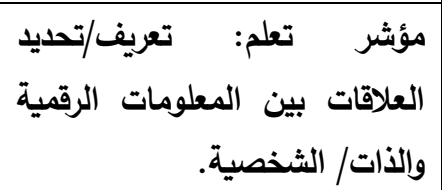 & 1-الصورة الذاتية \\
\hline ده & - & - & - & - & - & - & - & 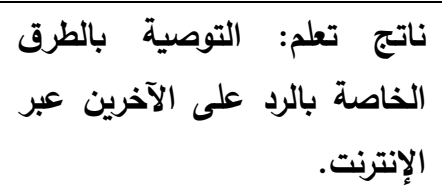 & ץ ا-العلاقات عبر \\
\hline- & - & - & - & - & - & - & - & & ب-الإلسمعة على \\
\hline- & - & - & - & - & - & - & - & & ؛ الالتنمر عبر \\
\hline- & - & فץ & - & - & ف | إץ & - & - & 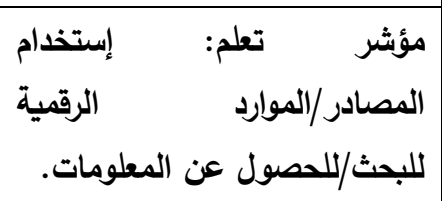 & هـ-إدارة المعلومات \\
\hline
\end{tabular}




\section{كلية التربية للطفولة المبكرة- جامعة بني سويف}

\begin{tabular}{|c|c|c|c|c|c|c|c|c|c|}
\hline فـ ف & ف فا & - & - & - & - & - & - & مؤشر تعلم: توضيح مدى تأثير & و -الصحة والرفاهية \\
\hline فـ & - & - & - & - & - & - & - & كلماتج تعلم: فهم أهمية حماية & والأمن V-الخصوصية \\
\hline ف ف & ف فا & - & - & ف فץ & - & - & - & 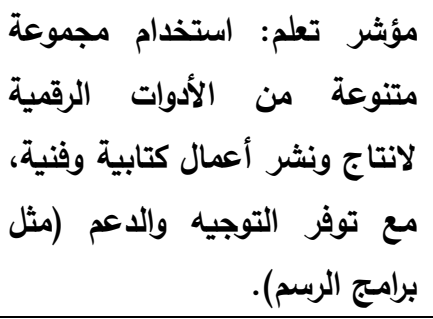 & ^-حقوق الملكية \\
\hline
\end{tabular}

\section{مشكلة الارراسة}

تتحدد مشكلة الدراسة الحالية في وجود قصور في تضمين التعليم من أجل عالم متصلEducation for a Connected World في منهج رياض الأطفال (•, (r)، مع وجود ندرة واضحة في محاولات تفعيل هذا النوع من التعليم في المنهج، الأمر الذي يتطلب إعداد تصور مقترح لتفعيل هذا النوع من التعليم في المنهج، في محاولة لإثرائه بما يتقق

$$
\text { والتوجهات العالمية المعاصرة. }
$$

\section{وعلى هذا فإن الدراسة الحالية سعت للإجابة عن التساؤل الرئيس التالي:}

Education for a مـا التصور المقترح لتفعيل التعليم من أجل عالم متصل Connected World في منهج رياض الأطفال (·,r) في ضوء الخبرات والتجارب العالمية

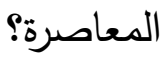

وقد تفرع من هذا التساؤل الرئيس، التساؤلات الفرعية التالية: 
Education for a (1) ما الإطار المفاهيمي والنظري للتعليم من أجل عالم متصل Connected World (Y) ما أبرز الخبرات والتجارب العالمية المعاصرة في مجال تفعيل التعليم من أجل عالم

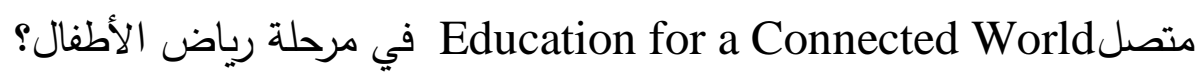
(r) ما أوجه الاستفادة من الخبرات والتجارب العالمية المعاصرة في تفعيل التعليم من أجل

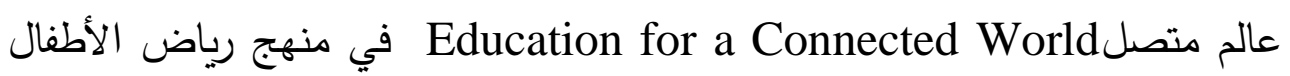
$\varphi(r, \bullet)$

Education for a ما الإطار العام المقترح لتفعيل التعليم من أجل عالم متصل Connected World أهداف الاراسة هدفت الدراسة الحالية إلى:

Education for a تحديد الإطار المفاهيمي والنظري للتعليم من أجل عالم متصل Connected World وصف وتحليل أبرز الخبرات والتجارب العالمية المعاصرة في مجال تقعيل التعليم من

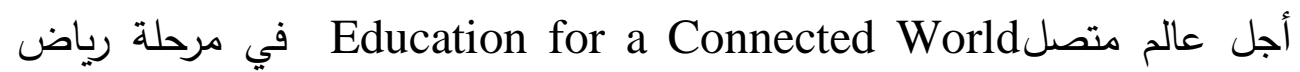
الأطفال.

توضيح أوجه الاستفادة الاستفادة من الخبرات والتجارب العالمية المعاصرة في تفعيل التعليم من أجل عالم متصل Education for a Connected World في منهج

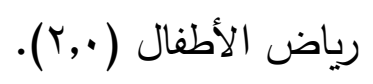

بناء إطار عام لتفعيل التعليم من أجل عالم متصل في منهج رياض الأطفال ( (ب). 
أهمية الدراسة

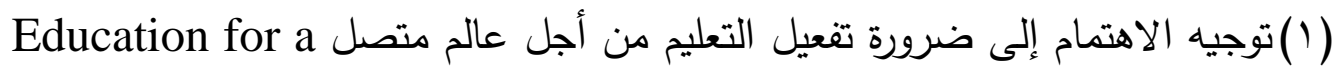
Connected Wor ld يتفق والتوجهات العالمية المعاصرة، خاصة مع وجود ندرة واضحة في محاولات تفعيل هذا النوع من التعليم في المنهج، على المستويين المحلي والإقليمي.

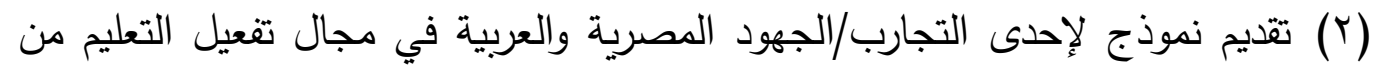

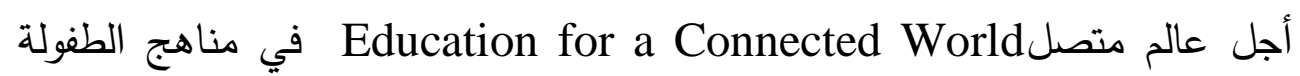
المبكرة، استجابة للتوجهات العالمية المعاصرة، والتزاماً بالمواثيق العالمية في هذا

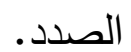

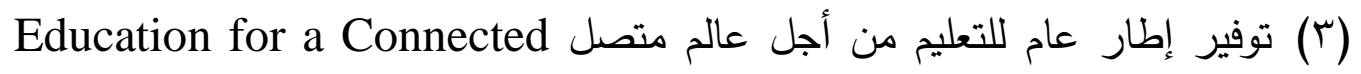
World

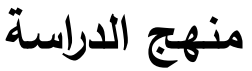

إستخدمت الدراسة الحالية المنهج الوصفي في عرض الأدبيات، والخبرات والتجارب

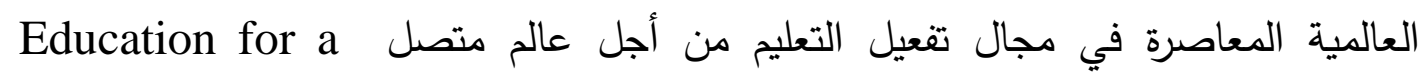

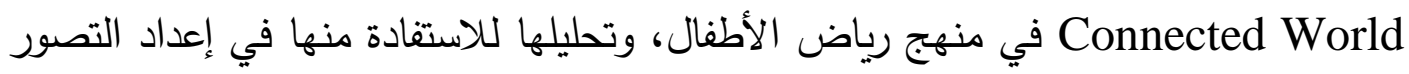

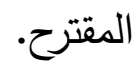

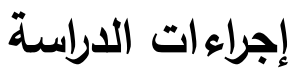

للإجابة على السؤال الأول من أسئلة الدراسة:

Education for استعرضت الباحثة الخلفية النظرية للتعليم من أجل عالم متصل a Connected World 


\section{مفهوم التعليم من أجل عالم متصل في مرحلة رياض الأطفال}

Education for a Connected "ظهر مصطلح "التعليم من أجل عالم متصل World الآمن(') Safer Internet Day (SID)، حيث أعلنت حكومة المملكة إطلاق إطارها التعليمي الجديد لعالم متصل، والمتضمن في وثيقة إطار عمل لـمجلس المملكة المتحدة لأمان الأطفال على الإنترنت" (UK Council for Child Internet Safety (UKCCIS)

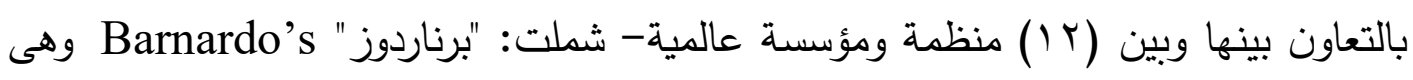
مؤسسة خيرية لحماية الأطفال الضعفاء في المملكة المتحدة، "مركز مكافحة استغلال Child Exploitation and Online Protection " الأطفال والحماية عبر الإنترنت National Crime التابع للوكالة الوطنية لمكافحة الجريمة Command (CEOP) Agency (NCA) والتعليم Department for Education، "وزارة الرقمية والثقافة والإعلام والرياضة" Kent "Department for Digital,Culture,Media\&Sports ، London Grid for Learning( LGfL) شبكة لندن للتعلم Council

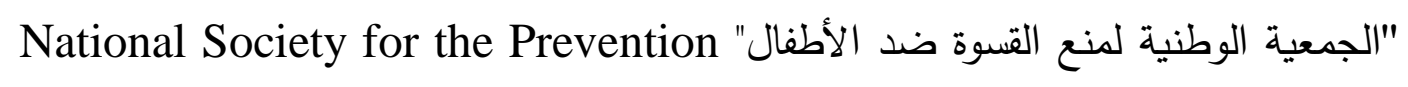
of Cruelty to Children (NSPCC) اجتماعية تستهدف مساعدة العائلات على الإبحار في المجال الرقمي، "شبكة ساوث ويست للتعلح" (South West Grid for Learning (SWGfL) الجمعية الوطنية للتعليم

(1) حدث عالمي يقام في فبراير من كل عام، لتعزيز الاستخدام الأكثر أماناً ومسؤولية لتكنولوجيا الإنترنت

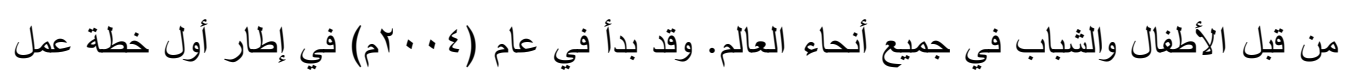

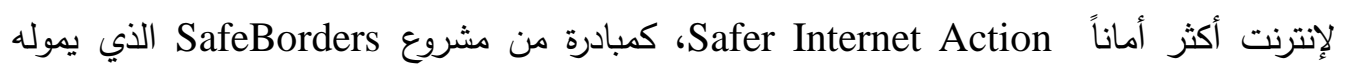

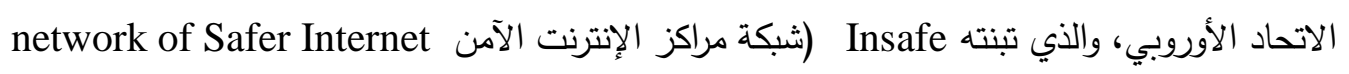

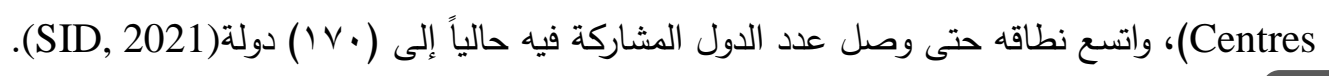


Personal Social Health and الشخصي والاجتماعي والصحي والاقتصادي UK "Economic(PSHE) Association professional dialogue حيث ظهر كنتاج لحوار مهني -Safer Internet Centre وتدقيق عالمي global audit -إستمر لمدة عام ونصف-حول السلوك عبر الإنترنت online behaviour المهارات والمعارف والسلوكيات التي يتوقع أن يمتلكها الأطفال والثباب، لتسدح لهم بالازدهار في استخدامهر للتكنولوجيا (UK Safer Internet Centre , 2018, pp.1-3). وتم تعريف التعليم من أجل عالم متصل Education for a Connected World المهارات skills والفهم understanding، التي يجب أن تتاح للأطفال والثباب فرصة تنميتها في مختلف الأعمار والمراحل" (UKCCIS, 2018, pp.1-2). ونُشر الإصدار الثاني للإطار في يونيو عام (•r.r.r)، بواسطة "مجلس المملكة المتحدة للأكان على الإنترنت UK Council for Internet Safety (UKCIS) -وهو الإني

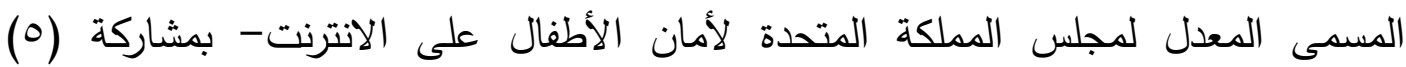

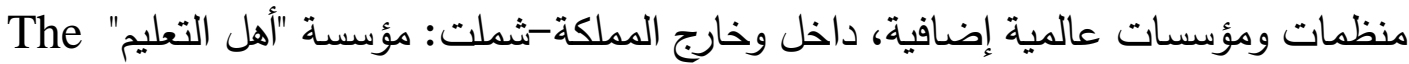
Education People التعليمية داخل المملكة المتحدة وخارجها، و "تعليم اسكتلندا" Education Scotland وهي وكالة تنفيذية للحكومة الاسكتلندية مكلفة بتحسين نوعية جودة النظام التعليمي الموجود في Safeguarding Board for Northern "البلاد، و "مجلس الحماية لأيرلندا الثمالية لهدية Havering Education (HES) مؤسسة هافرينج للخدمات التعليمية Ireland (SBNI) Services و و"حكومة ويلز" Welsh Government Llywodraeth Cymru- وتم فيه إجراء تعديل بسيط في التعريف، حيث تمت إضافة كلمة "المعرفة" knowledge إلى التعريف، وتم وضعها مع كلمة "الفهم" في ترتيب يسبق المهارات، بحيث أصبح الإطار 
"يصف المعرفة والفهم والمهارات التي يجب أن تتاح للأطفال والشباب فرصة تتميتها في مختلف الأعمار والمراحل"(UKCIS,2020, p.2) .

ويستخلص مما سبق أن التعليم من أجل عالم متصل في مرحلة رياض الأطفال هو

" إطار يصف المعرفة والفهم والمهارات التي يجب أن تتاح لأطفال الروضة فرص تنميتها لإعدادهم للحياة الرقمية".

\section{فلسفة التعليم من أجل عالم متصل في مرحلة رياض الأطفال}

يستند التعليم من أجل عالم متصل Education for a Connected World في مرحلة رياض الأطفال إلى فلسفة مؤداها: "تتغير التكنولوجيا بسرعة كبيرة بحيث لا يمكننا مواكبة ذلك بما يكفي للتأثير بنجاح على سلوك الأطفال عبر الإنترنت، إنهم يعرفون الكثير

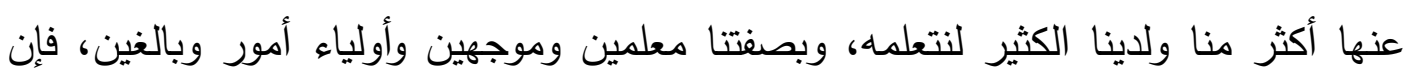
أحد الأشياء التي لم نكن سيئين فيها هو دعم نمو الأطفال ومعرفتهم وسلوكهم، لقد فعلنا ذلك ولكين لعدة قرون من خلال الصياغة الدقيقة لبرامج تتثيفية educative programmes، والتجريب والمراجعة والتقييم، لأننا نتكيف مع متطلبات العالم المتغيرة باستمرار ، والمجال الوحيد الذي لم لم

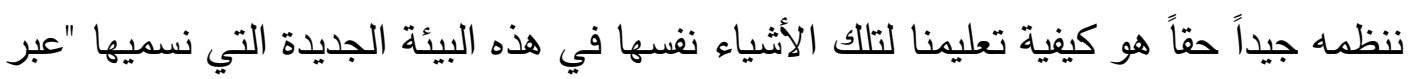
الإنترنت"، مما يظهر الحاجة إلى إطار عمل يجمع المشهد التكنولوجي الحالي عبر الإنترنت maps current online technology landscape التوقعات expectations فيما يتعلق بالسلوك عبر الانترنت، في مقابل العمر/ مرحلة النمو،

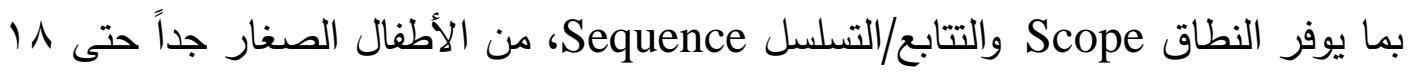
عاماً" (UK Safer Internet Centre , 2018, p.1). 


\section{أبعاد التعليم من أجل عالم متصل في مرحلة رياض الأطفال}

يركز التعليم من أجل عالم متصل Education for a Connected World في

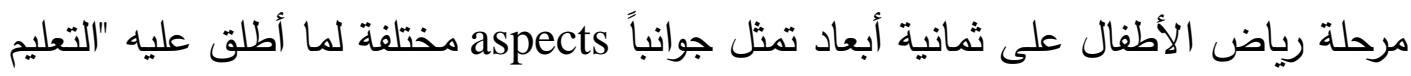
عبر الانترنت /الخط" online education، وتتمثل في (UKCIS,2020, p.4)

(1) Self-image and identity الصورة الذاتية والهوية

يستكثف هذا البعد الاختلافات بين الهوية عبر الإنترنت وغير المتصلة بالإنترنت،

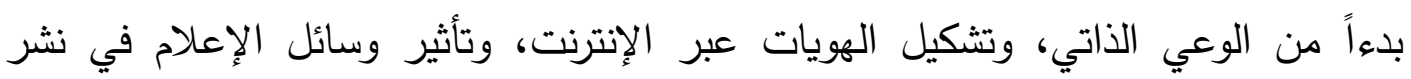

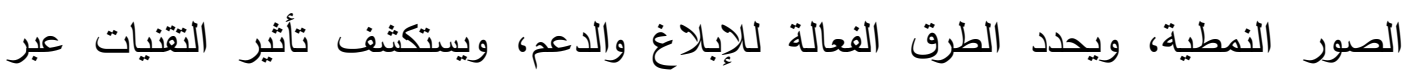
الإنترنت على الصورة الذاتية والسلوك.

(r) (العلاقات عبر الإنترنت Online relationships:

يستكثف هذا البعد كيف تثكل التكنولوجيا أنماط الاتصال، ويحدد استراتيجيات

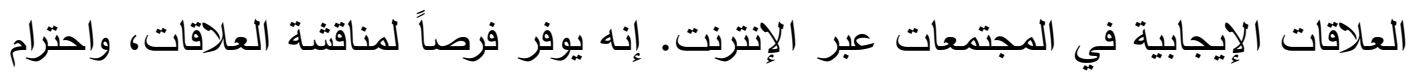

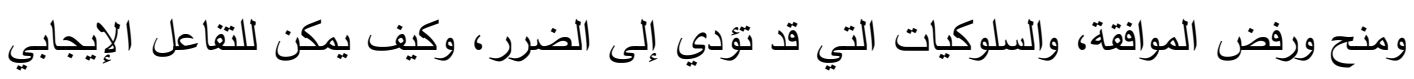

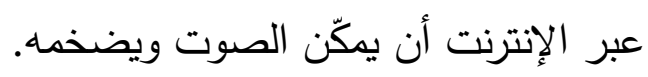

\section{( Online reputation السمعة على الإنترنت}

يستكثف هذا البعد مفهوم السمعة، وكيف يمكن للآخرين استخدام المعلومات عبر

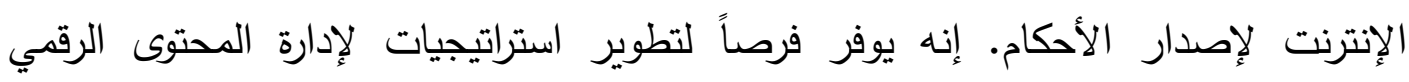

الثخصي بفعالية، والاستفادة من قدرة التكنولوجيا على إنثاء ملفات تعريف إيجابية فعالة.

\section{( ) (التنمر عبر الإنترنت Online bullying:}

يستكثف هذا البعد البلطجة والعدوانية عبر الإنترنت، وكيف تؤثر التكنولوجيا على هذه المشكلات، ويقدم استراتيجيات للإبلاغ الفعال والتدخل، وينظر في كيفية التهرن، وكية ارتباط التنمر

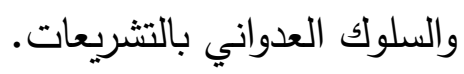

$\Lambda \leq 9$

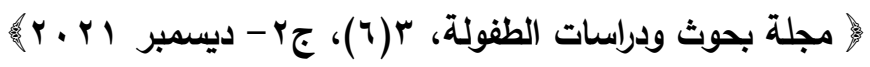


(0) إدارة المطلومات عبر الإنترنت Managing online information يستكشف هذا البعد كيفية العثور على المعلومات عبر الإنترنت وعرضها وتفسيرها،

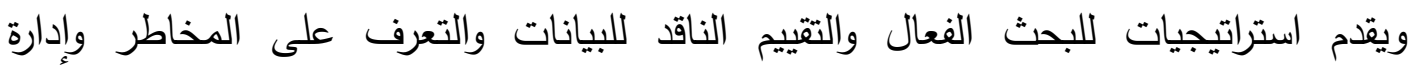
التهديدات والتحديات عبر الإنترنت، ويستكثف كيف يمكن أن تثكل التهديدات عبر الإنترنت

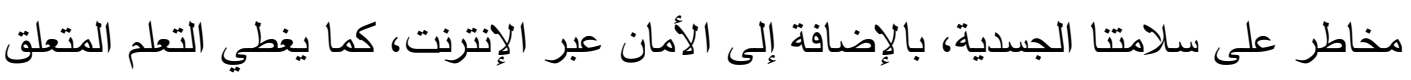
بالنشر الأخلاقي.

\section{(7) (الصحة والرفاهية ونمط الحياة Health, well-being and lifestyle}

يستكثف هذا البعد تأثير التكنولوجيا على الصحة والرفاهية وأسلوب الحياة، على الى

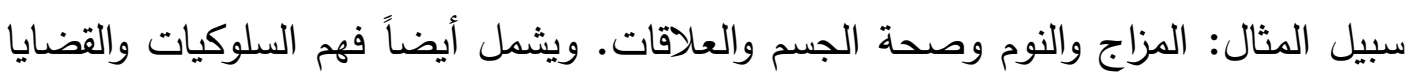
السلبية التي يتم تضخيمها واستدامتها من خلال تقتيات الإنترنت، واستراتيجيات التعامل معها.

\section{: Privacy and security الخصوصية والأمن (V)}

يستكثف هذا البعد كيف يمكن استخدام المعلومات الثخصية عبر الإنترنت

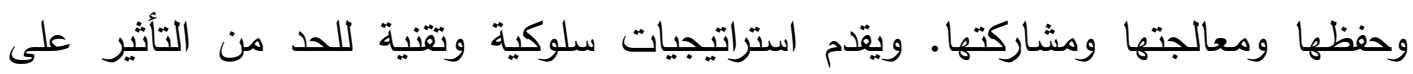
الخصوصية وحماية البيانات والأنظمة من الاختراق.

(^) حقوق النشر والملكية Copyright and ownership

يستكشف هذا البعد مفهوم ملكية الححتوى عبر الإنترنت، ويستكثف استراتيجيات

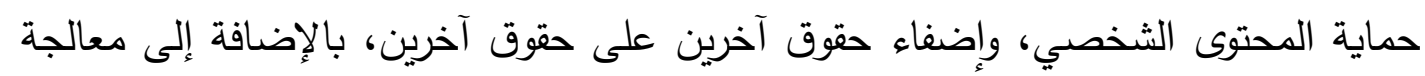
العواقب المحتملة للوصول والتتزيل والتوزيع غير القانونيين. خصائص التعليم من أجل عالم متصل في مرحلة رياض الأطفال تتحدد خصائص التعليم من أجل عالم متصل Education for a Connected

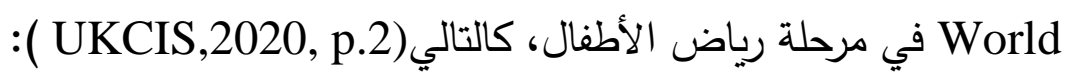


أ- هو ليس مجرد الأمان/السلامة على الإنترنت online safety، وإنما يتضمن عدداً من online الأبعاد المرتبطة بالحياة الرقمية online life، والسلوك والنشاط عبر الإنترنت الإنتان activity and behaviour للأطفال. ب- يسلط الضوء على ما يجب أن يعرفه الأطفال من حيث التكنولوجيا الحالية عبر

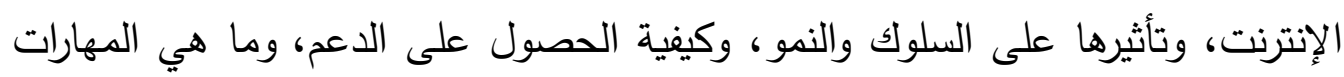

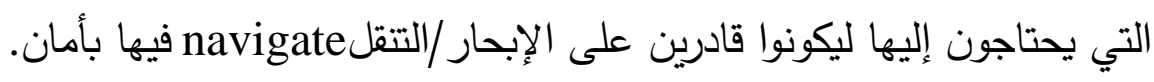
ج- يركز على تعليم الأطفال إحداث التوازن بين المنافع المقدمة بواسطة التكنولوجيا،

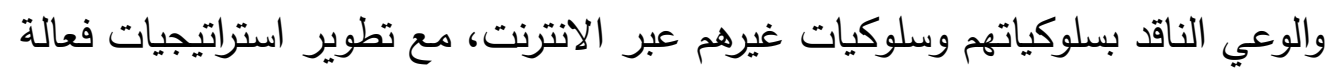

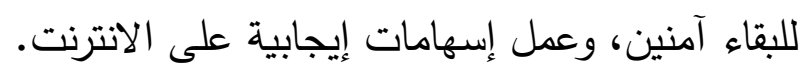

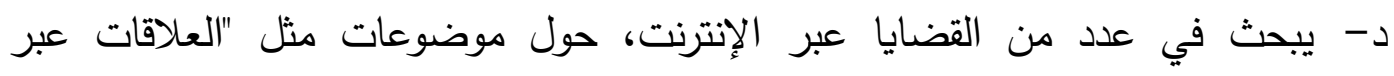

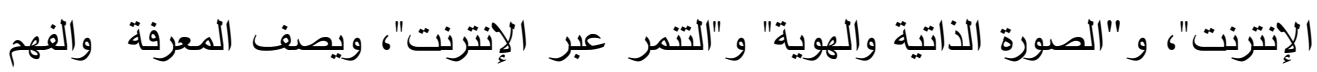

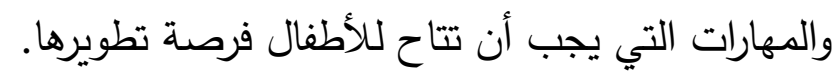

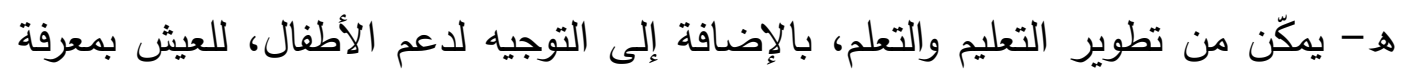
ومسؤولية وأمان في عالم رقمي.

التعليم من أجل عالم متصل لدى أطفال الروضة من منظور نمائي

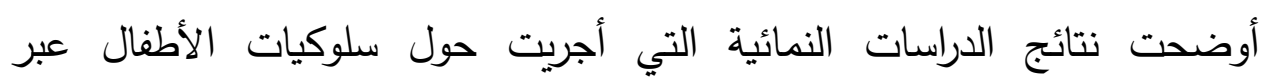

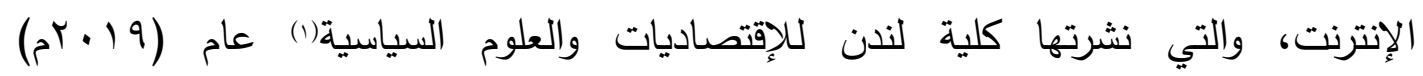
أن(London School of Economics and Political Science, 2019,pp.3-10) أولاً: هناك مظاهر تدل على استعداد أطفال مرحلة الطفولة المبكرة للتعلم من أجل عالم متصل المال: هناك

(1) عضو مؤسس في المبادرة العالمية "أطفال العالم على الإنترنت" Global Kids Online.

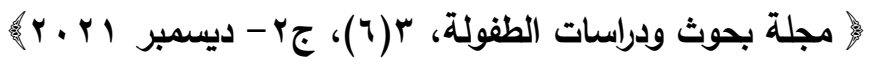


أ- يهتمون بخصوصياتهم privacy عبر الإنترنت، ويريدون أن يكونوا قادرين على تحديد

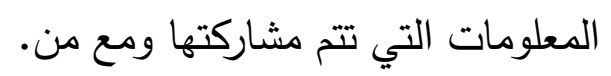

ب-ينخرطون في مجموعة واسعة من الاستراتيجيات للحفاظ على أجهزتهم وملفات تعريف

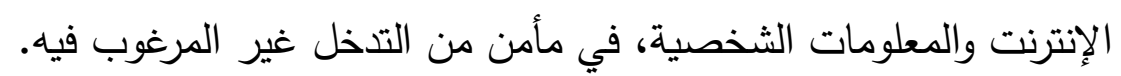

ج-يميلون إلى التفكير في الخصوصية عبر الإنترنت من حيث الأمان الإلكتروني، ويكافحون struggling من أجل فهم العلاقة بين الخصوصية والبيانات.

د- يركزون على البيانات التي يعرفون أنهم يقدمونها، أكثر بكثير من البيانات التي يتم أخذها أو استتاجها، ويعتقدون أن كل ذللك "ليس من شأنهم".

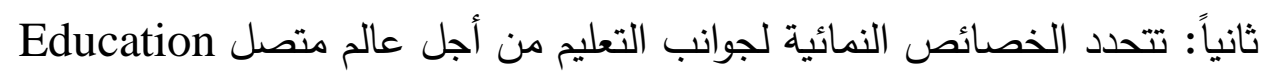
for a Connected World أ- يطورون شعوراً بالملكية fairness والعدالة ownership و والاستقلالية independence ب-يتعلمون القواعد، ولكن قد لا يتبعوها، ولا يدركوا العواقب. ج-يستخدمن الأجهزة الرقمية بثقة في نطاق ضيق من الأنشطة. د- يستوعبون فكرة الأسرار idea of secrets، ويعرفون كيفية الإخفاء، ولكن يميلون إلى الى

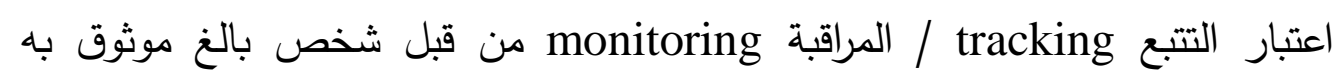
مغيداً. هـ - توجد لديهم شواهد/ أدلة محدودة على فهم العالم الرقمي.

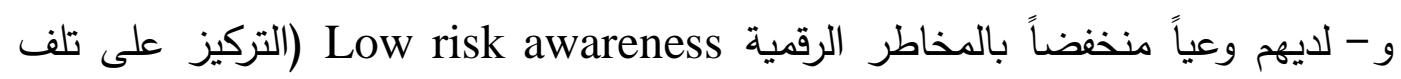

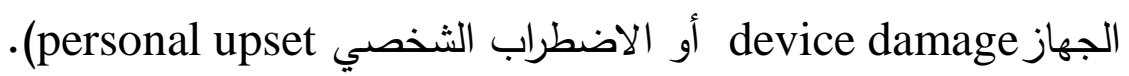


ز - لايهم استراتيجيات قليلة لمواجهة المخاطر الرقمية (يمكن إغلاق التطبيق، استدعاء أحد الوالدين للمساعدة).

ح-لديهم ثقة واسعة Broadly trusting في التعامل مع العالم الرقمي. أهداف التعليم من أجل عالم متصل في مرحلة رياض الأطفال

Education for a Connected World يهدف التعليم من أجل عالم متصل إلى تحقيق الأهداف الرئيسة التالية (UKCIS,2020, pp.2-3): أ- إعداد/تجهيز الأطفال للحياة الرقمية، بشكل يتم فيه تنمية سلوكيات طويلة الأجل آمنة ومناسبة. ب-تدعيم معلمات الروضة في تشكيل الثقافة في محيطهم وما بعده. ج-تطوير منهج ثري وفعال وتنموي، يدعم الأطفال ليكونوا آمنين، وصحيين، ومزدهرين، عبر الإنترنت.

د - مساعدة روضات الأطفال على دعم وتوسيع نطاق توفير تعليم الأمان/السلامة عبر الإنترنت، بحيث يتم التمكين وبناء المرونة وإحداث تغيير إيجابي في الثقافة.

\section{أهمية التعليم من أجل عالم متصل في منهج رياض الأطفال}

بالإضافة إلى ما تم تتاوله في مقدمة الدراسة، فإن التعليم من أجل عالم متصل Education for a Connected World الروضة بدور فاعل في:

(1) تفعيل أكثر من مادة من مواد اتفاقية حقوق الطفل بشكل متكامل، وتحديداً المادة (ب ( )،

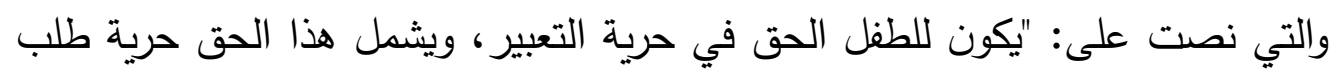

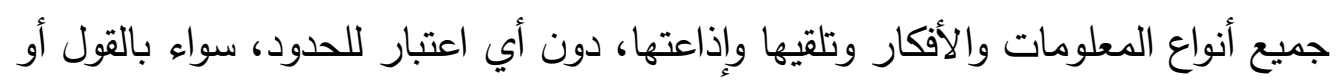
الكتابة أو الطباعة، أو الفن، أو بأية وسيلة أخرى يختارها الطفل"، والمادة(V V)، والتي 
نصت على: "إمكانية حصول الطفل على المعلومات والمواد من شتى المصادر الوطنية والعالمية، وبخاصة تلك التي تستهدف تعزيز رفاهيته الاجتماعية والروحية والمعنوية وصحته الجسدية والعقلية"، والمادة(9 (1) والتي نصت على: "اتخاذ جميع التدابير - ومنها التدابير التعليمية -الملائمة لحماية الطفل من كافة أشكال العنف أو الضرر أو الإساءة والهاء البدنية أو العقلية أو الاستغلال" (اليونيسيف، د.ت، ص ص ح ب-1).

(Y) تفعيل التوجهات العالمية في مجال حماية الأطفال من العنف، حيث تناول التقرير السنوي للممثلة الخاصة للأمين العام للأمم المتحدة المعنية بمسألة العنف ضد الأطفال عام (T 1 · ( (')، تكنولوجيا المعلومات والاتصالات كمحور مهم في المبادرات العالمية في مجال حماية الأطفال من العنف- كأولوية قائمة بذاتها في خطة التنمية المستدامة

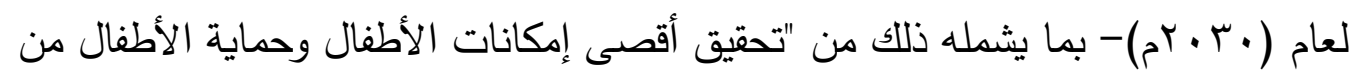
العنف عبر الإنترنت بما في ذلك الاستغلال الجنسي"، وبشكل يتم فيه التركيز على جانبين متوازنين: (أ) النهوض بخطة رقمية تتسم بالأمان والشمول والقدرة على إتاحة

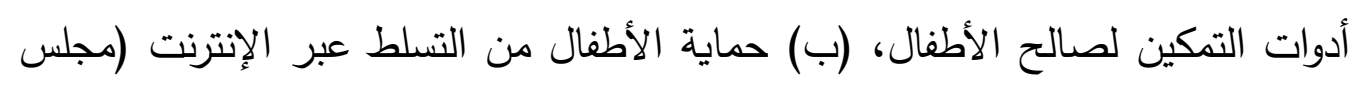

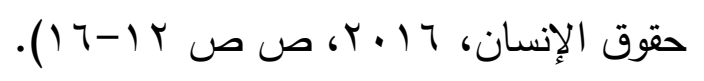

(r) ضمان حصول كل طفل على المهارات الرقمية ذات الصلة، في عالم متصل بشكل متزايد، بما يساعد في تعزيز التعليم الثامل والمنصف والتعلّم مدى الحياة للأطفال

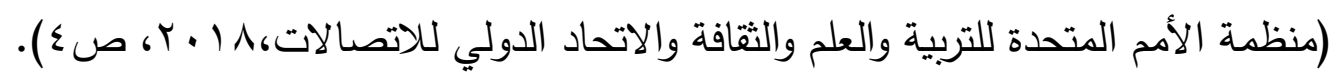

(ع) تفعيل الإعلان العالمي لأمان /سلامة الأطفال على الخط Child Online Safety Universal Declaration

(') تم عرض هذا التقرير في سياق الدورة الحادية والثلاثين لمجلس حقوق الإنسان، في البند(ץ) من جدول

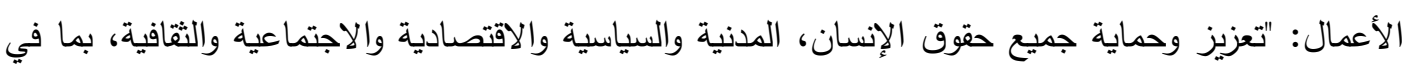
ذللك الحق في التتمية". 


\section{كلية التربية للطفولة المبكرة- جامعة بني سويف}

المستدامة" (r) عام (9 1 ب rم)، والذي تمثل هدفه العام في: "حماية الأطفال أثناء وصولهم

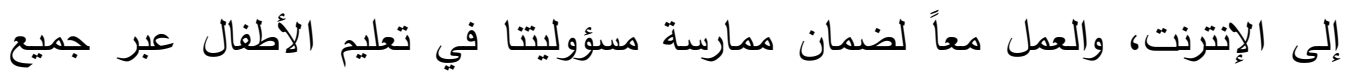

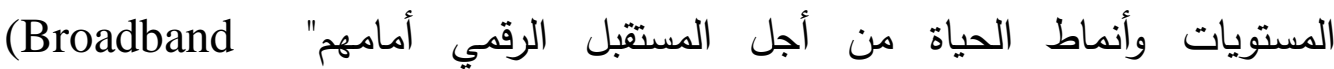
.Commission for Sustainable Development, 2019, p.3) (0) تحقيق"الهدف العالمي للتوصيلية الثاملة Universal Connectivity"، والذي أعلنته "لجنة النطاق العريض المعنية بالتتمية المستدامة"، في بيانها الذي يحمل نفس العنوان

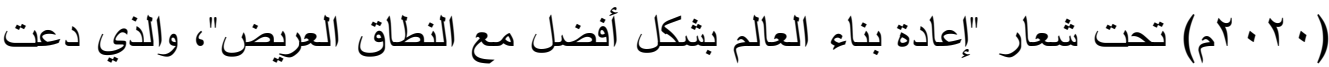

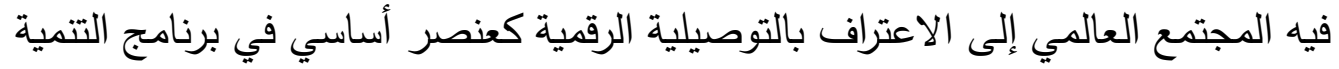
المستدامة، موضحة أن الوضع الطبيعي الجديد للعالم، يتمثل في عدم ترك أحد متخلفاً

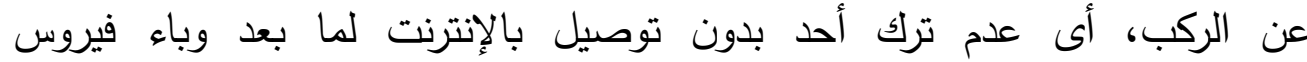
كورونا(COVID-19)، وكان من أهم التوصيات: "تهيئة بيئات تنظيمية تمكينية

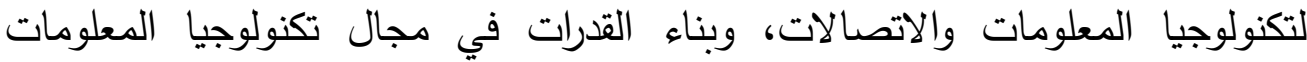

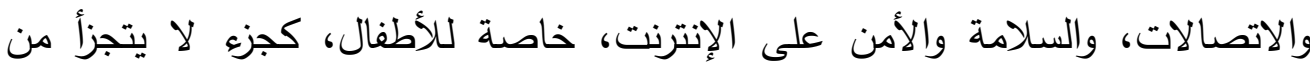

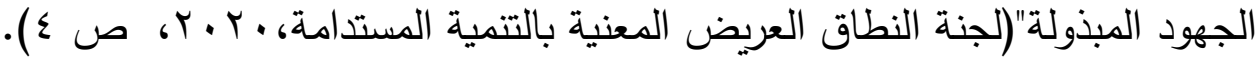
(†) تعزيز الذكاء الرقمي DQ (Digital Intelligence) لدى أطفال الروضة، والذي يُعرف

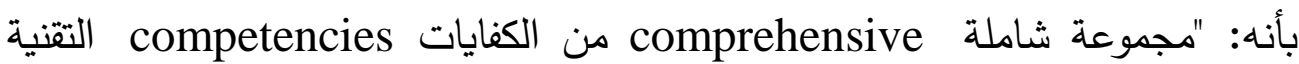
والمعرفية وما وراء المعرفية والاجتماعية -العاطفية، التي ترتكز على القيم الأخلاقية العالمية، والتي تمكن الأفراد من مواجهة التحديات والاستفادة من فرص الحياة الرقمية"،

(r) لجنة أنشأتها اليونسكو والاتحاد الدولي للاتصالات (ITU) -وكالة الأمم المتحدة التتصصة في مجال

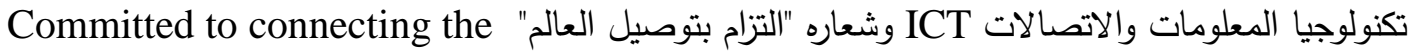
world

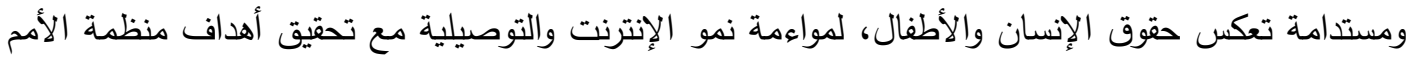

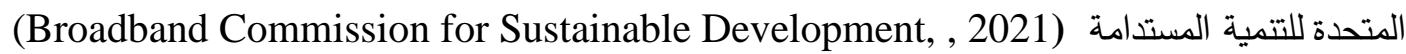


ويعد أول معيار عالمي في العالم(') World's first global standard للثقافة

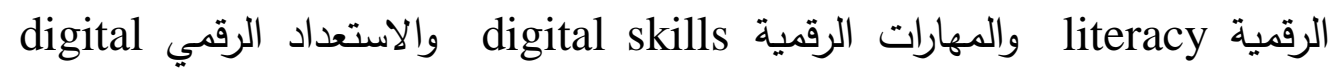
Digital Citizenship readiness ويتضمن ثلاث مستويات هي : المواطنة الرقمية

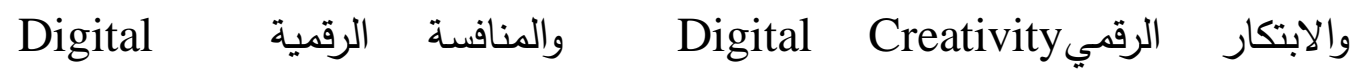
Competitiveness الرقمي (צ') كفاية (DQ Institute, 2020). وترى الدراسة الحالية انه يمكن توضيح أبعاد التعليم من أجل عالم متصل Education for a Connected World وكفي اعليات الأكاء الرقمي DQ competencies ذات العلاقة، كما بجدول(Y). توظيف إطار تعليمي مستتد لنتائج الأبحاث والدراسات التي تمت في إطار المبادرة (V) العالمية "أطفال العالم على الإنترنت" Global Kids Online، وهي مبادرة تم تأسيسها عام (10 • rم) بالتعاون بين اليونيسيف UNICEF وكلية لندن للاقتصاديات والعلوم السياسية London School of Economics and Political Science "أطفال الاتحاد الأوروبي على الانترنت" EU Kids Online، والمبادرة تهتم بدراسة تجارب الأطفال الرقمية حول العالم، وما يحبون القيام به عبر الإنترنت والمهارات والكفاءات التي يكتسبونها في هذه العملية، بالإضافة إلى المخاطر الإنترنت التي يواجهونها عبر الإنترنت، والأضرار المحتملة (UNICEF, 2019, p.8).

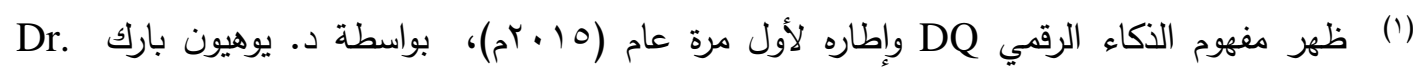
Yuhyun Park

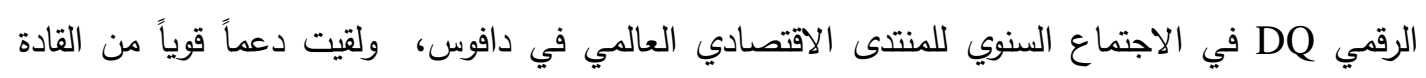

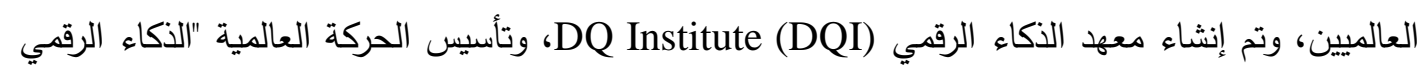
لكل طفل" DQEveryChild initiative في نفس العام ، كما تم إنشاء تحالف عالمي للذكاء الرقمي عام

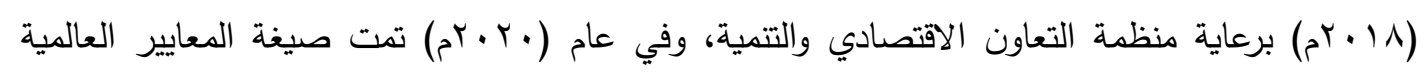
للذكاء الرقمي(DQ Institute, 2020). 
Internet "مواجهة التحديات العالمية التي ترتبت على ظهور ما يعرف ب"إنترنت الأشياء (^)

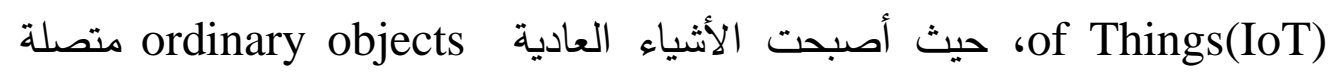
بالإنترنت، فقد يتم الآن إرسال البيانات باستمرار إلى الأطفال خلال فترات أنشطتهم

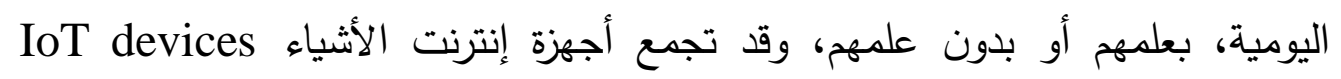

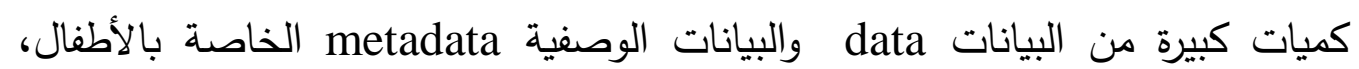
وتشاركها مع أطراف مختلفة، قادرة على استخراج البيانات حول مكان وجود الأطفال، لأطيات

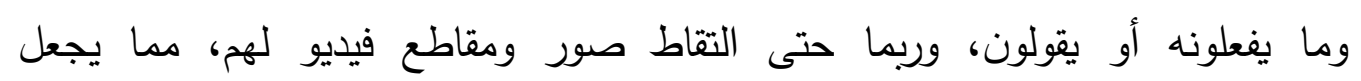

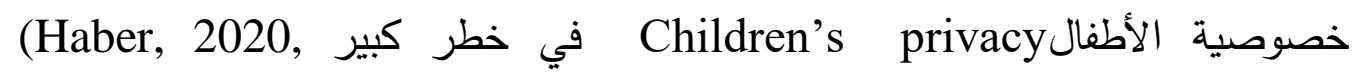
.p.1209)

(9) تدعيم الجهود المحلية في مجال حماية الأطفال على الإنترنت، مثل حملة الإنترنت

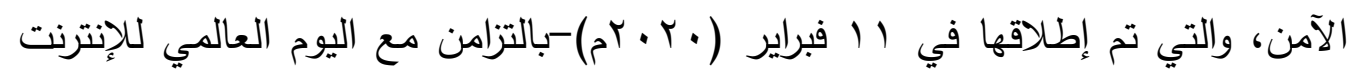

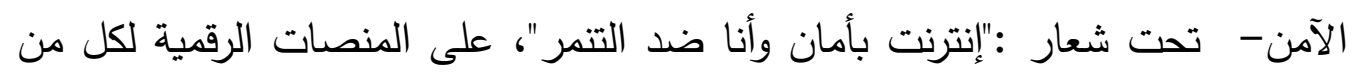
المجلس القومي للطفولة والأمومة، ووزارة التربية والتعليم والتعليم الفني، واليونيسف، والاتحاد الأوروبي، بهدف تعزيز وجود فضاء إلكتروني أكثر أمناً وأريحية للأطفال والنشء، من خلال مناهضة التتمر الاككتروني وتعزيز الحماية عبر الإنترنت (يونيسف

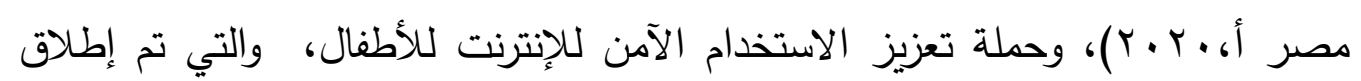

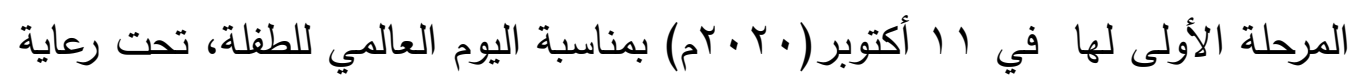
المجلس القومي للطفولة والأمومة، بالتعاون مع اليونيسف، وبتمويل من الاتحاد الأوروبي، بهدف رفع مستوى الوعي بين الأطفال والآباء ومقدمي الرعاية بالإجراءات والتدابير الخاصة بحماية الأطفال والنشء من التهديدات الجديدة التي قد يواجهونها في عالم الإنترنت، أو التعرض لمحتوى ضار، أو الإساءة، فضلًا عن توفير وسائل للإِبلاغ

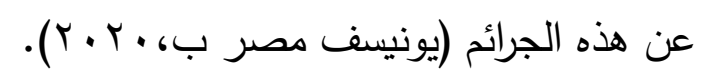




\section{جدول(r)}

أبعاد التعليم من أجل عالم متصل وكفايات الذكاء الرقمي ذات العلاقة

\begin{tabular}{|c|c|}
\hline كفايات الذكاء الرقمي ذات العلاقة & أبعاد التعليم من أجل عالم \\
\hline 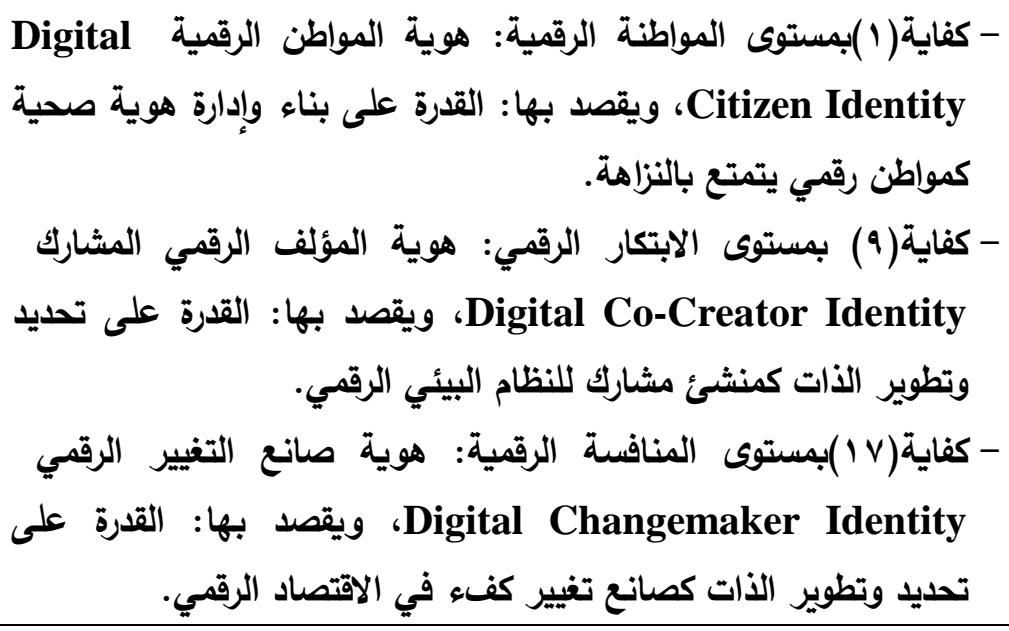 & $\begin{array}{c}\text { - الصورة الذاتية والهوية } \\
\text { Self-image and } \\
\text { identity }\end{array}$ \\
\hline 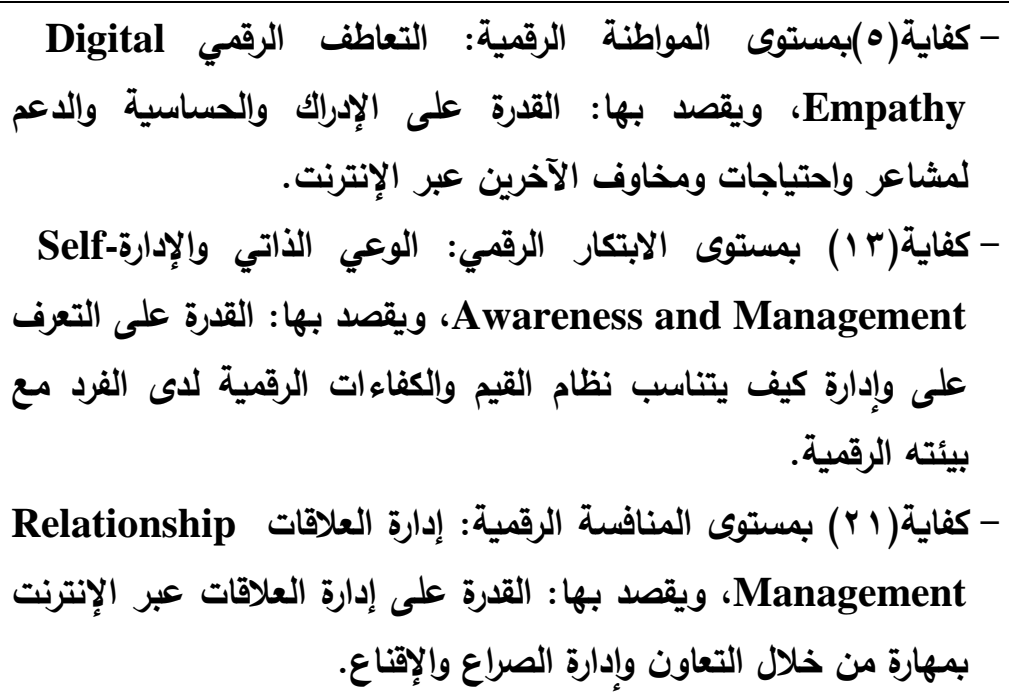 & $\begin{array}{l}\text { Y العلاقات عبر الإنترنت } \\
\text { Online relationships }\end{array}$ \\
\hline
\end{tabular}


- كفاية(؟) بمستوى المواطنة الرقمية: إدارة البصمة الرقمية Digital ب - السمعة على الإنترنت Footprint Management البصمات الرقية وعواقبها الواقعية، وإدارتها بمسؤولية، وبناء سمعة ولفهاء رقمية إيجابية بثكل فعال.

- كفاية(؛ 1) بمستوى الابتكار الرقمي: التواصل والتعاون عبر الإنترنت Online Communication and Collaboration القدرة على استخدام التكنولوجيا بثكل فعال للتواصل والتعاون بثكل

$$
\text { جماعي، بما في ذلك عن بعد. }
$$

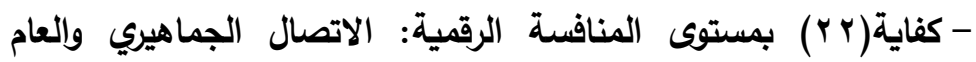
Public and Mass Communication التواصل مع جمهور عبر الإنترنت بثكل فعال لتبادل الرسائل والأفكار

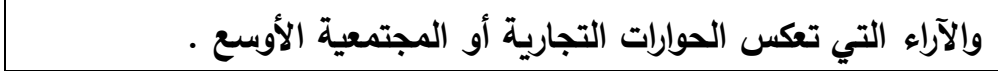

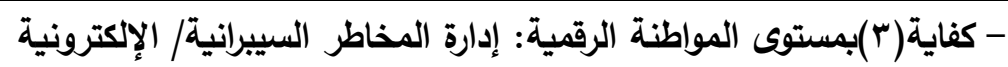
السلوكية Behavioral Cyber-Risk Management، ويقصد

צ - التنمر عبر الإنترنت Online bullying

بها: القدرة على تحديد المخاطر الإكترونية وتخفيفها وإدارتها (مثل

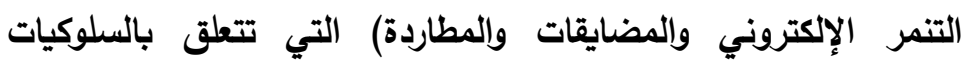

$$
\text { الثخصية عبر الإنترنت. }
$$

- كفاية(1) بمستوى الابتكار الرقي: إدارة المخاطر السيبرانية/ الإكترونية للمحتوى Content Cyber-Risk Management ويقصد بها: القدرة على تحديد وتخفيف وإدارة المخاطر السيبرانية عبر الإندرئ

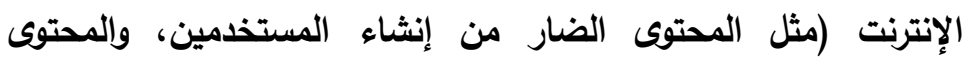

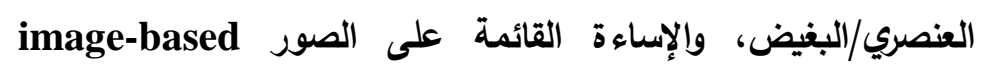
.(abuse - كفاية(9 (1) )بمستوى المنافسة الرقمية: إدارة المخاطر السيبرانية التجارية والمجتمعية Commercial and Community Cyber-Risk Management

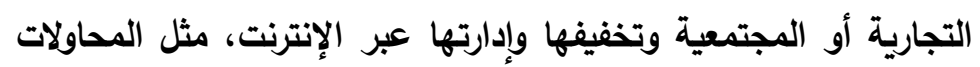

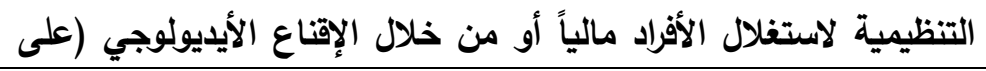


سبيل المثال: التسويق المضمّن، والدعاية عبر الإنترنت، والمقامرة).

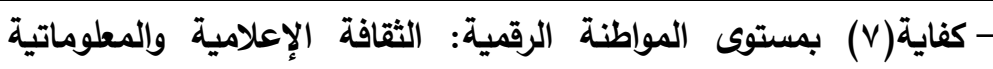
Media and Information Literacy إيجاد وتنظيم وتحليل وتقييم الوسائط والمعلومات مع الاستدلال الناقد - كفاية(0) مستوى الابتكار الرقمي: إنثاء المحتوى والثقافة الحاسوبية Content Creation and Computational Literacy بها: القدرة على تجميع وإنثاء وإنتاج المعلومات والوسائط وإلتكنولوجيا بطريقة مبتكرة وخلاقة.

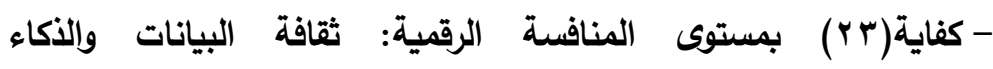
الاصطناعي Data and AI Literacy، ويقصد بها: القدرة على إنى إنشاء ومعالجة وتحليل وتقديم معلومات ذات مغزى من البيانات وتطوير

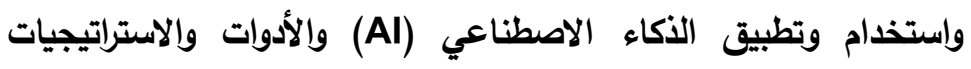

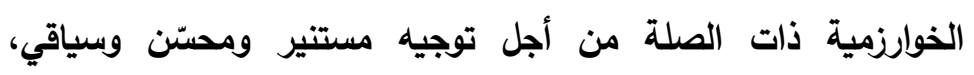
لعمليات صنع القرار ذات الصلة.

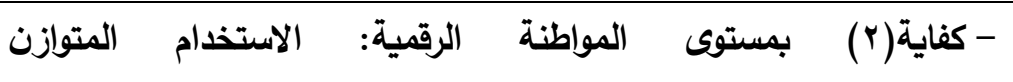
للتكنولوجيا Balanced Use of Technology، ويقصد بها: القدرة على إدارة حياة الفرد عبر الإنترنت أو دون الاتصال بالإنترنت بطريقة

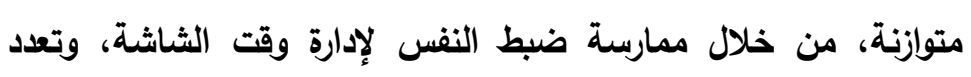
المهام، وتفاعل الفرد مع الوسائط والأجهزة الرقمية. - كفاية (• (1) بمستوى الابتكار الرقمي: الاستخدام الصحي للتكنولوجيا Healthy Use of Technology وأضرار التكنولوجيا على الصحة العقلية والبدنية للفرد واستخدام

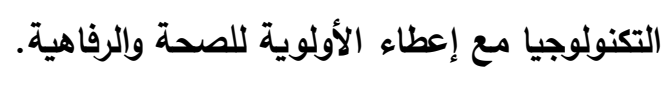

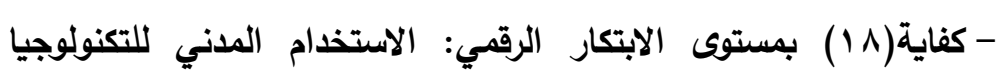

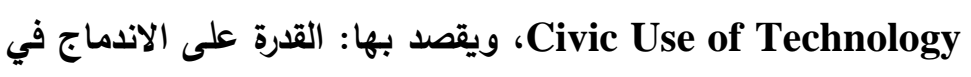

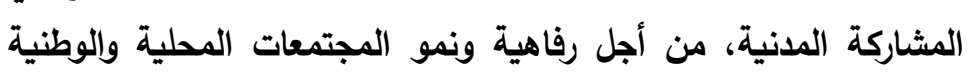
والعالمية باستخدام التكنولوجيا.
•- - إدارة المعلومات عبر

$$
\text { الإنترنت }
$$

Managing online information
7 - الصحة والرفاهية ونمط الحياة

Health, well-being and lifestyle 
Privacy كفاية(^) بمستوى المواطنة الرقمية: إدارة الخصوصية Management المطومات الثخصية التي تتم مشاركتها عبر الإنترنت، لحماية خصوصية الفرد والآخرين. - كفاية(؛) بمستوى المواطنة الرقمية إدارة الأمن السيبراني الثخصي Personal Cyber Security Management على اكتشاف التهايدات السيبرانية (مثل القرصنة والاحتيال والبرامج الضارة) ضد البيانات الثخصية والجهاز، واستخدام استراتيجيات الأمان

$$
\text { وأدوات الحماية المناسبة. }
$$

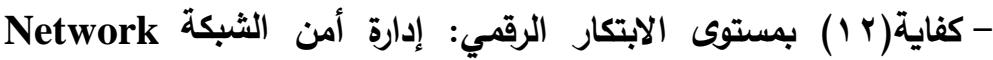
Security Management وإدارة التهايدات السيبرانية للبيئات الرقمية التعاونية القائمة على لهافئل السحابة.

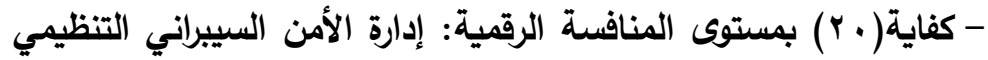
Organizational Cyber Security Management بها: القدرة على التعرف على دفاعات الأمن السيبراني التنظيمية وتخطيطها وتنفيذها.

- كفاية(7 1) بمستوى الابتكار الرقمي: إدارة حقوق الملكية الفكرية Intellectual Property Rights Management القدرة على فهم وإدارة حقوق الملكية الفكرية (مثل حقوق النشر والعلامات التجارية وبراءات الاختراع) عند استخدام وإنثاء المحتوى

$$
\text { والتكنولوجيا. }
$$

- كفاية(؟؟) بمستوى المنافسة الرقمية: إدارة الحقوق التشاركية Participatory Rights Management فهم وممارسة صلاحيات الفرد وحقه في المشاركة عبر الإنترنت (على المان

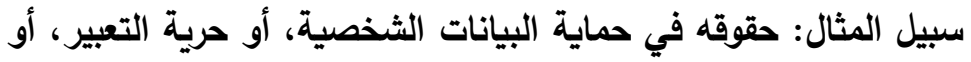
(to be forgotten النسيان. 
online (·) حماية الأطفال من المخاطر التي يتعرضون لها أثناء استخدامهم للانترنت

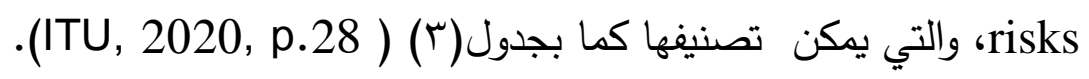

جدول(")

تصنيف المخاطر التي يتعرض لها الأطفال أثناء استخدمهم للانترنت

\begin{tabular}{|c|c|c|c|}
\hline 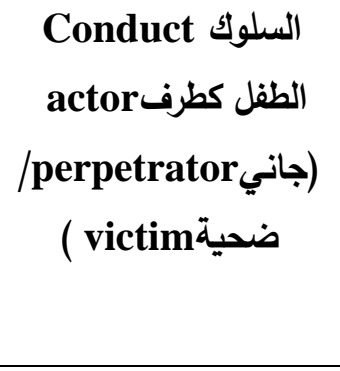 & $\begin{array}{c}\text { Contact الطفل كمشارك } \\
\text { الطال } \\
\text { فيادر به شخص بالغ } 2 \text { participant } \\
\text { adult-initiated } \\
\text { activity }\end{array}$ & 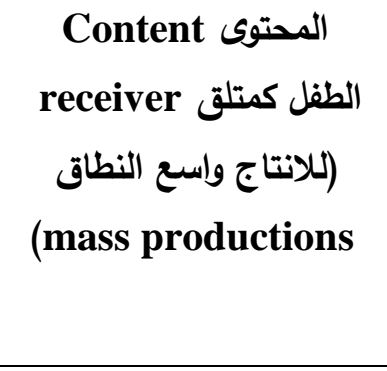 & \\
\hline 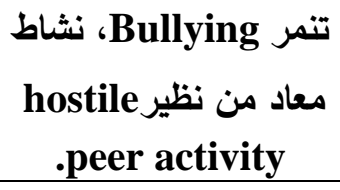 & مضايقة Harassment، تعقب . stalking & $\begin{array}{c}\text { محتوى عنيف/دموي } \\
\text { Violent/gory content }\end{array}$ & $\begin{array}{c}\text { عدواني } \\
\text { Aggressive }\end{array}$ \\
\hline 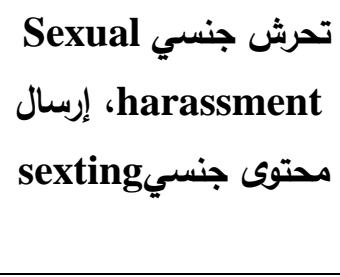 & 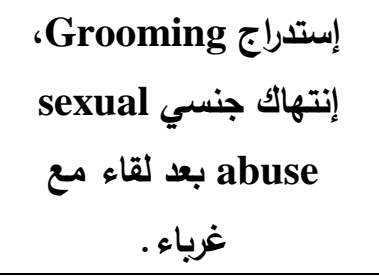 & $\begin{array}{l}\text { محتوى إباحي } \\
\text { Pornographic } \\
\text { content }\end{array}$ & جنسي \\
\hline $\begin{array}{c}\text { المستخدمين - محتوى من إنشاء } \\
\text { user } \\
\text { generated content } \\
\text { يكتمل أن يكون ضاراً. }\end{array}$ & $\begin{array}{l}\text { إقناع أيديولوجي } \\
\text { Ideological } \\
\text { persuasion }\end{array}$ & $\begin{array}{c}\text { محتوى عنصري/ محرض الكراهية } \\
\text { Racist/ hateful } \\
\text { content }\end{array}$ & يخص القيم \\
\hline $\begin{array}{c}\text { القمارGambling، التعدي على حقوق } \\
\text { الملكية الفكرية } \\
\text { copyright } \\
\text { infringement }\end{array}$ & 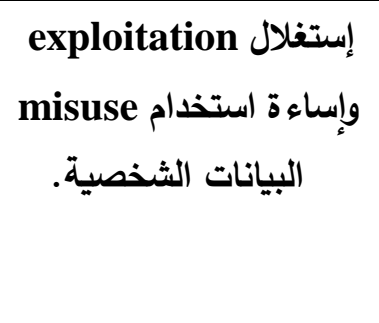 & $\begin{array}{c}\text { إعلانات تسويق متضمن } \\
\text { embedded } \\
\text { marketing }\end{array}$ & $\begin{array}{c}\text { تجاري } \\
\text { Commercial }\end{array}$ \\
\hline
\end{tabular}


نواتج التعلم المرتبطة بأبعاد التعليم من أجل عالم متصل في مناهج مرحلة الطفولة

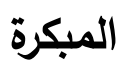

قام مجلس السلامة على الإنترنت بالمملكة المتحدة (UKCIS)، في الوثيقة التي

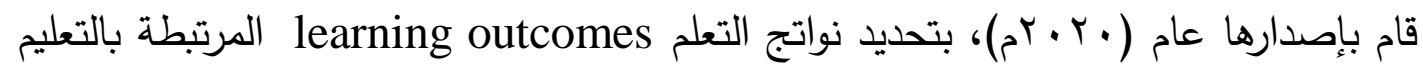
من أجل عالم متصل Education for a Connected World، في المناهج الداهج الدراسية

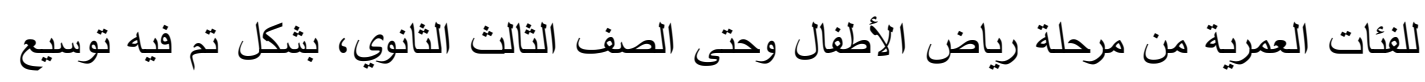

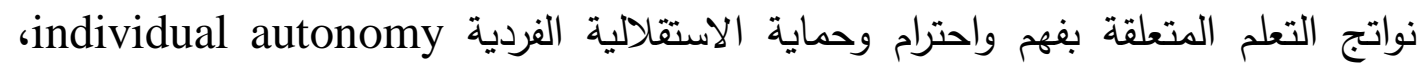

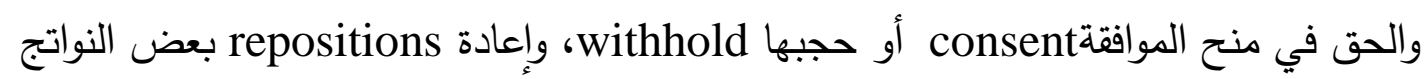
استجابةً للسلوكيات الجديدة المتعلقة بالحماية safeguarding، مع التأكيد على تكامل تلكاتك

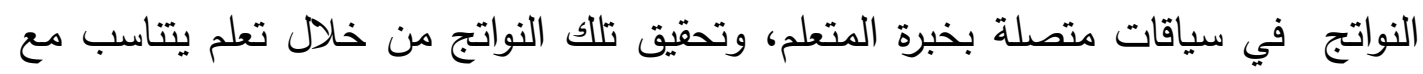

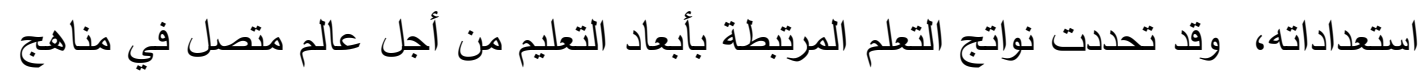

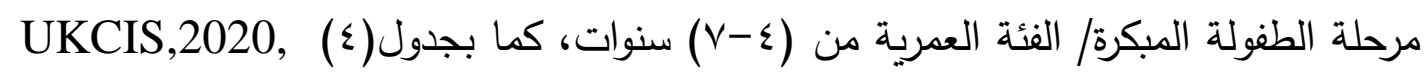

.(pp.5-46)

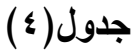

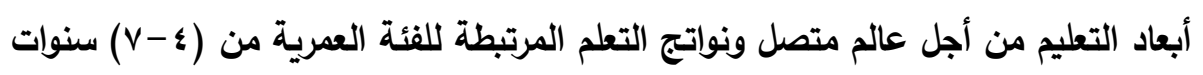

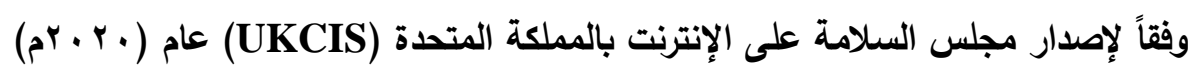

\begin{tabular}{|c|c|}
\hline نواتج التعلم للفئة العمرية من (ع-V- سنوات & البعد \\
\hline - يتعرف عبر الإنترنت أو دون الاتصال بالإنترنت، على أنه يمكن لأي شخص أن يقول & (1) الصورة الذاتية \\
\hline 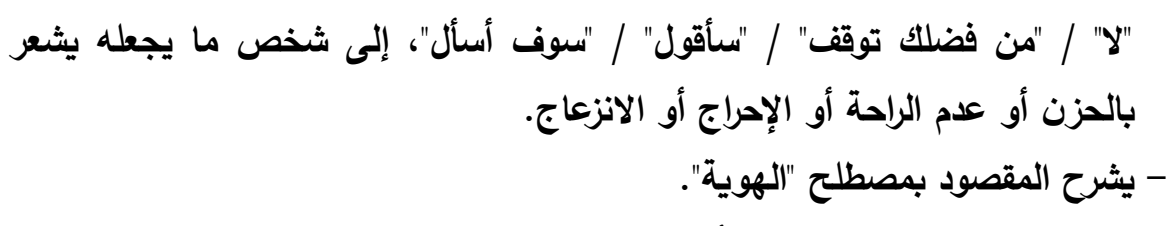 & $\begin{array}{c}\text { والهوية } \\
\text { Self-image and } \\
\text { identity }\end{array}$ \\
\hline - يشرح كيف يمكن للناس تثثيل أنفسه بطرق مختلفة عبر الإنترنت & \\
\hline - يشرح الطرق التي قد يغير بها شخص ما هويته اعتماداً على ما يفعله عبر الإنترنت & 0 \\
\hline (مثل الألعاب، واستخدام الصورة الرمزية، ووسائل التواصل الاجتماعي) والسبب. & \\
\hline - يططي أمثلة عن كيفية استذام الإنترنت ووسائل التواصل الاجتماعي للترويج الذاتي & \\
\hline
\end{tabular}

ᄉт

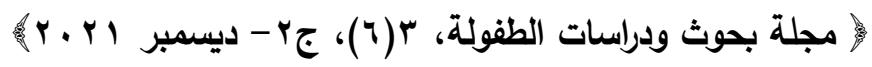




$$
\text { الإيجابي. }
$$

- يشرح كيف يمكن لأي شخص تنسيق هويته وتجربتها عبر الإنترنت ولماذا قد يرغب في القيام بذلك.

- يررك أن نشاط الشخص على الإنترنت أو تاريخه أو ملفه الثخصي (شخصيته

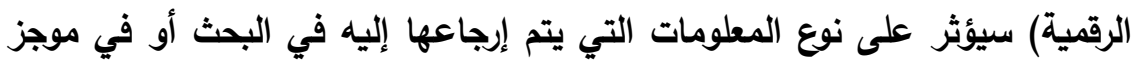

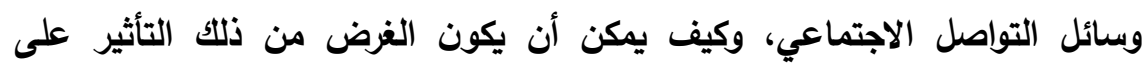
معتقداتهم، والإجراءات والاختيارات.

- يشرح كيف يمكن للمحتوى عبر الإنترنت أن يحد من استقلاليتنا من خلال التأثير

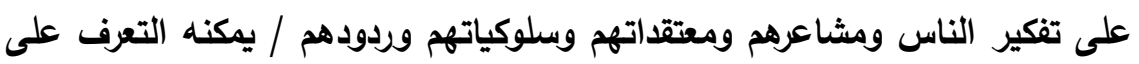
وتقييم العوامل المختلفة وتأثيرها.

- يشرح كيف يمكن تثكيل المحتوى عبر الإنترنت واستهدافه للتأثير على صورة الجسم التماتئ

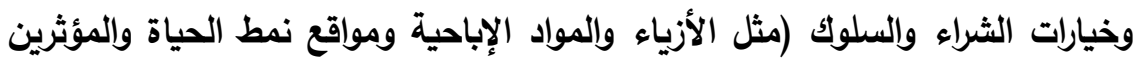

$$
\text { على وسائل التواصل الاجتماعي). }
$$

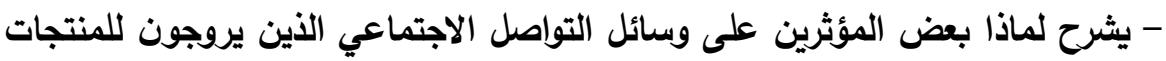
وأسلوب الحياة يمكن أن يكونوا "(فتراضيين" (شخصيات تم إنثاؤها بواسطة الكمبيوتر) وليسوا أشخاصاً حقيقيين. - يشرح المقصود بالذكاء الاصطناعي (Al) وكيف يمكنه حصد هويته وتثكيل تجاربه عبر الإنترنت.

- يتعرف على بعض الطرق التي يمكن من خلالها استخدام الإنترنت للتواصل. العلاقات عبر

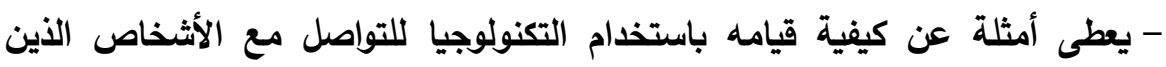
الإنترنت يعرفهر. - يصف طرقاً يمكن للأثخاص الذين لديهم اهتمامات وإعجابات متشابهة أن يجتمعوا معًا عبر الإنترنت. - يشرح معنى "معرفة شخص ما" عبر الإنترنت ولماذا قد يختلف هذا عن معرفة شخص ما في وضع عدم الاتصال. Online relationships

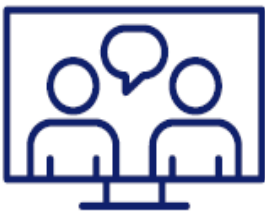
- يشرح المقصود بعبارة "الوثوق بشخص الاته ما عبر الإنترنت "، ولماذا يختلف ذلك عن

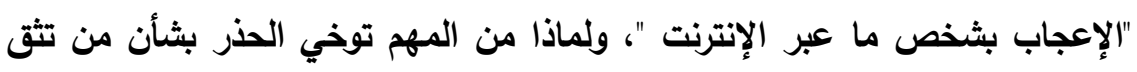

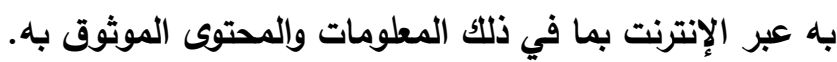


- يشرح لماذا قد يغير شخص ما رأيه بثأن الوثوق بأي شخص بثيء ما إذا شعر إلور بالتوتر أو عدم الراحة أو القلق.

- يشرح كيف يمكن أن تتأذى مشاعر شخص او ما من خلال ما يقال أو يكتب على الإنترنت.

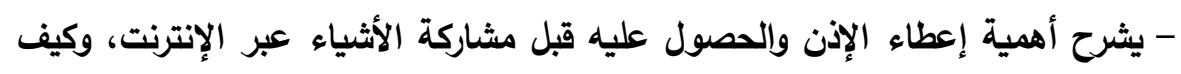

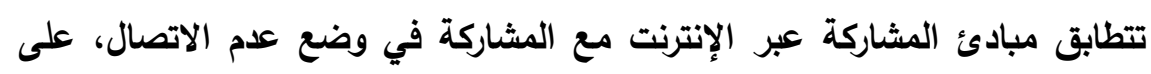
سبيل المثال مشاركة الصور ومقاطع الفيديو. - يشرح أهمية وجود خيار وإعطاء الآخرين خيارًا عبر الإنترنت.

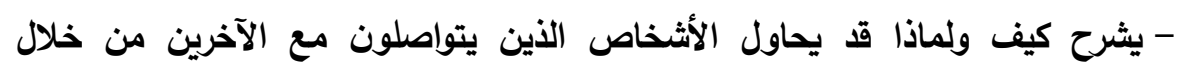

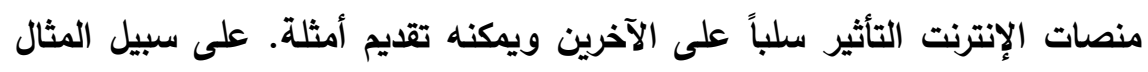

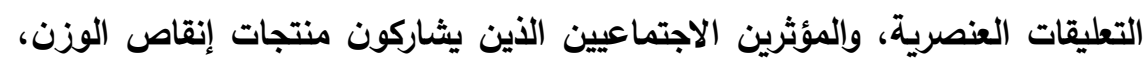
والاستمالة، والتطرف، والإكراه.

- يشرح استراتيجيات لتقييم درجة الثقة التي يضعها في الأثخاص أو المنظمات عبر الإنترنت.

- يصف بعض علامات المواقف الضارة عبر الإنترنت، مثل: التحرش الجنسي، الاستمالة، التسلط عبر الإنترنت.

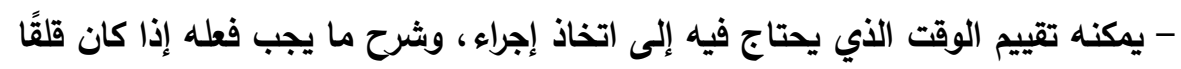

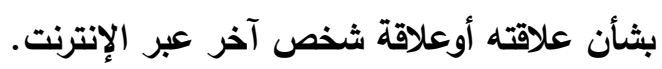

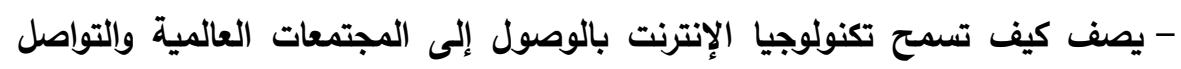
معها.

- يعطي أمثلة عن كيفية قيام أى شخص بتكييف سلوكه للمشاركة بثكل إيجابي

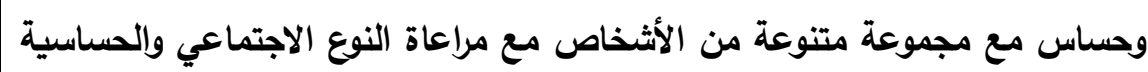
الثقافية والمعتقدات السياسية والاينية وما إلى ذلك.

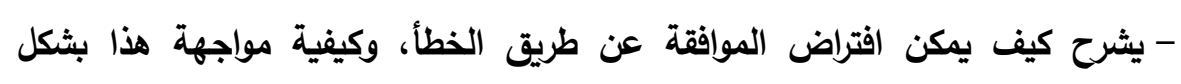
مناسب، على سبيل المثال: ضمن صداقات راسخة، أو معممة، أو سبق إعطاؤها.

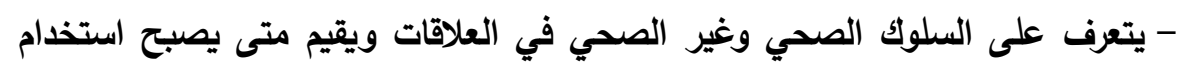

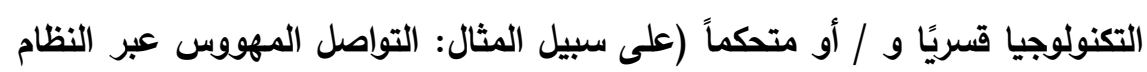

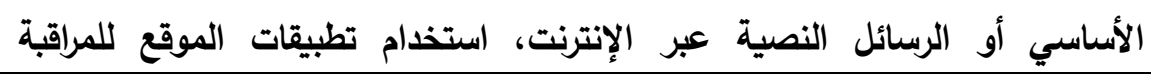




$$
\text { والتلاعب). }
$$

- يشرح متى يكون هذا مسيئاً، وما استراتيجيات الحصول على المساعدة والدعم.

$$
\text { - يشدد الطرق التي يمكنه من خلالها وضع المعلومات على الإنترنت. }
$$

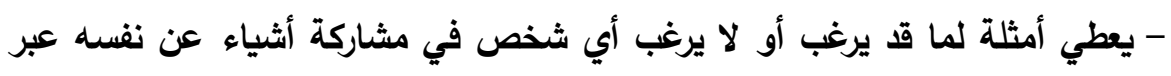

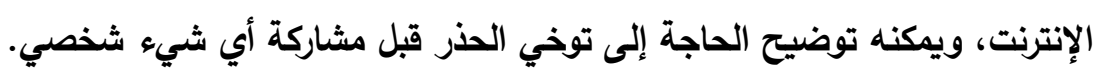

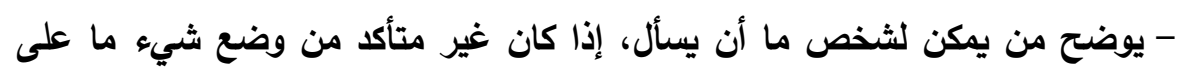
الإنترنت.

- يصف ويقيم الفوائد والمخاطر المحتملة لمشاركة المعلومات عبر الإنترنت.

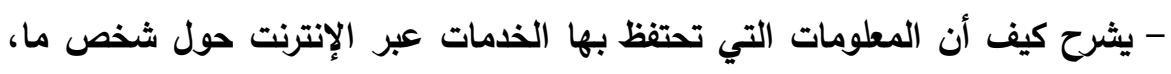

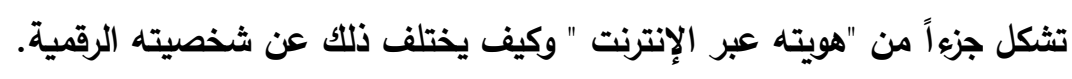

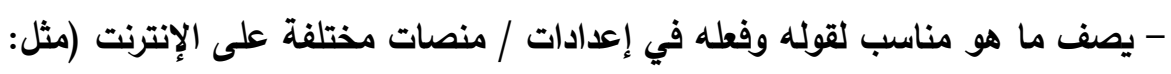

$$
\text { الآراء والقيم والمطلومات والمشاركات والإعجابات والمهاجمون). }
$$

- يشرح كيف يمكن ربط جوانب هوية شخص ما عبر الإنترنت معاً، وبينما يمكن

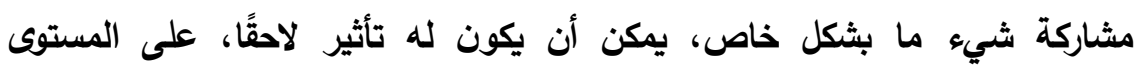

$$
\text { الثخصي والمهني. }
$$

- يشرح أهمية سمعة شخص ما عبر الإنترنت (خاصة بالنسبة لمستقبلهم المهني) ويمكنه وصف طرق إدارة ذلك. - يصف كيفية مواجهة المحتوى أو السلوك الذي قد يكون له تأثير سلبي على سمعة شخص ما عبر الإنترنت بشكل مناسب.

- يصف الطرق التي يمكن أن يكون بها بعض الأشخاص على على الإنترنت غير لطفاء.

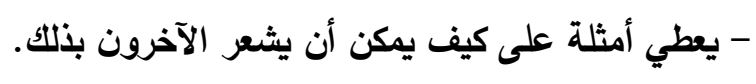

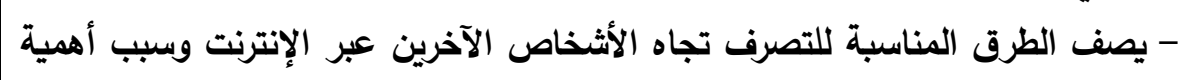
ذلك.

- يعطي أمثلة عن كيفية ظهور سلوك التنمر على الإنترنت وكيف يمكن لشخص ما الحصول على الدعم.

- يصف كيف يمكن أن يتغير التنمر مع تقدمنا في العمر والتعرف على وقت حدوثه عبر ( ) التنمر عبر الإنترنت Online bullying

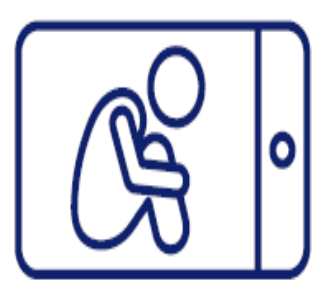


- يصف مجموعة من أنواع وسلوكيات التنمر المختلفة وتقييم وقت حدوثها (على سبيل المثال: العنصرية، والتمييز بين الجنسين/ التمييز على أساس الجنس، والتمييز واستبعاد الآخرين من أثكال الاتصال عبر الإنترنت، وإنشاء ملفات تعريف مزيفية التينة

$$
\text { لثخص آخر). }
$$

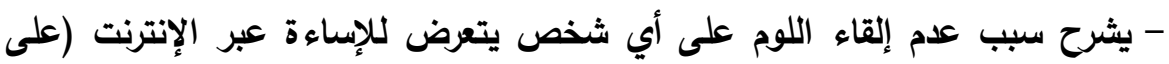
سبيل المثال: إلقاء اللوم على الضحية) وأن يوحي بأنه مخطئ.

- يحدد ويعرض الإجراء ات لاعم الآخرين الذين يواجهون صعويات عبر الإنترنت.

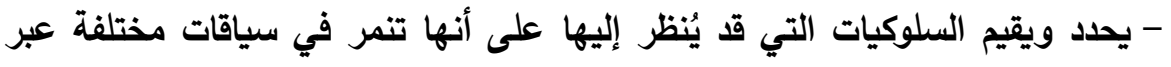
الإنترنت (مثل مجموعات الصداقة الوثيقة مقابل المنتديات العامة) ويعدل سلوكه وفئًا

لذلك.

- يتحدث عن كيفية استخدام الإنترنت كوسيلة للعثور على المعلومات. - يحد الأجهزة التي يمكنه استخدامها للوصول إلى المعلومات على الإنترنت.

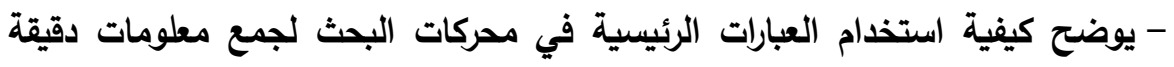
عبر الإنترنت.

- يثرح ماهية الإكمال التلقائي وكيفية اختيار أفضل اقتراح. - يشرح كيفية استخدام الإنترنت لبيع وشراء الأثشياء. - يشرح الفرق بين "المتقد" و "الرأي" و "الحقيقة". ويقدم أمثلة على كيفية ومكان الأنياء مشاركتها عبر الإنترنت، على سبيل المثال: في مقاطع الفيديو، الميمات (مصطلح

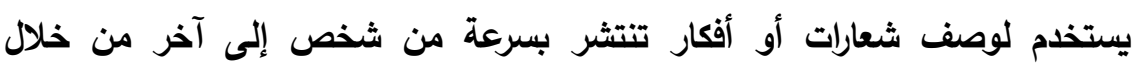

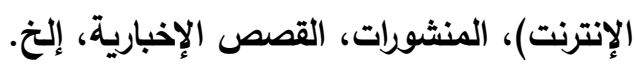
- يوضح أنه لا يجوز للآخرين قبول جميع الآراء المشتركة على أنها صحيحة أو عادلة الإنة (مثل الوحوش تحت السرير).

- يصف ويثبت كيف يمكننا الحصول على المساعدة من شخص بالغ الغ موثوق به إذاذ

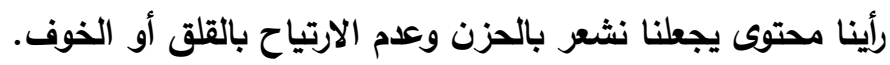

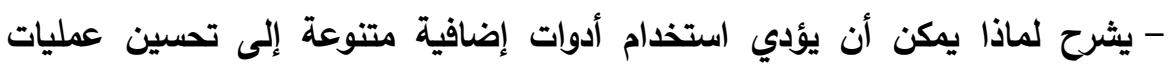

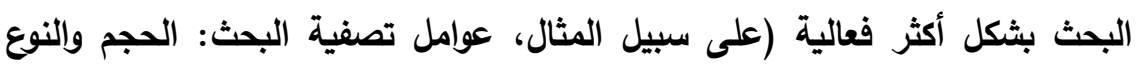

$$
\text { وحقوق الاستخدام وما إلى ذلك). }
$$

- يشرح كيف يمكن للآخرين تفسير المحتوى عبر الإنترنت الأي ينشره فرد ما بثكل
(•) (إرة المعلومات عبر الإنترنت

Managing online information

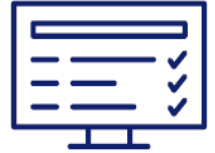


مختلف.

- يوضح كيف أن "الإعجاب" أو "المشاركة" أو "إعادة التوجيه" للمحتوى عبر الإنترنت يمكن أن يغير آراء الأثخاص تجاه شخص ما (على سبيل المثال: المساهمة في

سمعتهم عبر الإنترنت أو الإضرار بها).

- يشرح كيف يمكن "بلأسواق عبر الإنترنت" تمكين الثركات الصغيرة أو الأفراد من

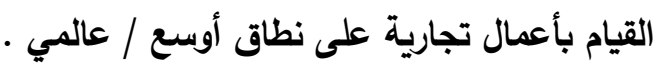

- يقيم فوائد وقيود التجارة عبر الإنترنت.

- يتعرف على وقت تصميم المحتوى عبر الإنترنت وتحليله للتأثير على أفكار الأثخاص

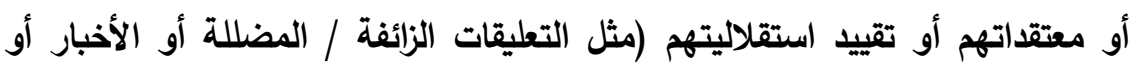

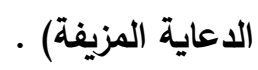

- يميز بين المواقع الإخبارية الحقيقية والمواقع الإخبارية المزيفة (أو المقلدة) التي لها عناوين ويب متشابهة. - يشرح لماذا قد تستمر المؤامرات القائمة على المعلومات المضللة في جذب الناس حتى دون أن تستند إلى أدلة حقيقية. - يوضح المسارات المناسبة إذا كان بحاجة إلى الإبلاغ عن محتوى غير قانوني، على

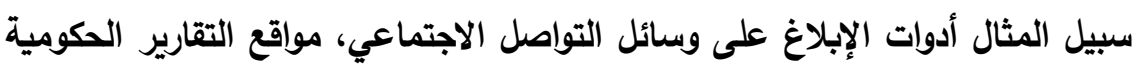
(مواد إرهابية).

- يحدد القواعد التي تساعدنا في الحفاظ على سلامتنا وصحتنا داخل المنزل وخارجه عند استخدام التكنولوجيا. - يعطي بعض الأمثلة البسيطة لهذه القواعد. (7) آل الصحة والرفاهية ونمط الحياة

Health, well-being and lifestyle

- يفسر سبب تأثير قضاء الكثير من الوقت في استخدام التكنولوجيا في بعض الأحيان بثكل سلبي على أي شخص، على سبيل المثال المزاج والنوم والجسد والعلاقات؛ يعطي بعض الأمثلة على كل من الأنشطة الإيجابية والسلبية حيث يسهل قضاء الكثير من الوقت في المشاركة (مثل أداء الواجبات المنزلية والألعاب والأفلام ومقاطع

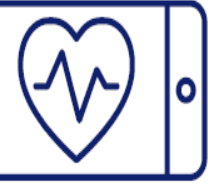
(الفيديو).

- يشرح سبب وجود قيود عمرية على بعض الأنشطة عبر الإنترنت، ولماذا من المهم متابعتها ومعرفة من يمكنه التحدث إليه إذا ضغطه الآخرون على المشاهدة أو القيام بثيء ما عبر الإنترنت يجعله يشعر بعدم الارتياح (مثل الألعاب أو مواقع الويب 


$$
\text { (المقيدة بحسب العمر). }
$$

- يدرك الضغوط التي يمكن أن تفرضها التكنولوجيا على شخص ما ويمكنه مناقثتها (على سبيل المثال: الاستجابة الفورية على وسائل التواصل الاجتماعي وتطبيقات الفئل

$$
\text { المراسلة؛ متاحة دائماً، المشاركة السريعة). }
$$

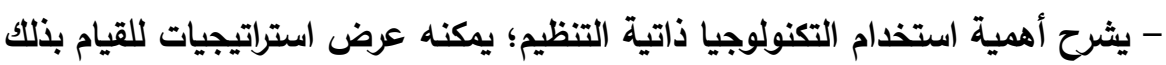

$$
\text { (مثل مراقبة الوقت الأي يقضيه على الإنترنت، وتجنب الحوادث). }
$$

- يشرح كيف يمكن لشخص أن يدرك أنه بحاجة إلى الدعم لإدارة استخدامهم

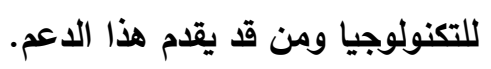

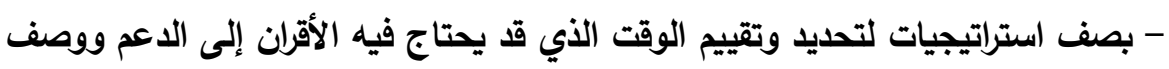
طرق لمساعدة الأقران الذين قد يواجهون صعوبات.

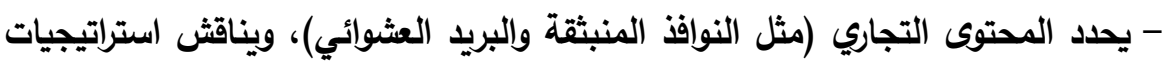

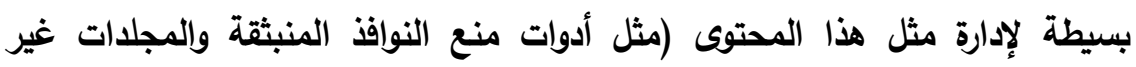
(المرغوب فيها وإلغاء الاشتراك).

- يحدد ويقيم الميزات التي قد تثير إلى أن موقعاً ما أو مجموعة اجتماعية يمكن أن تؤثر سلباً على الرفاهية.

- يقدم استراتيجيات لتحديد وتقييم المساعدة من المواقع أو المنظمات المحترمة التي قد تكون أكثر فائدة.

- يشرح فوائد ومخاطر استخدام المصادر عبر الإنترنت للتشخيص الذاتي والعلاج الذاتي ولماذا يجب على شخص ما استشارة أخصائي طبي إذا كان قلقًا بثأن صحته. - يحدد بعض الأمثلة البسيطة لمعلوماته الثخصية (مثل الاسم والعنوان وتاريخ الميلاد الثياد والعمر والموقع). الخصوصية والأمن (V) Privacy and - يشرح من سيكون جديراً بالثقة لمشاركة هذه المعلومات معه؛ يشرح سبب الوثوق security

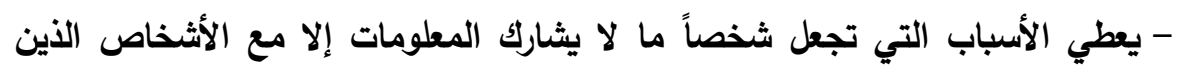

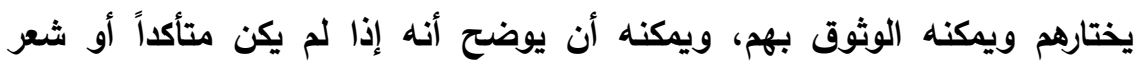

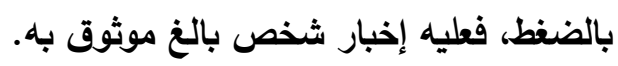

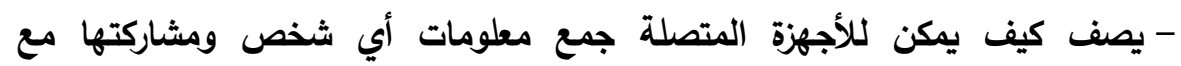


- يشرح سبب استخدام شخص ما لكلمة مرور قوية ومنفصلة لحساب بريده الإكتروني، كبوابة للحسابات الأخرى عبر الإنترنت.

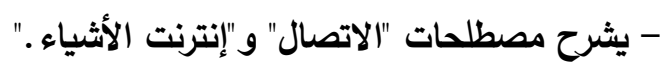
- يتعرف على أن الأجهزة يمكنها جمع البيانات ومشاركتها حول المستخدمين بمعرفتهر الأبياء .

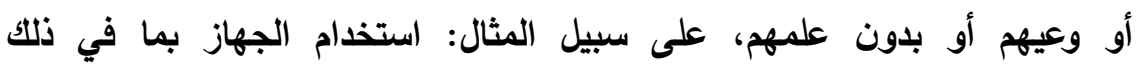
الميكروفون والكاميرا والموقع الجغرافي. - يتفهم فوائد المصادقة الثنائية ويستخدمها حيثما كان ذلكئ متاحاً.

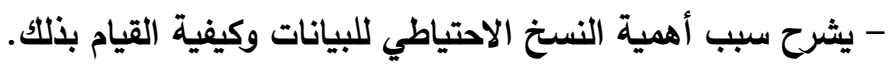

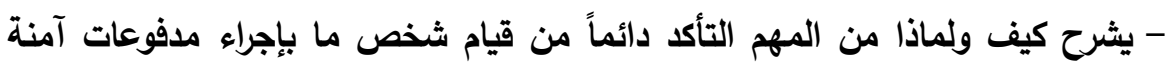
عبر الإنترنت. - يشرح سبب وجود شروط وأحكام للخدمات عبر الإنترنت تحكم استخدامها، ويعطي

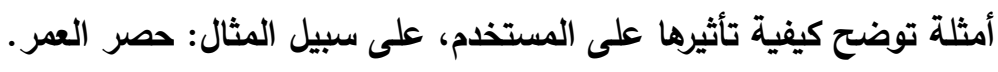

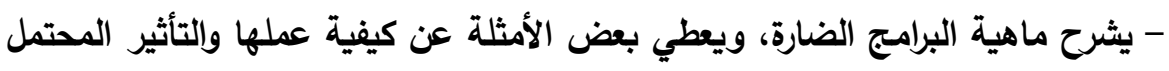

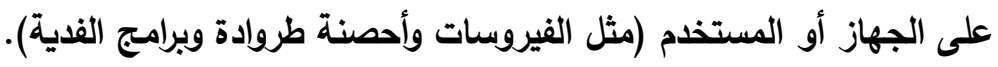

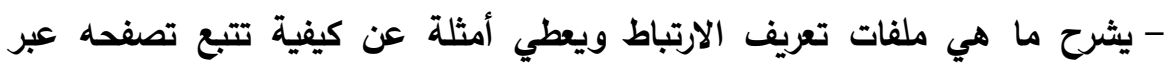
الإنترنت واستخدامه بواسطة الآخرين (مثل برامج الإعلانات المتسللة).

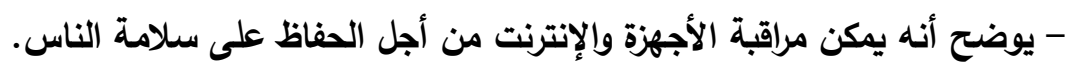

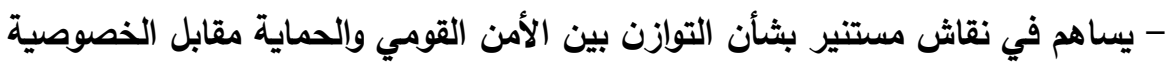
الشخصية.

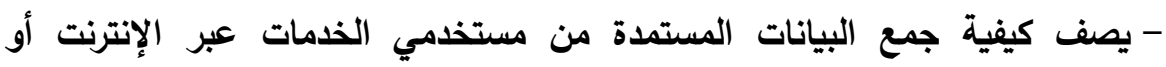

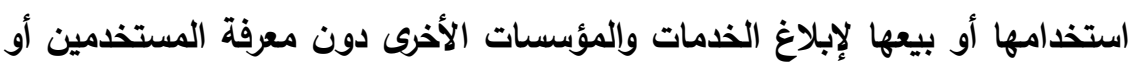
موافقتهم، ويعطي أمثلة على ذلك. - يوضح طرقاً إضافية لحماية البيانات الموجودة على أجزاته وإدارتها (مثل: العثور على هاتفه، والوصول عن بُعد، وحذف البيانات عن بُعد). - يعرف أن العمل الأي يقوم بإنشائه ملك له له. - يمكنه تسمية عمله حتى يعرف الآخرون أنه ملك له. - يشرح لماذا يعتبر نسخ عمل شخص آخر من الإنترنت بدون إذن أمراً غير عادل، ئه الأهرن (^) Copyright and ownership 


\section{كلية التربية للطفولة المبكرة- جامعة بني سويف}

ويمكنه شرح المثكلات التي قد يسببها هذا.

- يدرك أنه يمكن عرض المحتوى التجاري عبر الإنترنت أو الوصول إليه أو تنزيله بثكل غير قانوني. - يعطي بعض الأمثلة على الوصول غير القانوني (مثل البث غير القانوني ومواقع القرصنة ومواقع التورنت والمشاركة بين الأقران) والمخاطر المرتبطة بذلك. - يحدد مفهوم الانتحال بدقة. - يستخدم هذا التعريف لتقييم المصادر عبر الإنترنت. - يطبق رخصة المشاع الإبداعي(1) Creative Commons على عمله الخاص.

\section{وللإجابة على السؤال الثاني من أسئلة الدراسة:}

قامت الباحثة بعرض تحليلي لأبرز : (أ)البرامج والمشروعات العالمية المعاصرة التي تناولت تفعيل كافة أبعاد التعليم من أجل عالم متصل Education for a World Connected تناولت تفعيل بعض أبعاد التعليم من أجل عالم متصل Education for a Connected

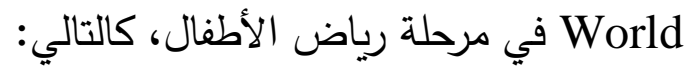
(أ)البرامج والمشروعات العالمية المعاصرة التي تناولت تفعيل كافة أبعاد التعليم من أجل عالم متصل Education for a Connected World في منهج رياض الأطفال وتمثل هذه البرامج والمشروعات نماذج للخبرات والتجارب العالمية المعاصرة في مجال تفعيل إطار التعليم من أجل عالم متصل Education for a Connected World

(1) المشاع الإبداعي هو منظمة عالمية غير ربحية، مقرها مدينة سان فرانسيسكو بالولايات المتحدة الأمريكية، تساعد في التغلب على العقبات القانونية لمشاركة المعرفة والإبداع، لمواجهة التحديات الملحة

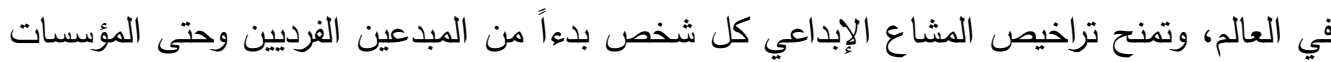
الكبيرة، طريقة موحدة لمنح الجمهور الإذن باستخدام أعمالهم الإبداعية، بموجب قانون حقوق النشر . 
بشكل متكامل في مناهج مرحلة الطفولة المبكرة، وهي ما تزال محدودة نظراً لحداثة الإطار، ومن أبرز هذه البرامج والمشروعات:

(أ- ( ) مشروع "بربل ماش" Purple Mash للتعليم من أجل عالم متصل

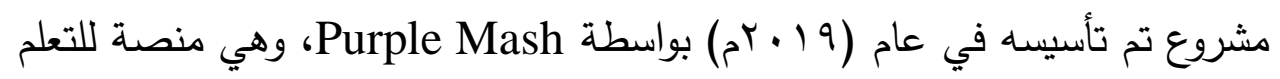
عبر الإنترنت online learning platform بالمملكة المتحدة، شعارها "إجعل المنهج بأكمله ينبض بالحياة" Bring the whole curriculum to life، وهي حائزة على العديد من الجوائز في مجال المناهج الدراسية لأطفال الروضة والمدرسة الابتدائية.

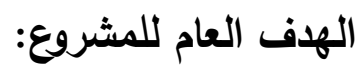

وضع خريطة منهج curriculum map، يتم فيها تجزئة أهداف التعلم-التي تم

تحديدها في الإطار الحكومي government framework للتعليم من أجل عالم متصلفي إطار مجموعات عمرية، مع إعطاء أمثلة لموارد Purple Mash، التي يمكن استخدامها لاعم support الأهداف.

الفئات العمرية المستهدفة:

الأطفال من رياض الأطفال Early Years، وحتى الصف السادس الابتدائي .

Year 6

وصف المشروع:

تتضمن خريطة منهج التعليم من أجل عالم متصل بالمشروع-لكل مجموعة عمرية-

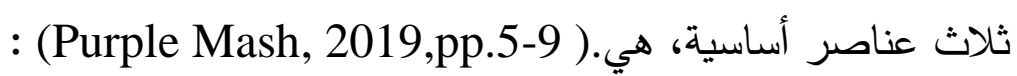

أ-الأهداف Objective الخاصة بكل بعد من الأبعاد الثمانية التعليم من أجل عالم

متصل. 
ب-الموارد Purple Mash Resources، وفيها تم توضيح استراتيجيات التعليم والتعلم

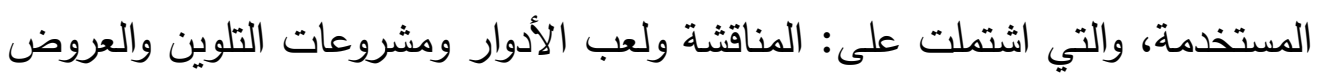

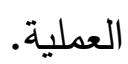

ج جروابط الموارد Link to Resources

ويوضح جدول(ه) أبعاد التعليم من أجل عالم متصل وأهداف التعلم المرتبطة

لمرحلة رياض الأطفال وفقاً لمنهج مشروع Purple Mash بالمملكة المتحدة.

National Online Safety مشروع المنظمة الوطنية للسلامة على الإنترنت (Y)

(NOS)

مشروع تم تأسيسه في عام (9 (1) بم) بالمملكة المتحدة، بواسطة المنظمة المشار

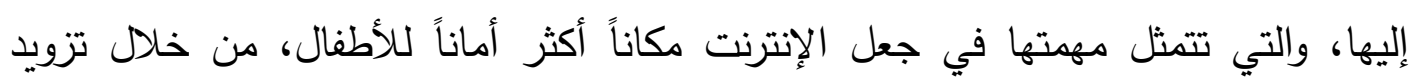

المعلمين وأولياء الأمور والأطفال بالمعرفة التي يحتاجون إليها لفهم المخاطر عبر الإنترنت.

الهذف العام للمشروع: - إن

تزويد الأطفال بالمعرفة لحماية أنفسهم من المخاطر التي يواجهونها عند استخدام

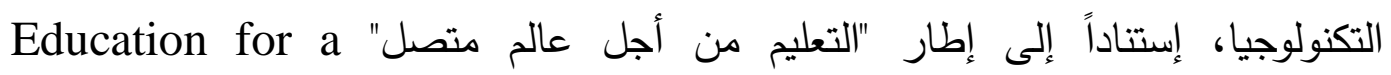

.Connected World

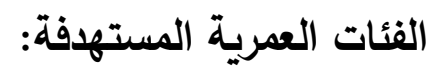

المتعلمون من مرحلة ما قبل الددرسة وحتى المرحلة الثانوية.

وصف المشروع:

يتضمن جزء المشروع المخصص للأطفال من (ع-V) سنوات حزمة خطط دروس

interactive video lessons تتضمن دروس فيديو تثاعلية Lesson Plans Bundle تم إنتاجها في بيئة الفصل الدراسي للمساعدة في تثجيع الأطفال على التواصل والتفاعل

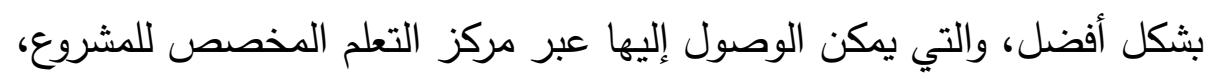

$\Lambda \vee r$

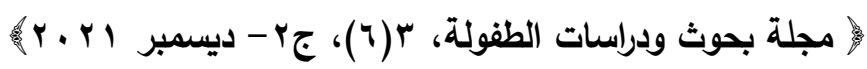




\section{جدول(0)}

أبعاد التعليم من أجل عالم متصل وأهداف التعلم المرتبطة لمرحلة رياض الأطفال وفقاً لمنهج مشروع Purple Mash

\begin{tabular}{|c|c|}
\hline أهداف الت & ن أجل عالم متصل \\
\hline 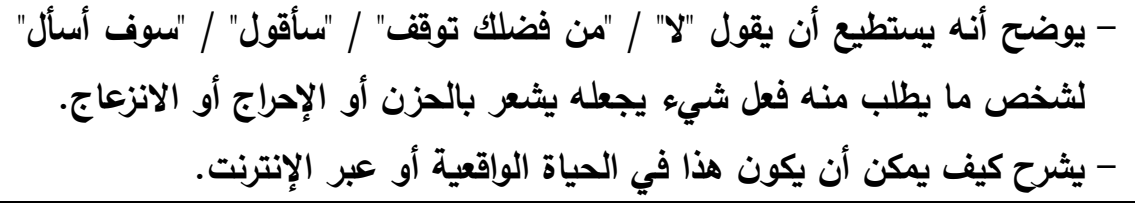 & $\begin{array}{c}\text { (1) ( الصورة الذاتية والهوية } \\
\text { Self-image and identity }\end{array}$ \\
\hline 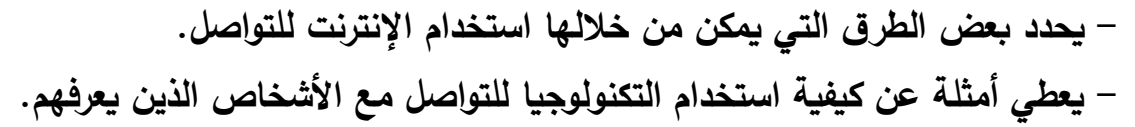 & $\begin{array}{l}\text { (r) (العلاقات عبر الإنترنت } \\
\text { Online relationships }\end{array}$ \\
\hline - يحدد الطرق التي يمكنه من خلالها وضع المعلومات على الإنترنت. & $\begin{array}{l}\text { (r) (السمعة على الإنترنت } \\
\text { Online reputation }\end{array}$ \\
\hline - يقدف أمثلة على كيف يمكن لذي يمن أن يتعامل بها بعض أن يجعل الآخرون يشعرون. & $\begin{array}{c}\text { ( ) التنمر عبر الإنترنت } \\
\text { Online bullying }\end{array}$ \\
\hline - يتحدث عن كيفية استخدام الإنترنت لاكتشاف الأثياء. & 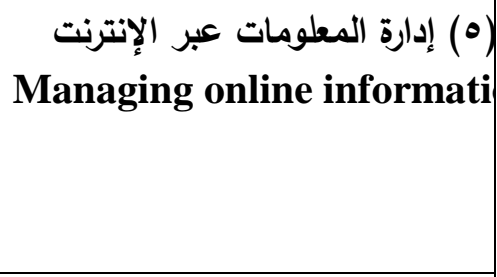 \\
\hline 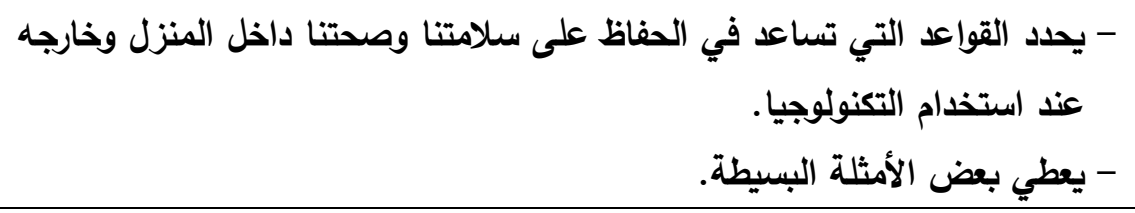 & $\begin{array}{l}\text { Health, well-being and } \\
\quad \text { lifestyle }\end{array}$ \\
\hline 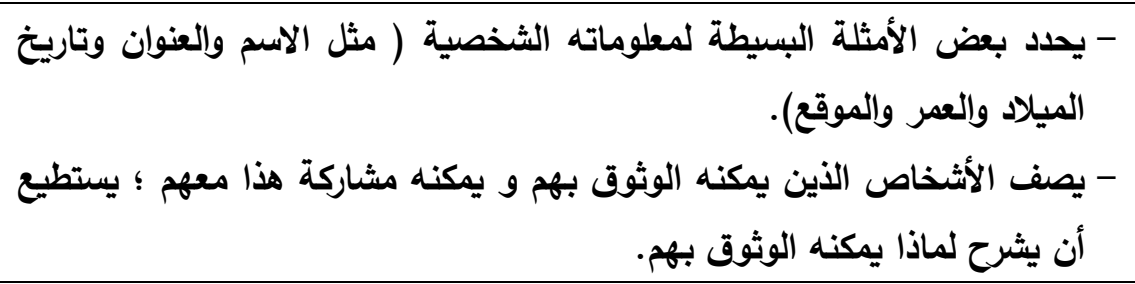 & $\begin{array}{c}\text { الخصوصية والأمن (V) } \\
\text { Privacy and security }\end{array}$ \\
\hline - يعرف أن العمل الذي يقوم بإنثائه ملك له. & $\begin{array}{c}\left.\text { حقوق النشر والملكية (^) }()^{\wedge}\right) \\
\text { Copyright and ownership }\end{array}$ \\
\hline
\end{tabular}


جنباً إلى جنب مع حزم دروس قابلة للتنزيل يطلق عليها "حزمة الدروس التكميلية"

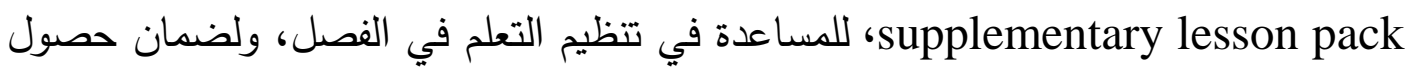

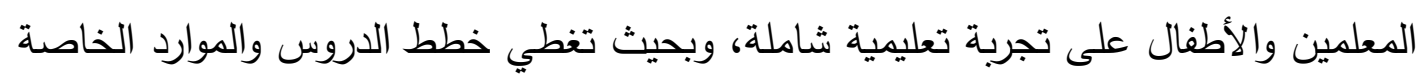

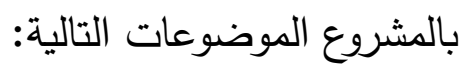

1- الصورة الذاتية والهوية Self Image \& Identity: يغطي هذا الموضوع فهم المشاعر والاستجابة للسيناريوهات التي تجعل الأطفال يشعرون بعدم الارتياح عبر الإنترنت.

r- العلاقات عبر الإنترنت Online Relationships: يغطي هذا الموضوع الطرق التي

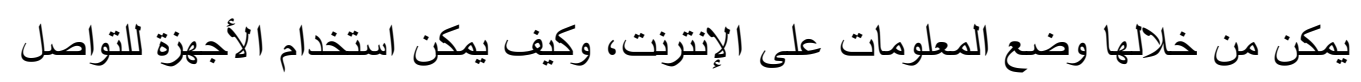

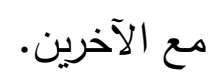

r- السمعة عبر الإنترنت Online Reputation: يغطي هذا الموضوع الطرق التي يمكن للناس من خلالها استخدام التكنولوجيا للتواصل. ؟- التتمر عبر الإنترنت Online Bullying: يغطي هذا الموضوع التعرف على السلوك السلبي عبر الإنترنت وتأثيره.

ه- إدارة المعلومات عبر الإنترنت Managing Online Information: يحدد هذا الموضوع التتنيات المختلفة التي يمكن استخدامها للوصول إلى الإنترنت.

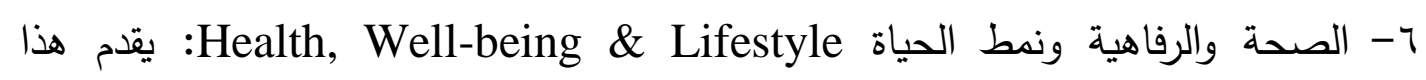
الموضوع القواعد الأساسية للمساعدة في الحفاظ على أمان الأطفال عبر الإنترنت. V- الخصوصية والأمن Privacy \& Security: يقدم هذا الموضوع أنواع المعلومات

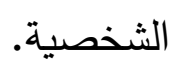
^- حقوق النشر والملكية Copyright \& Ownership: يهدف هذا الموضوع إلى تعليم

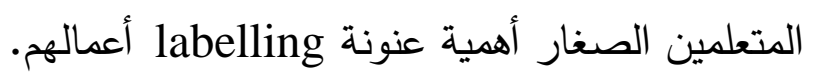


وتسير خطوات استراتيجية التعليم والتعلم الرئيسة في المشروع، وفقاً للخطوات

الثلاث التالية:

$$
\text { 1- تقديم ومشاهدة الفيديو التفاعلي. }
$$

r - بتيار الطفل لنشاط التعلم بقيادة المعلم.

r- تشجيع الأطفال على تطوير التعلم المستقل حول الموضوع.

وتتتوع الأنشطة لتشمل الأنشطة التي يقودها المعلم teacher-led، والأنشطة

المستقلة independent، مع تكليفات assignments منزلية ذات صلة، للمساعدة في تضمين التعلم خارج الفصل الدراسي (NOS, 2019a, NOS, 2019b).

\section{PROJECT EVOLVE (أ-r) مشروع إيفولف}

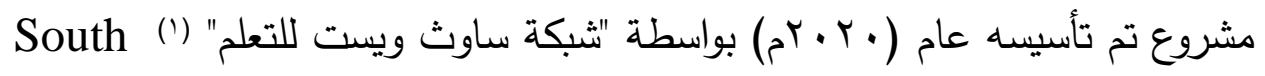
بالمملكة المتحدة، بالشراكة مع كل من مركز for Learning West Grid (SWGfL)

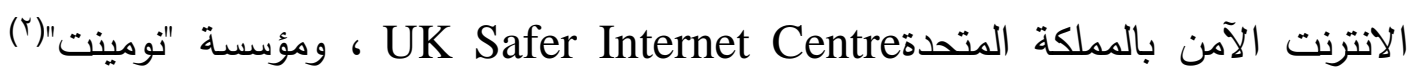

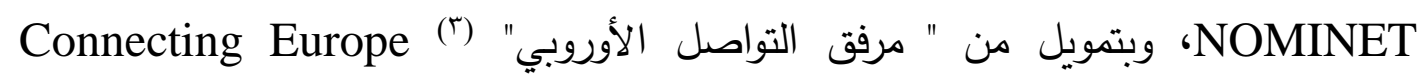
.Facility (CEF)

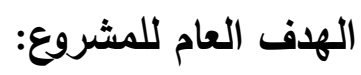
prepare the learners for the digital world إعداد المتعمين للعالم الرقمي

(1) مؤسسة غير ربحية تهدف أن تضمن للجميع الاستفادة من التكنولوجيا الخالية من الأذى، يشكل خبراؤها //T من مركز الإنترنت الآمن في المملكة المتحدة. (Y) المؤسسة المسؤولة عن أسماء نطاقات شبكة الإنترنت في المملكة المتحدة.

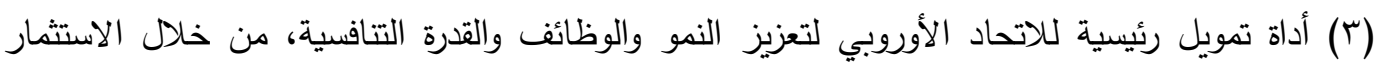

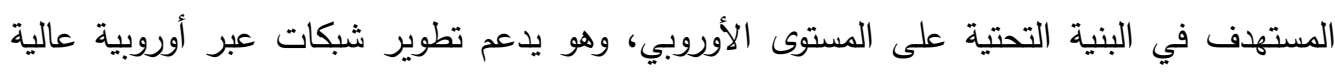
الأداء ومستدامة ومترابطة بشكل فعال، في مجالات النقل والطاقة والخدمات الرقمية. 


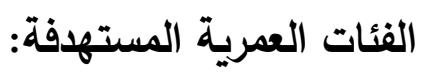

المتعلمون من رياض الأطفال وحتى الصف الثالث الثانوي(ع-1 ( ) سنة

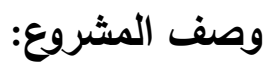

يمثل المشروع مجموعة أدوات للتعليم الرقمي digital education toolkit تستند

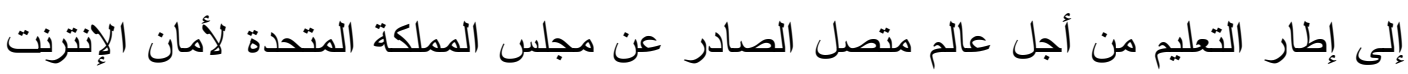

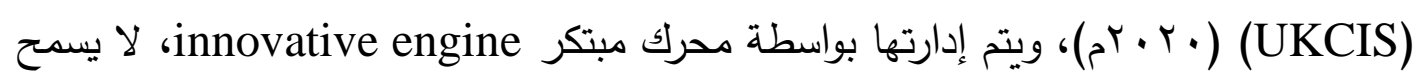
للمستخدمين بالإبحار/التتقل navigating في المحتوى فقط، ولكنه يسمح لهم أيضاً بإضفاء لإنهاء الطابع الثخصي personalize على المحتوى الذي يجمعونه.

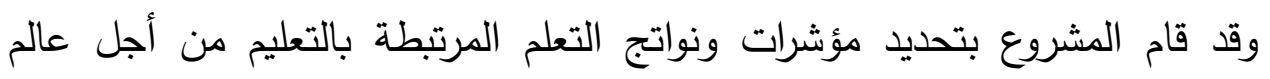

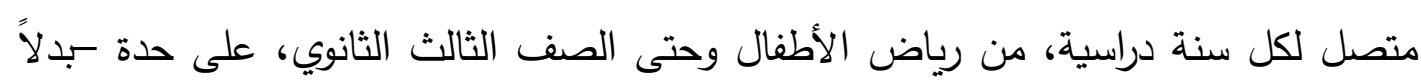

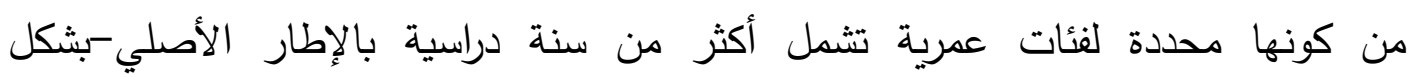

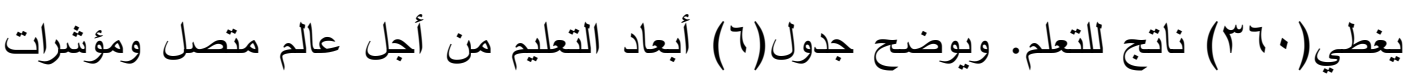

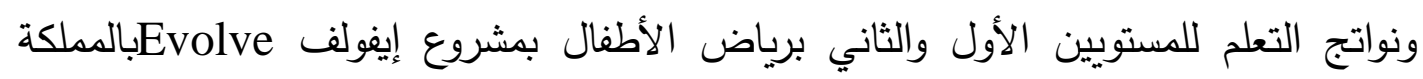

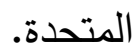

ويتضمن كل نشاط من الأثطة الموجهة للأطفال العناصر الآتية: نواتج التعلم

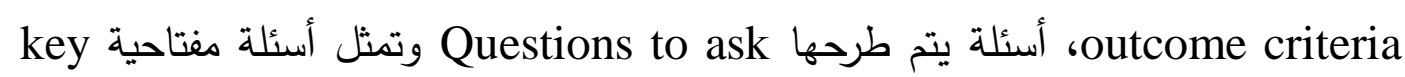

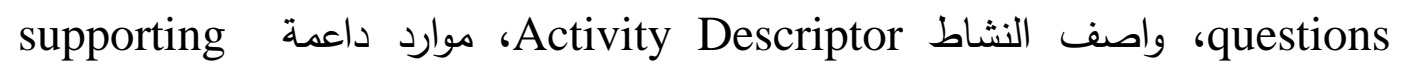

.(SWGfL,2020) resources 


\section{جدول(7)}

أبعاد التعليم من أجل عالم متصل ومؤشرات ونواتج التعلم للمستويين الأول والثاني برياض الأطفال بمشروع إيفولف Evolve بالمملكة المتحدة

\begin{tabular}{|c|c|c|c|}
\hline نواتج التعلم & مؤشرات التعلم & العمرية & 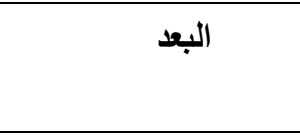 \\
\hline 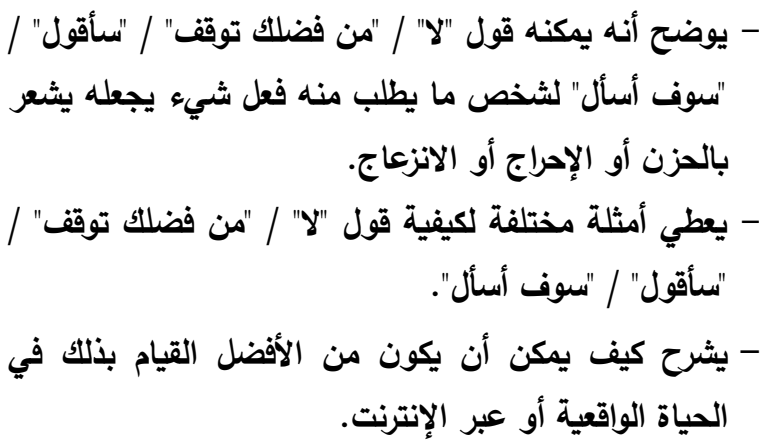 & 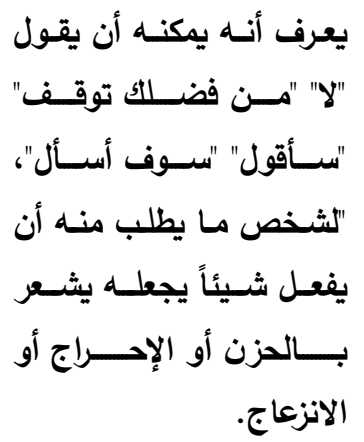 & & $\begin{array}{c}\text { والهوية الصورة الذاتية } \\
\text { والهو-Image and } \\
\text { Identity } \\
\text { Self }\end{array}$ \\
\hline 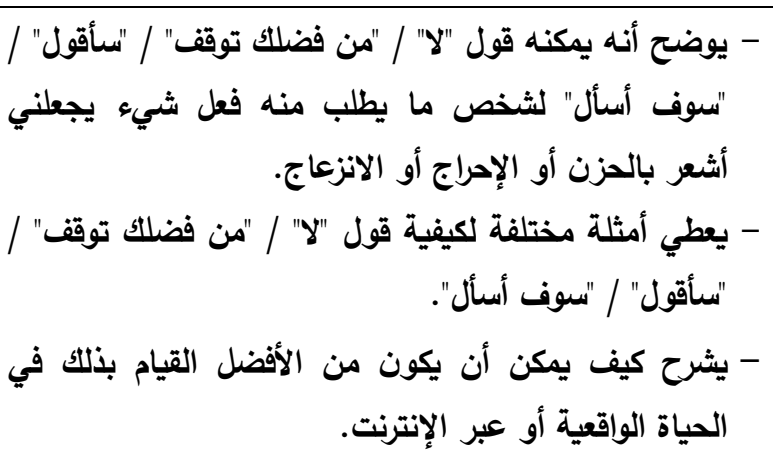 & هذا فيرح كيف يمكن أن يكون الإنترنت & $\frac{3}{3}$ & \\
\hline 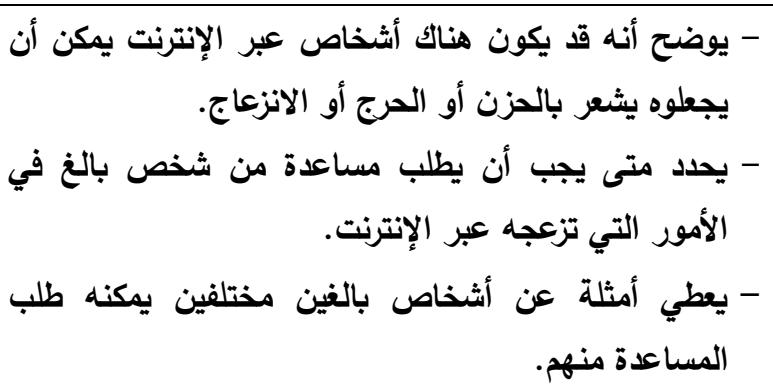 & 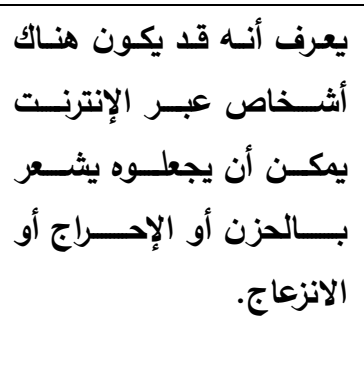 & & \\
\hline 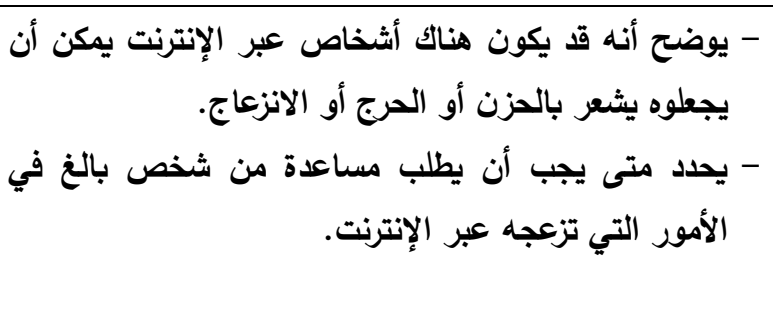 & 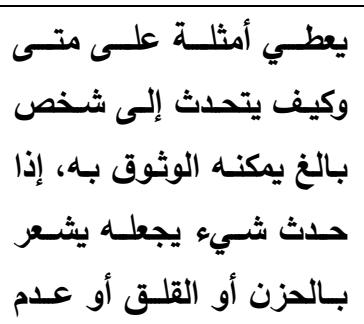 & 每 & \\
\hline
\end{tabular}




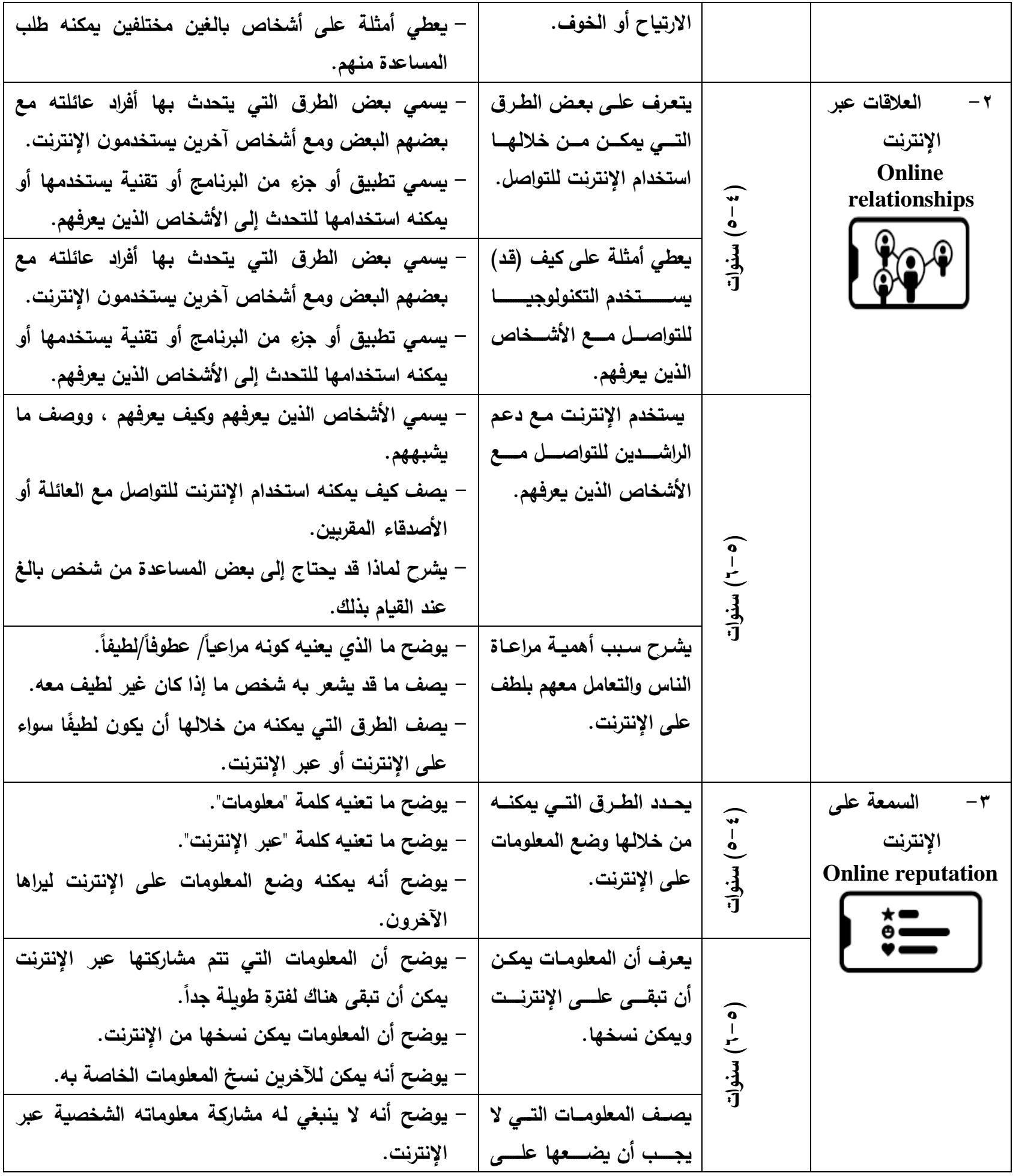




\begin{tabular}{|c|c|c|c|}
\hline 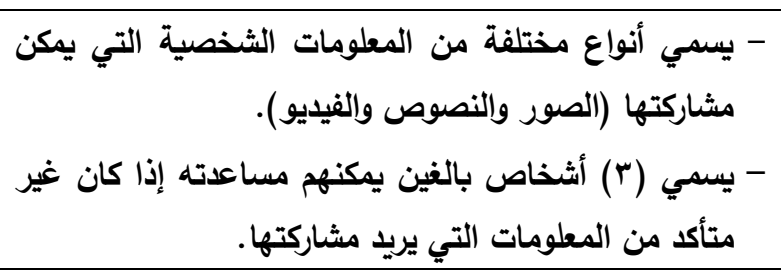 & شخصصًا بالغاً أولاً. & & \\
\hline 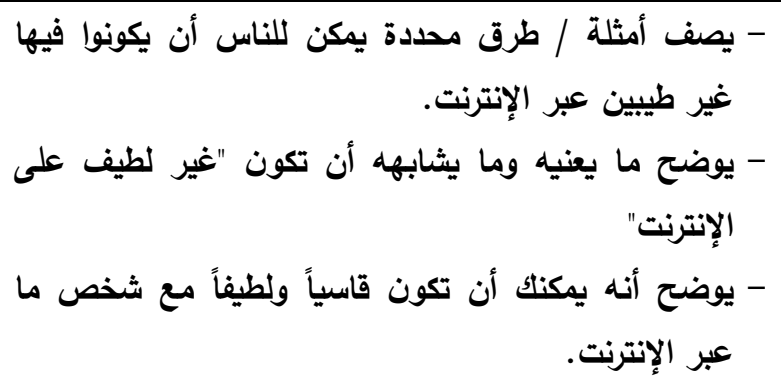 & يصف الطرق بهاء التي يمكن أن بعض الناس غير الإنترنت. & \multirow[t]{2}{*}{$\begin{array}{l}20 \\
\vdots \\
0 \\
\frac{3}{3} \\
\frac{3}{3}\end{array}$} & \multirow[t]{3}{*}{ 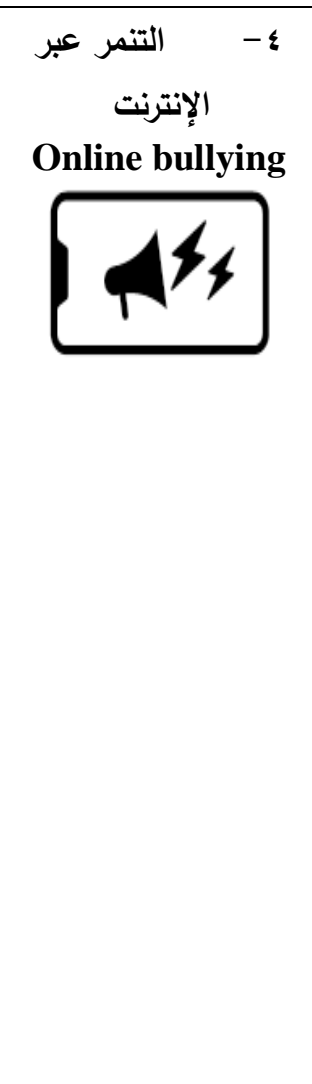 } \\
\hline - يعطي أمثلة على الكلمات غير اللطيفة على الإنترنت التي & 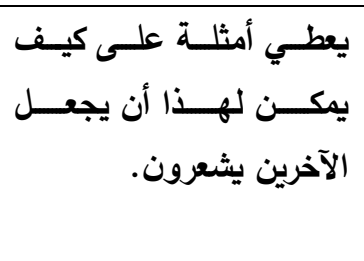 & & \\
\hline - - - يوضح أن بعض الآخرين. & 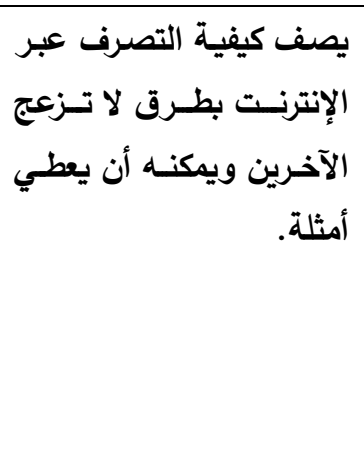 & $\frac{\sigma}{1}$ & \\
\hline 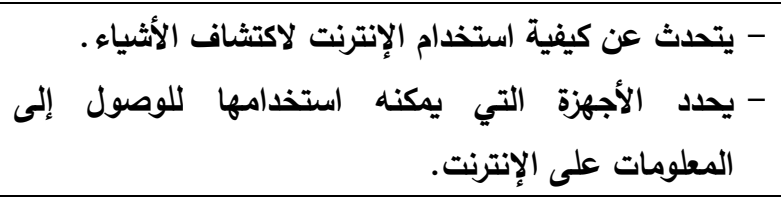 & $\begin{array}{r}\text { الإنترنت لاكتثـاف عن الأثشياء استخدام } \\
\text {.find things out }\end{array}$ & \multirow{3}{*}{ 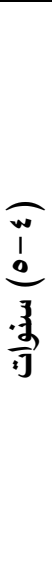 } & \multirow{3}{*}{$\begin{array}{l}\text { المعلومات عبر الإنترنت } \\
\text { Managing online } \\
\text { information } \\
\text { 三 }\end{array}$} \\
\hline 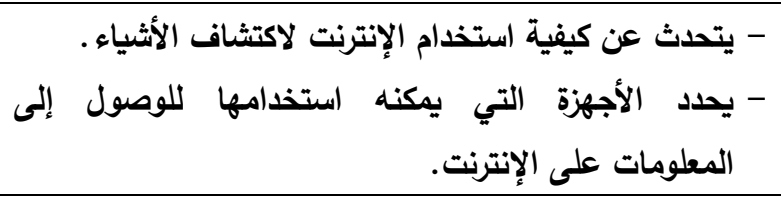 & اســــد الأجهـزة التــي يمكنهـ & & \\
\hline 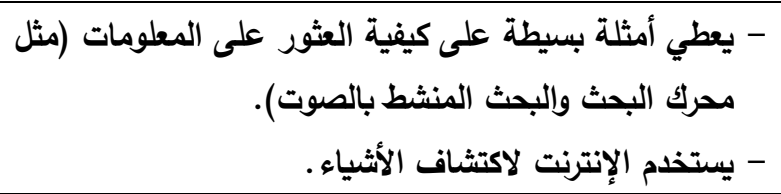 & 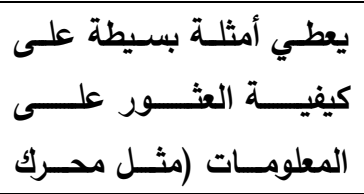 & & \\
\hline
\end{tabular}




\section{كلية التربية للطفولة المبكرة- جامعة بني سويف}

\begin{tabular}{|c|c|c|c|}
\hline & بالصوت). البحـث والبحـث المنثــط & & \\
\hline 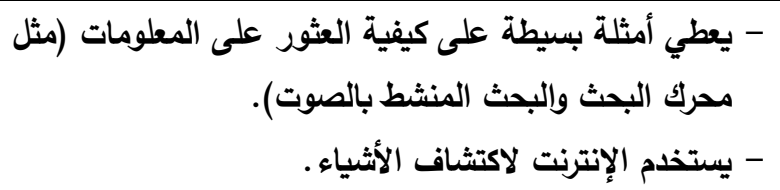 & الأشثياء. & \multirow{3}{*}{ 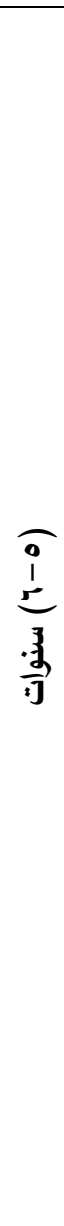 } & \\
\hline 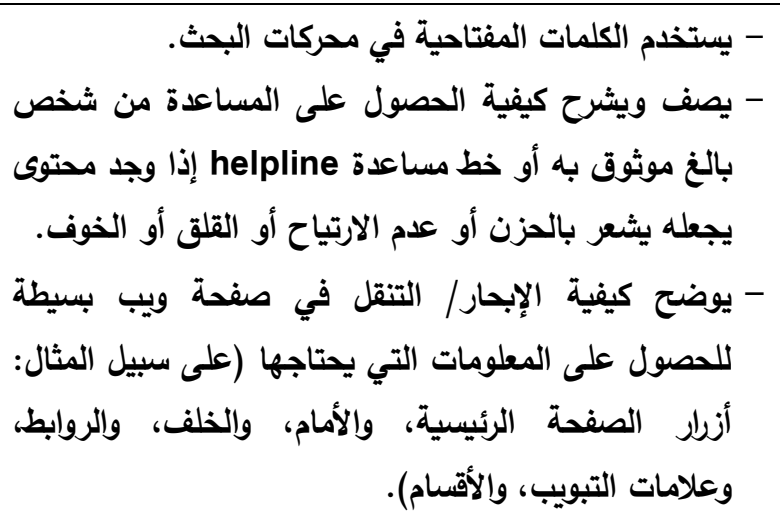 & بسيطة في محركات كلمــات مفتاحيــة & & \\
\hline 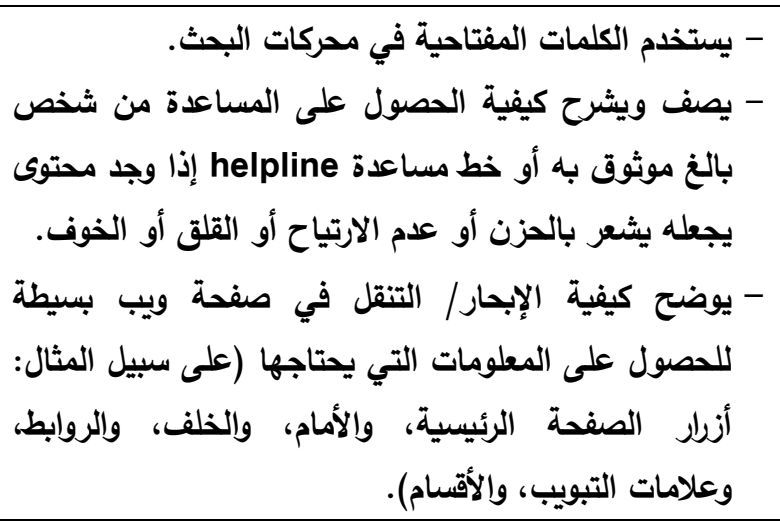 & 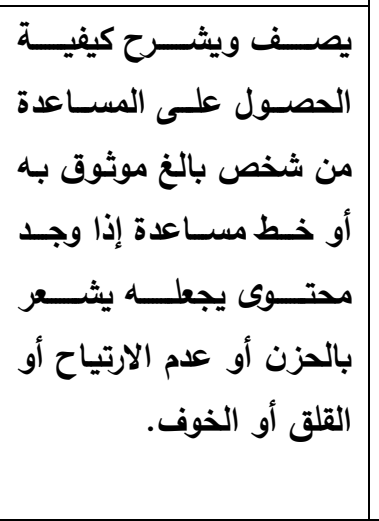 & & \\
\hline 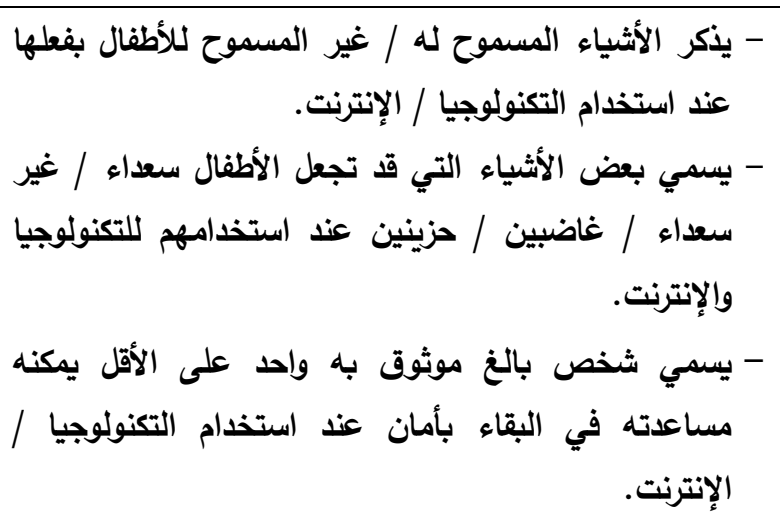 & 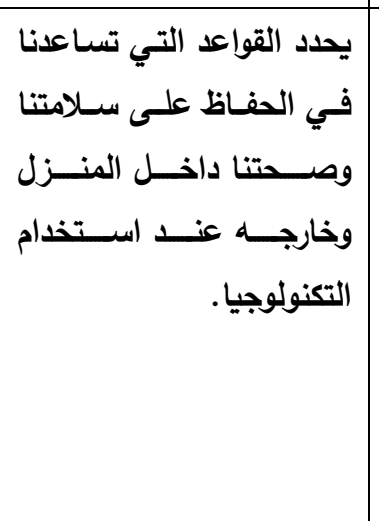 & 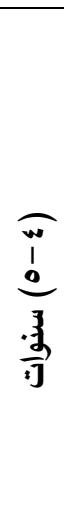 & $\begin{array}{c}\text { والرفاهية ونمط الحياة } \\
\text { Health, well- } \\
\text { being and lifestyle }\end{array}$ \\
\hline
\end{tabular}

$\wedge \wedge 1$

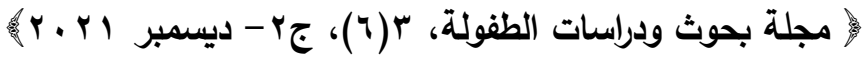




\begin{tabular}{|c|c|c|c|}
\hline - - يعطي بعض الأمثلة على القواعد التي لديه حول استخدام & 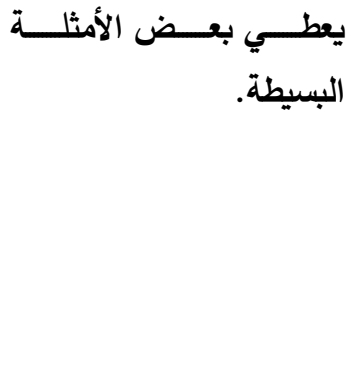 & & \\
\hline 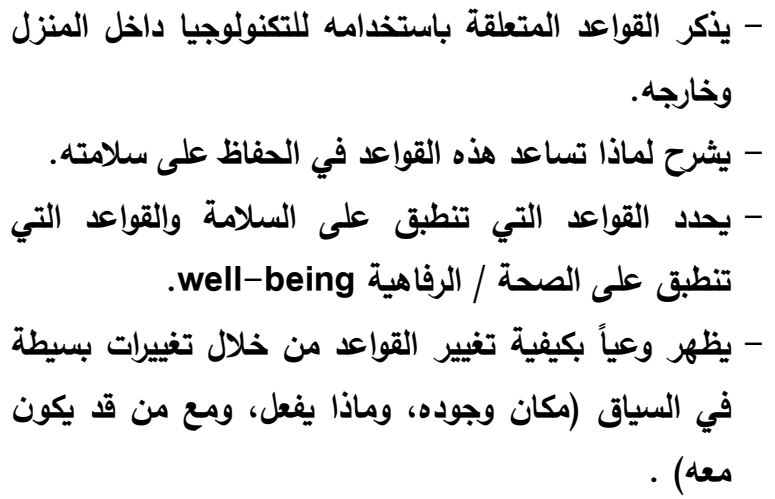 & 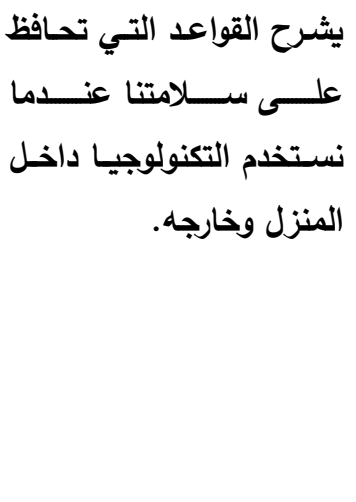 & \multirow[t]{2}{*}{$\frac{2}{i} \underset{\frac{1}{3}}{\frac{3}{3}}$} & \\
\hline 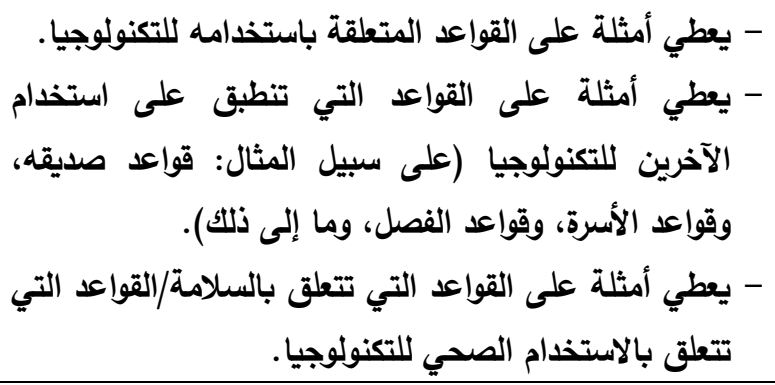 & يعطي أمثلة على بعض هذه & & \\
\hline - يذكر ويسمي أمثلة لمعلوماته الثخصية. & 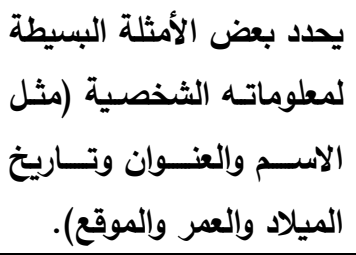 & (1) & $\begin{array}{c}\text { والأمن } \quad-v \\
\text { Privacy and } \\
\text { security }\end{array}$ \\
\hline - يحدد ويسمي أمثلة لمعلوماته الثخصية. & 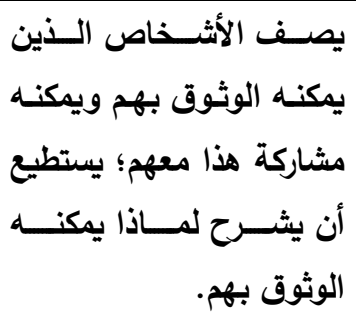 & $\underbrace{\frac{1}{3}}_{\frac{3}{3}}$ & \\
\hline
\end{tabular}




\begin{tabular}{|c|c|c|c|}
\hline - يوضح - يوضح أنواع البيانات التي قد تكون شخصية بالنسبة له. & 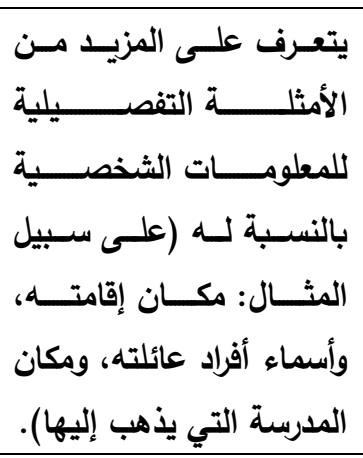 & \multirow{3}{*}{ 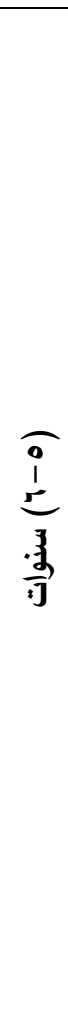 } & \\
\hline 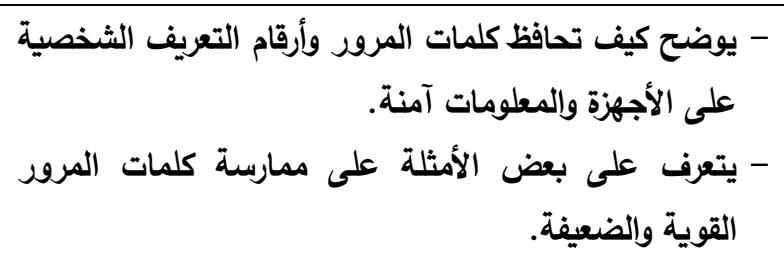 & 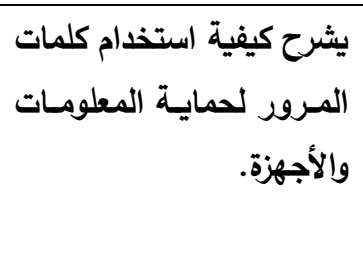 & & \\
\hline - يوضح - يوضغ أنواع البيانات التي قد تكون شخصية بالنسبة له. & 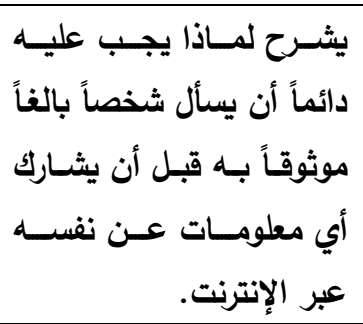 & & \\
\hline - يش - يوضح كيف وأن الأثشاء والعمل يمتلك العمل الرقمي أن تخصه. & بإنشائه ملكاً له. & 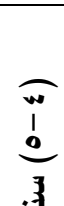 & 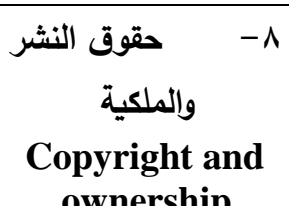 \\
\hline 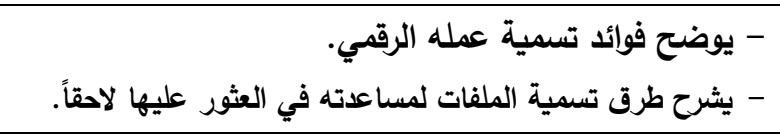 & الآخرون أنه يخصه. علـه حتـى يعرف & $\frac{1}{3}$ & ownersmip \\
\hline 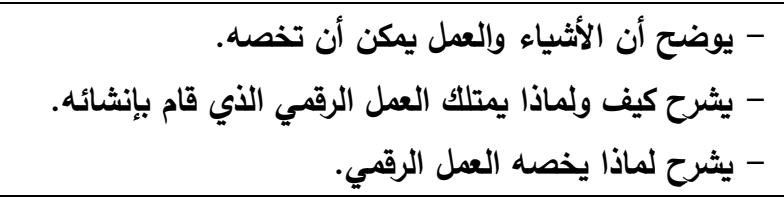 & 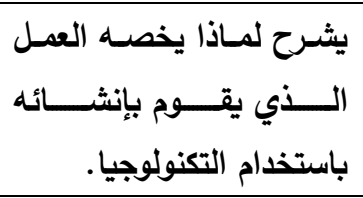 & & \\
\hline 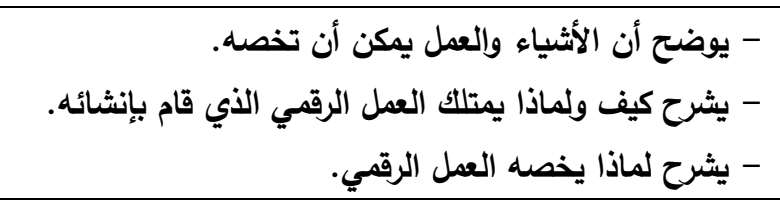 & فككنه أن يقول لماذا تخصه سيبل المثال: "إنها & 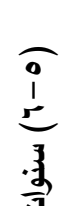 & \\
\hline - يشرح طرق فوائد تسمية عمله الرقمي. & سآيحفظ عملـه حتـى يعـرف & & \\
\hline
\end{tabular}


(ب)(البرامج والمشروعات العالمية المعاصرة التي تناولت تفعيل بعض أبعاد التعليم من أجل عالم متصل Education for a Connected World في مرحلة رياض الأطفال تمثل هذه البرامج والمشروعات نماذج للخبرات والتجارب العالمية المعاصرة في

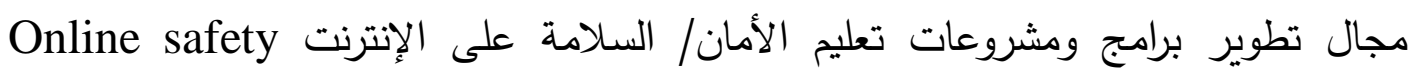

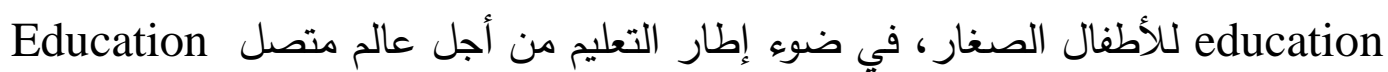
for a Connected World

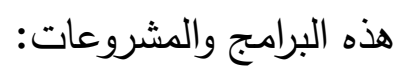

The Power of Kindness program "ب (1) برنامج "قوة العطف

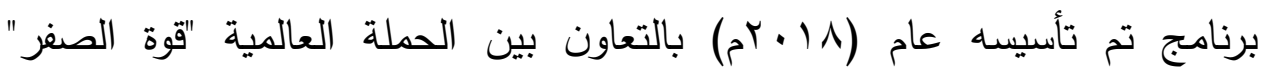

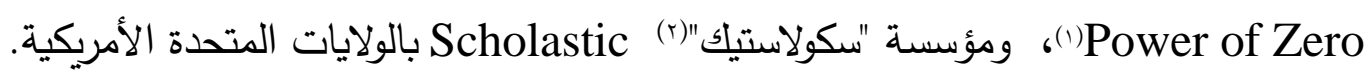

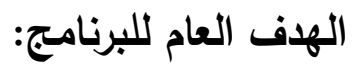
تعليم الأطفال قوة الكلمات power of words، شخصياً وعبر الإنترنت، بحيث

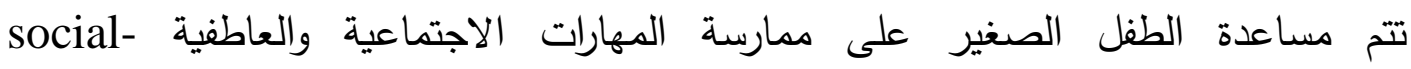
emotional skills

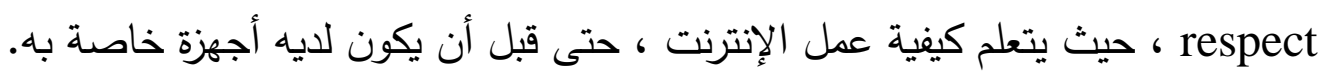
الفئات العمرية المستهدفة:

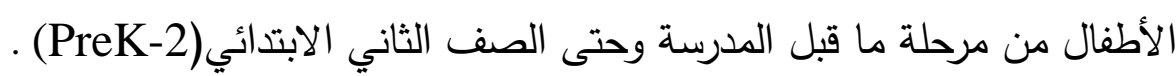
أبعاد التعليم من أجل عالم متصل التي يتناولها البرنامج:

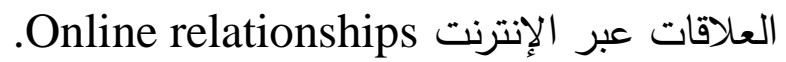

Learn. Connect. (1) حملة عالمية لإعادة تثكيل التعلم المبكر لعالم متصل، شعارها تعلم -اتصل-إزدهر Thrive شارك في تأسيسها منظمة الأمم المتحدة للتربية والعلوم والثقافة (اليونسكو).

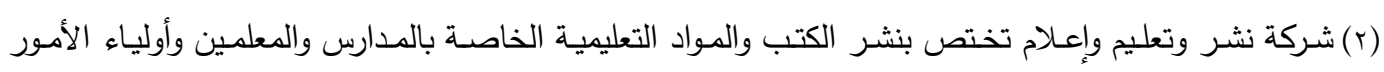
والأطفال 
يستند البرنامج إلى فلسفة مؤداها:" إن تعليم أطفالنا السلوك المسؤول عبر الإنترنت navigate responsible online behavior بأمان ونجاح أثناء نموهم، في العالم الرقمي الآخذ في الاتساع"، ويعتمد البرنامج على لإبى استراتيجية مفتاحية key strategy للمساعدة في حماية الطفل من الحقارة عبر الإنترنت Teach your child to "meanness online PAUSE، ويوضح جدول (V) المعنى المشار في الحروف المكونة لمسمى تلك الاستراتيجية (Power of Zero, 2018).

\section{جدول (v)}

PAUSE المعنى المشار إليه في الحروف المكونة لمسمى الاستراتيجية المفتاحية

في برنامج قوة العطف The Power of Kindness program

\begin{tabular}{|c|c|}
\hline المعنى المشار إليه & المسمى الاستراتيجية \\
\hline يستخدمون كلمات لئيمة أو دنيئة mean نفك من خلال الإبلاغ أو حظرهم Brotecting عن الأثخاص الذين & $\mathbf{P}$ \\
\hline وتغني دائماً Always يتم إخبار أحد الوالدين أو المعلم أو شخص بالغ موثوق به. & $\Delta$ \\
\hline 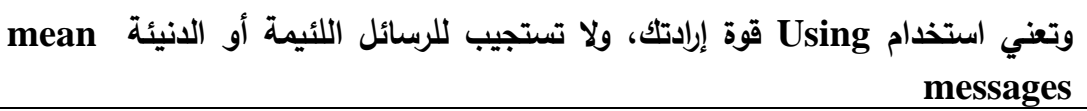 & U \\
\hline مؤنية، وإبلاغ شخص Saving أو طباعة أو التقاط لقطة شاشة لرسائل أو صور مزعجة أو & $\mathbf{S}$ \\
\hline وتعني أن كل شخص Everyone يستحق أن يعامل معاملة طيبة kindly. & E \\
\hline
\end{tabular}

\section{(ب-recrets are allowed project}

مشروع تم تأسيسه عام (19 (19) بالتعاون بين "جامعة زيورخ لتعليم المعلمين" Zurich University of Teacher Education و "هيئة حماية البيانات في كانتون زيورخ"Data Protection Authority of the Canton of Zurich بسويسرا. 110 
وتشير كلمة "الأسرار" في عنوان المشروع إلى البيانات التي يتم جمعها في كل مكان بواسطة الهواتف الذكية والأجهزة الأخرى في عصر الإنترنت. والمشروع حاصل على "جائزة Global Privacy and Data Protection الخصوصية وحماية البيانات العالمية" Award الهدف العام للمشروع: - إ online والخصوصية على الانترنت data security تنمية الوعي بأمن البيانات .privacy الفئات العمرية المستهوفة: أطفال الروضة والسنوات الأولى من المرحلة الابتدائية من (ع-9) سنوات. أبعاد التعليم من أجل عالم متصل التي يتناولها المشروع:

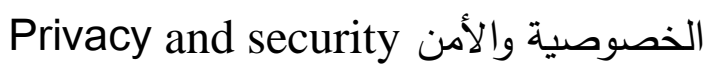
وصف المشروع:

يتضمن المشروع خمس موديولات تعليمية، تتناول موضوعات وجوانب متعلقة بالخصوصية وحماية البيانات، بشكل يتم فيه التركيز على بناء المعرفة المناسبة التي تمكن الأطفال من التصرف بأكبر قدر مدكن من الكفاءة مع المهارات التي اكتسبوها في مواقف مختلفة أو التفكير في سلوكهم الشخصي. وبحيث يمكن دمج أنشطة الموديولات في خطة المنهج الفعلي بشكل مستقل عن بعضها البعض-بما يتماشى مع السياق والمناسبة -أو استخدامها على التوالي.

وتثتمل المديولات الخمس على: موديول لأطفال الروضة من سن(ع-7) سنوات

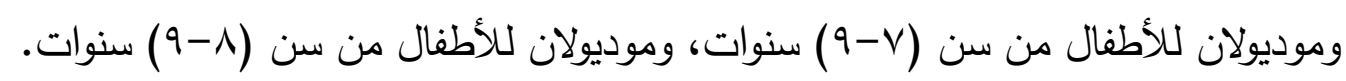




\section{كلية التربية للطفولة المبكرة- جامعة بني سويف}

ويتاول الموديول المخصص لأطفال الروضة موضوع "التعامل مع الأسرار" Dealing with secrets "ماتي" Matti

ويتم التركيز في هذا الموديول على الكفايات Competencies الآتية:

- الحساسية في التعامل مع المعلومات الشخصية. - الاعتراف بأن الثجاعة الدننية civil courage قوة. - العلم أنه يمكن للمرء الحصول على المساعدة، وكيف. كما يتم التركيز على مؤشرات التعلم الآتية، والتي تتضمن أن يعرف الطفل أن: - كل شخص، وبالتالي كل طفل، له الحق في حماية بياناته. - الثقة وحفظ أو خيانة الأسرار الثخصية هي عمليات عاطفية/وجدانية emotional -

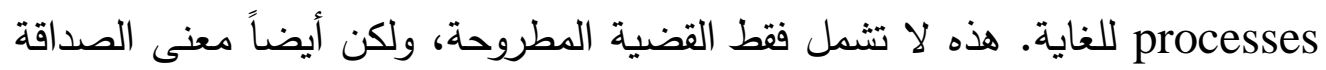
والثقة والتسامح.

- ليس هناك خيار واحد فقط، بل عدة خيارات لكيفية التصرف في المواقف الصعبة. - الجميع يرتكبون أخطاء، ويمكن للمرء التحدث عنها معاً، والاعتذار والبحث عن حل. ويتضمن الموديول ثلاث أنشطة متسلسلة ومتتابعة كالتالي: Animation "Matti's النشاط الأول: عرض فيلم رسوم متحركة بعنوان "سر ماتي "Secret ويتم فيه التركيز على استكشاف الموضوع من خلال ما تشعر به شخصيات الفيلم حول ما يفعلونه، وتكمن طريقة التعليم الأساسية في البداية في المناقشة الجماعية، بحيث

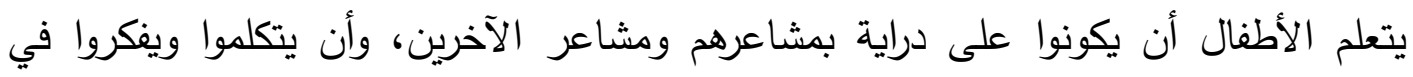

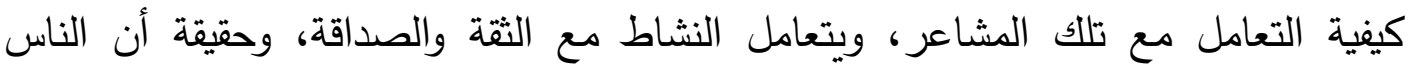


يخطئون أحياناً وكيفية التعامل مع ذلك، مع تشجيع الأطفال على نقل ما تعلموه في هذا النشاط إلى حياتهم اليومية، بحيث يمكن أن يقدموا أمثلة من تجاربهم ومشاعرهم (على أساس تطوعي بحت)، بالإضافة إلى طرح أفكار حول كيفية التعامل مع الأسرار والصداقات وارتكاب الأخطاء.

Y النشاط الثاني: تتويعات في التمرين الموسع Variations on extended exercise ويتم فيه التركيز على متابعة الأنشطة مع شخصيات الفيلم في سياق عمليات إبداعية. بحيث يمكن للأطفال التفكير في قصة الفيلم بطرق مختلفة، وتصميم الثخصيات من خلال الرسم والحرف اليدوية، وإعادة صياغة القصة أثناء اللعب الحر أو التمثيل، كما يمكن للأطفال أيضاً إنشاء فيلم رسوم متحركة خاص بهه، باستخدام تطبيقات لأجهزة الأيباد iPad وأجهزة الأندرويد Android اللوحية التي تتيح للأطفال تحقيق نتائج رائعة. كما يمكن سرد القصة من خلال لعب الأدوار، وباستخدام أزياء تساعد الأطفال على الاندماج في الأدوار وإبعاد أنفسهم عن هوياتهم، كما تساعدهم على التمييز بين الأدوار المختلفة.

The making of to the film النشاط الثالث: صنع الفيلم

ويتم فيه التركيز على إعطاء الأطفال نظرة سريعة وراء الكواليس أثناء إنتاج فيلم رسوم

متحركة، بحيث يتم استخدام الصور لفهم ومعرفة كيفية صنع الفيلم، من تأليف القصة وعملية الرسم والرسوم المتحركة للأشكال، إلى عمل فنان الصوت ومصمم الصوت، بحيث يتعلم لأطفال أن الأفلام من صنع الأشخاص، ويمكن تصميمها وفقاً لأفكارهم. وللتشجيع على انتقال أثر التعلم، يقوم المعلم بمساعدة الأطفال في إنشاء فيلمه الخاص، وذلك بالاستعانة ببعض المواد التي يوفرها المشروع للتحميل والطباعة(LERNPRIVACY, 2020). 


\section{Jessie \& Friends Program "ب- برنامج "جيسي وأصدقائها)}

برنامج تعليمي تم تصميمه عام (9 ( ب rم) في إطار البرنامج القومي لتعليم الأمان/ السلامة على الإنترنتThinkuknow، والمؤسس بواسطة "مركز مكافحة استغلال الأطفال Child Exploitation and Online Protection Command " والحماية عبر الإنترنت الإنتانع

National Crime Agency (NCA) التابع للوكالة الوطنية لدكافحة الجريمة (CEOP)

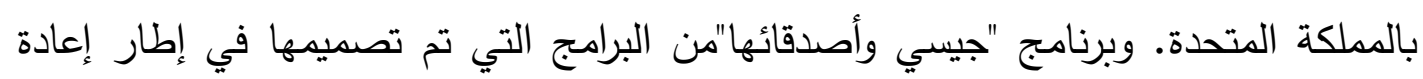

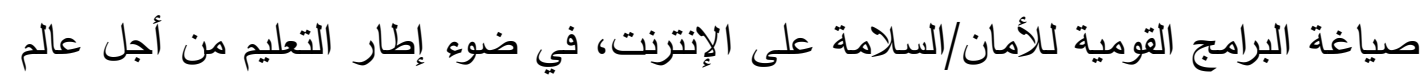
متصل، والبرنامج حاصل على علامة الجودة Quality Mark من الجمعية الوطنية للتعليم

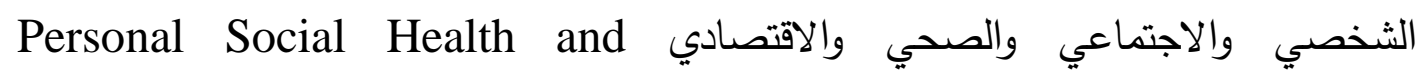
Economic (PSHE) Association

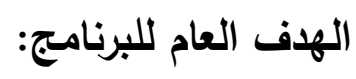

تزويد الأطفال بالمعرفة والمهارات والثقة للمساعدة في حمايتهم من الانتهاك

الجنسي sexual abuse، والمخاطر الأخرى التي قد يواجهونها عبر الإنترنت.

الفئات العمرية المستهدفة: - الفئ

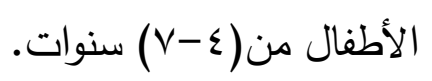

أبعاد التعليم من أجل عالم متصل التي يتناولها البرنامج: العلاقات عبر الإنترنت Online relationships -التتمر عبر الإنترنت Health, Well-being \& الصحة والرفاهية ونمط الحياة -Online bullying . Privacy and security الخصوصية والأمن Lifestyle

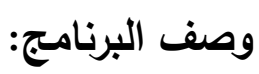

$\wedge \wedge 9$

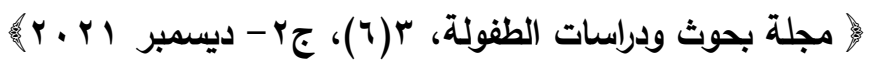


يركز البرنامج على نواتج التعلم الآتية، والتي تتضدن أن يكون الطفل قادراً على أن: - يطلب المساعدة من شخص بالغ يثق به، إذا شعر بالقلق بشأن أي شيء يحدث عبر الإنترنت.

- يحدد السلوك المتلاعب manipulative والضاغط pressurising وغير الصحي unhealthy - يراعي سلامة وحقوق الأطفال الآخرين عند مشاركة المحتوى عبر الإنترنت. ويتضمن المحتوى الرئيس للبرنامج سلسلة من ثلاث رسوم متحركة ممتعة ومناسبة للعمر، تدور أحداثها حول الطفلة "جيسي" واثثين من أصدقائها، وهم يبدأون في التنقل في عالم الإنترنت ومشاهدة مقاطع الفيديو ومشاركة الصور وممارسة الألعاب، وكل حلقة من حلقات الرسوم المتحركة الثلاث موجهة لفئة عمرية معينة، كالتالي: - الحلقة (1) بعنوان: مشاهدة الفيديوهات Watching Videos، موجهة للأطفال من

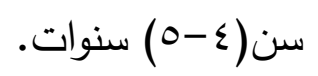
- الحلقة(r) بعنوان: مشاركة الصور Sharing Pictures، موجهة للأطفال من سن

$$
\text { (7-0) }
$$

- الحلقة (ץ) بعنوان: لعب الألعاب Playing Games، موجهة للأطفال من سن (7-

$$
\text { ( ) سنوات. }
$$

والرسوم المتحركة مصحوبة بما يلي:

$$
\text { - أغنية جذابة وكتب قصص وملصقات. }
$$

- حزمة إرشادات مفصلة مع أنشطة التعلم الجذابة حول الموضوعات الرئيسية، بما في تشمله من السلوكيات الصحية وغير الصحية عبر الإنترنت. 
- إرشادات للوالدين حول استخدام البرنامج لبدء محادثات أمان/سلامة عبر الإنترنت إيجابية ومناسبة للعمر مع أطفالهم.

ويمكن تطبيق أنشطة البرنامج على مستوى الفصل ككل، أو في مجموعات صغيرة، أو بشكل فردي، كما يمكن أن تطبق في المنزل بمساعدة الوالدين (Thinkuknow,2020).

(ب) - ع برنامج "عالم هيكتور" Hector's World Program

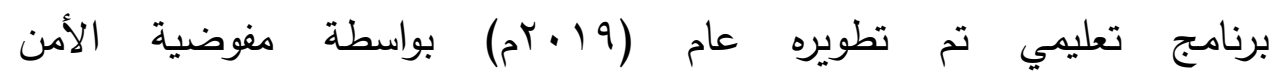
الالكتروني/السلامة الالكترونية eSafety Commissioner باستراليا.

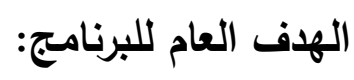
تقديم أساس جيد للمعرفة والمهارات للأطفال الصغار عند استخدامه لتكنولوجيا

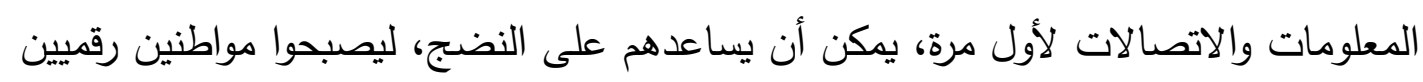
واثقين ومسؤولين.

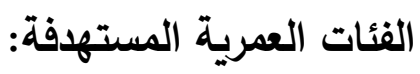
أطفال الروضة والمرحلة الابتدائية. أبعاد التعليم من أجل عالم متصل التي يتناولها البرنامج:

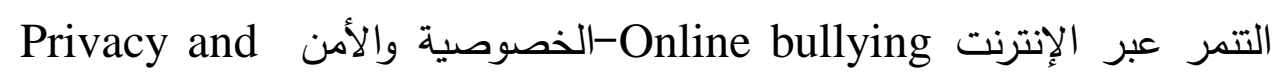
.security وصف البرنامج: الثخصية المحورية في البرنامج هو دولفين صغير يدعى "هيكتور بروتكتور" Hector Protector

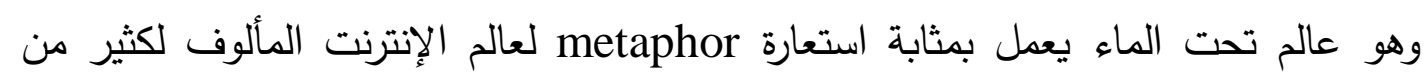

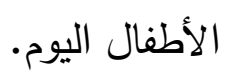

والمحتوى الأساسي لبرنامج "عالم هيكتور" الموجه لأطفال الروضة هو (V) حلقات

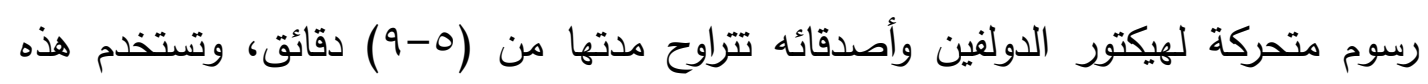


الحلقات في سياق(V) دروس/أنشطة، ولكل حلقة موارد لاعم للمعلمين وأولياء الأمور، تشمل: خطط الدروس/الأشطة، دليل المعلم، بطاقات مصورة للشخصيات، أوراق أغاني، كتب قصصية للأطفال، أوراق عمل.

وتتحدد مؤشرات التعلم المرتبطة بأبعاد التعليم من أجل عالم متصل في برنامج

"عالم هيكتور"، كما يتضح بجدول(^) (eSafety Commissioner , 2019a; eSafety"

.Commissioner , 2019b )

(ب-0) مشروع بومة الإنترنت -كن لطيفًا على الإنترنت

The Internet Owl Project - Be Kind Online مشروع تم تأسيسه عام (·r • • مج) بواسطة مؤسسة OpenView Education بالمملكة المتحدة، وهي مؤسسة غير حكومية تهتم بتوظيف تقنيات الدراما والأداء مثل سرد القصص والدمى ولعب الأدوار، في تعليم السلامة على الإنترنت ومكافحة التنمر، بمراحل التعليم ما bring learning to life قبل الجامعي، بطرق مبتكرة ومسلية وتفاعلية، بهدف إحياء التعلم بطريقة يتذكرها المتعلمون.

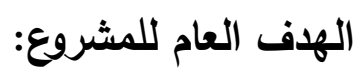
مكافحة التتمر عبر الإنترنت لدى أطفال مرحلة الطفولة المبكرة. الفئات العمرية المستهدفة:

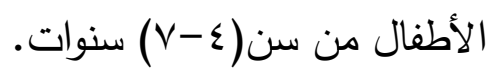
أبعاد التعليم من أجل عالم متصل التي يتناولها المشروع: التتمر عبر الإنترنت Online bullying. 


\section{جدول(^)}

أبعاد التعليم من أجل متصل ومؤشرات التعلم المرتبطة بكل بعد في برنامج "عالم هيكتور"

\begin{tabular}{|c|c|}
\hline مؤشرات التعلم المرتبطة بكل بعد & متصل في برنامـج عالم هيكتور \\
\hline 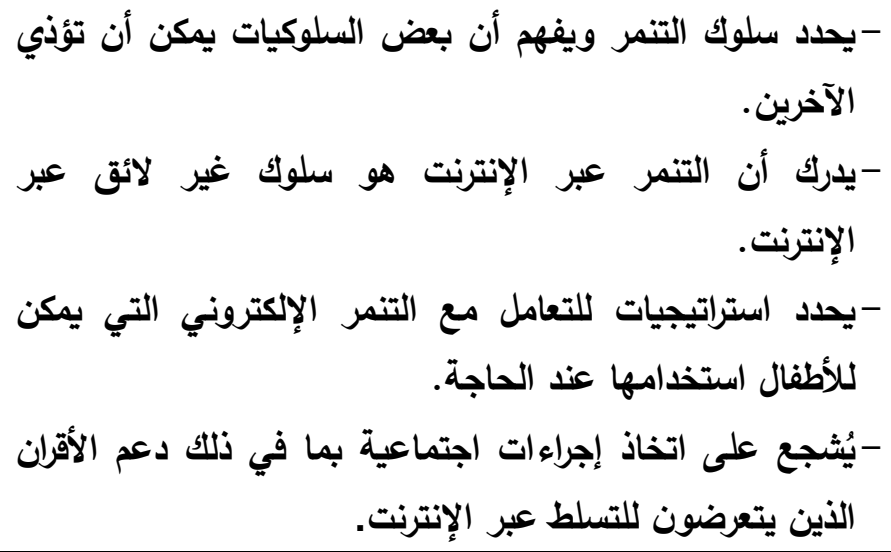 & I. التنمر عبر الإنترنت \\
\hline 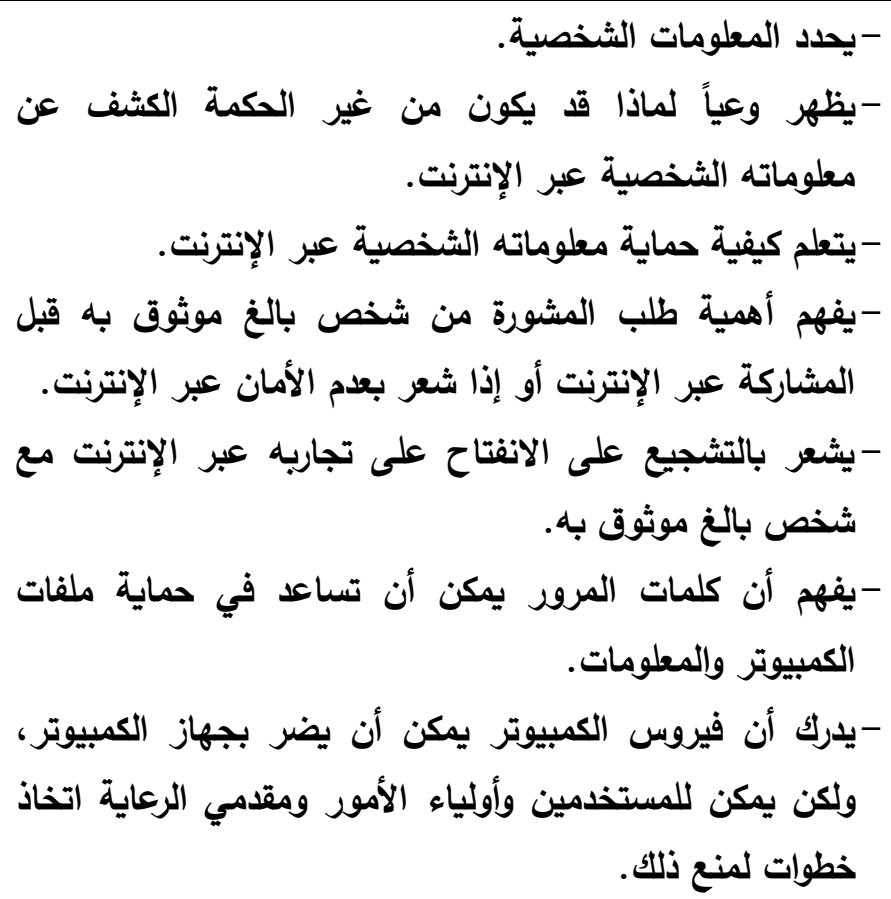 & $\begin{array}{c}\text { Y. الخصوصية والأمن } \\
\text { Privacy and security }\end{array}$ \\
\hline
\end{tabular}




\section{وصف المشروع:}

يركز المشروع على نواتج التعلم الآتية -والمشتقة من الإطار الحكومي التعليم من

أجل عالم متصل بالمملكة المتحدة-والتي تتضمن أن يكون الطفل قادراً على أن:

- يتحدث عن كيفية حصول أي شخص يتعرض للتنمر على المساعدة.

- يصف كيفية التصرف عبر الإنترنت بطرق لا تزعج الآخرين ويعطي أمثلة.

- يصف الطرق التي يمكن أن يكون بها بعض الناس غير لطفاء عبر الإنترنت، ويقدم

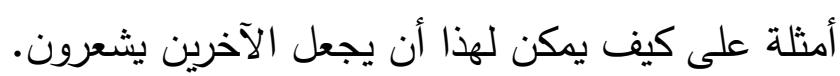

ويتضمن المشروع قصة كرتونية يقوم فيها الأطفال بالذهاب في رحلة تفاعلية

Internet Owl مع شخصية محورية هي "بومة الإنترنت interactive journey ويساعدونها في تعليم جميع الحيوانات في غابة الإنترنت Internet Jungle كيف يكونوا لطفاء على الإنترنت، وبحيث تركز الأنشطة المصاحبة للقصة على تشجيع الأطفال على المشاركة في الأحداث والتحدث عن نقاط التعلم الرئيسة، وفي النهاية يقوم الأطفال جميعهم بالمشاركة في إنشاء ملصقات "كن لطيفاً على الإنترنت" Be Kind Online، مما يساعدهم على تذكر الدروس المهمة المستفادة (OpenView Education, 2020).

(ب- Online with SANGO " (بروع "على الخط مع سانغو مشروع تم تأسيسه عام(·r.r. م) بالتعاون بين الاتحاد الدولي للاتصالات

Child (International Telecommunication Union (ITU)

(1) شبكة عالمية من المنظمات غير الحكومية مقرها جنيف بسويسرا، تعمل على تمكين الددافعين عن حقوق الأطفال، وتعزيز آليات الأمم المتحدة لحقوق الإنسان (1) (Child Rights Connect,2020). 
Rights Connect Western Sydney University /الانترنت (r) Child Online Protection (COP) ، وقد تمت ترجمة هذا المشروع العالمي الى (0) لغات منها اللغة العربية.

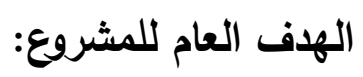
تعليم الأطفال حقوقهم وسلامتهم على الخط /الانترنت. الفئات العمرية المستهدفة: الأطفال أقل من 9 سنوات.

أبعاد التعليم من أجل عالم متصل التي يتناولها المشروع: الخصوصية والأمن Privacy and security-الصحة والرفاهية ونمط الحياة

Health, well-being and lifestyle وصف المشروع:

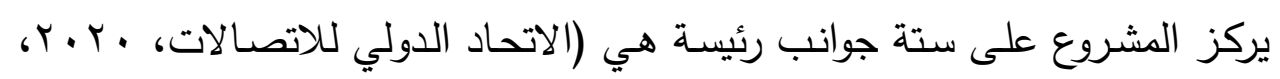

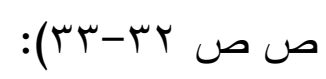

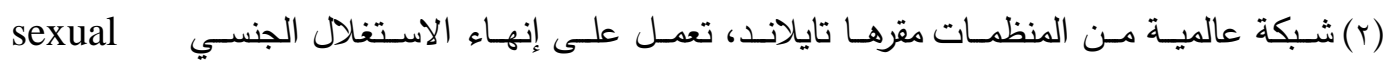
exploitation

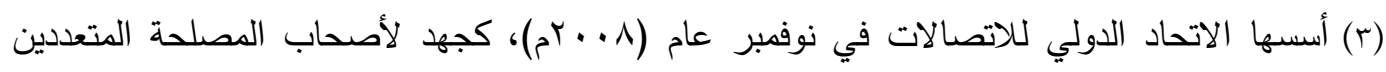

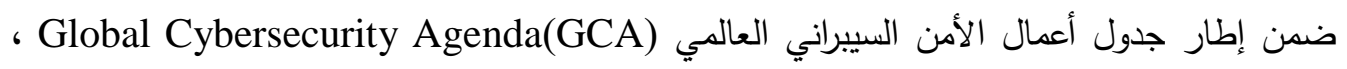
وتجمع المبادرة شركاء من جميع قطاعات المجتمع العالمي، لخلق تجربة آمنة وتمكينية عبر الإنترنت 190 للأطفال في جميع أنحاء العالم(ITU.2021). 
ا. الحق في اللعب على الخط: لكل الأطفال الحق في اللعب. ويمكن أن يشمل ذلك ممارسة الألعاب ومشاهدة الفيديوهات والتواصل مع الأصدقاء والأسرة على الخط، بما

$$
\text { يتناسب مع أعمارهم. }
$$

r. إدارة وقت المشاهدة: من المهم لصحة الطفل ورفاهيته أن يكون وقت المشاهدة متوازناً مع الأنشطة غير المتصلة بالخط. ويمكن أن تشتمل الأنشطة المدتعة المتاحة بدون

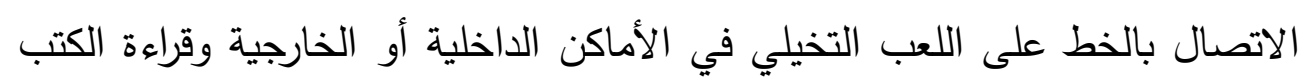
وممارسة الفنون وممارسة الرياضة.

r. التعرض لمحتوى غير لائق: في بعض الأحيان، يتعرض الأطفال عن طريق الخطأ لشيء ما على الخط مخيف أو مزعج أو غير مهذب. ومن المهم أن يعرف الأطفال

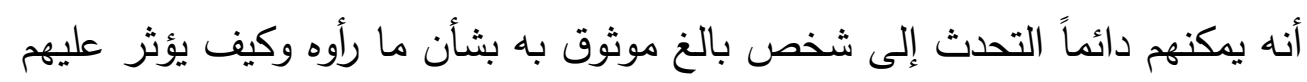
وما الذي يمكن أن يفعلوه عندما تحدث هذه الأشياء.

ع. الحق في استخدام الوسائط الرقمية للتعلم: لجميع الأطفال الحق في الوصول إلى المعلومات والتعلم وتتمية مهارات جديدة، ويمكن أن تدعم الوسائط الرقمية هذه الهي

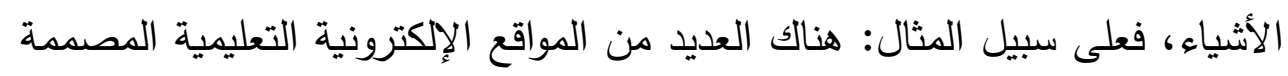
للأطفال فقط.

ه. الخصوصية: للأطفال الحق في الخصوصية، والحفاظ على خصوصية المعلومات الشخصية، بما في ذلك الصور، يساعد على الحفاظ على أمان الأطفال على الخط، وتحتوي العديد من المواقع الإلكترونية والتطبيقات على إعدادات الخصوصية، التي يمكن استخدامها للمساعدة في الحفاظ على خصوصية معلومات الطفل. 7. دور البالغين كقدوة في استخدام الوسائط الرقمية بشكل إيجابي: يتعلم الأطفال من خلال القدوة، ولذلك يشجع الاتحاد الآباء والبالغين على أن يكونوا قدوة جيدة عند الندائل استخدام الوسائط الرقمية. 
ويتم تتاول هذه الجوانب من خلا ستة سيناريوهات مصورة كثيراً ما يواجهها الأطفال فيما يتعلق بالبيئة الرقمية، ويتم عرض السيناريوهات على الأطفال من خلال هل

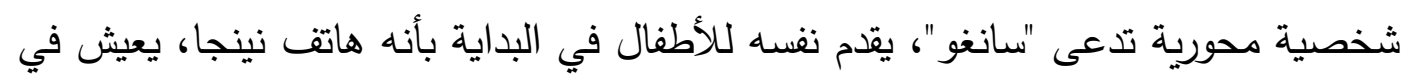
اليابان مع أسرته، ووظيفته مساعدة الأطفال على أن يكونوا آمنين على الخط ويستمتعون به. وبحيث يوجه كل سيناريو مصور للطفل سؤالاً وإجابتين محتملتين، وبشكل يتم فيه تشجيع الطفل على التحدث بصراحة حول ما يراه ويفعله على الخط، مع التأكيد على طمأنة الطفل أنه يمكن أن يتحدث الى الوالدين في أي وقت حول الأشياء التي تحدث على الخط، وأنه لن الن النه يواجه أي مشاكل بغض النظر عما يقوله.

\section{وللإجابة على السؤال الثالث من أسئلة الدراسة:}

قامت الباحثة باستخلاص أوجه الاستفادة من البرامج والمشروعات العالمية السابق عرضها في إعداد التصور المقترح، حيث استفادت الدراسة الحالية من تلك البرامج والمشروعات في:

أولاً: صياغة التعريفات الإجرائية لأبعاد التعليم من أجل عالم متصل في منهج رياض الأطفال

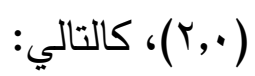

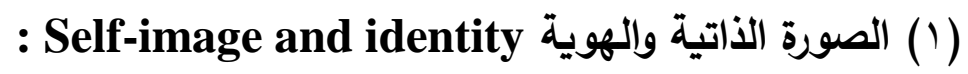

قيام الطفل بتحديد الاختلافات بين الهوية عبر الإنترنت وغير المتصلة بالإنترنت، والطرق الفعالة للابلاغ والدعم في حال طلب منه شخص ما فعل شيء يجعله يشعر بالحزن

$$
\text { أو الإحراج أو الانزعاج. }
$$

\section{(r) العلاقات عبر الإنترنت Online relationships:}

قيام الطفل بتحديد بعض الطرق التي يمكن من خلالها استخدام الإنترنت للتواصل، مع إعطاء أمثلة عن كيفية استخدام التكنولوجيا للتواصل مع الأشخاص الذين يعرفهم، وشرح أسباب أهمية مراعاة الآخرين والتعامل معهم بلطف على الإنترنت. 


\section{( Online reputation السمعة على الإنترنت}

قيام الطفل بتحديد الطرق التي يمكنه من خلالها وضع المعلومات على الإنترنت،

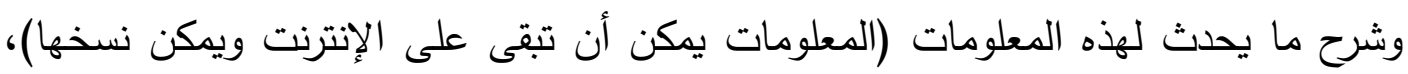

ووصف المعلومات التي لا يجب أن يضعها على الإنترنت دون أن يسأل شخصاً بالغاً أولاً.

( ) (التنمر عبر الإنترنت Online bullying

قيام الطفل بوصف الطرق /الأساليب التي يمكن أن يتعامل بها بعض الأشخاص

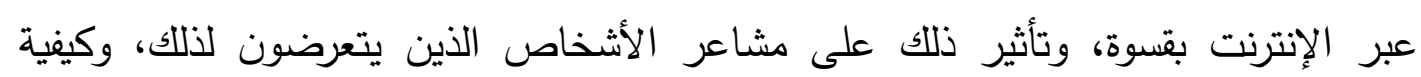
التصرف عبر الإنترنت بطرق لا تزعج الآخرين مع إعطاء أمثلة.

(•) Managing online information إدارة المعلومات عبر الإنترنت

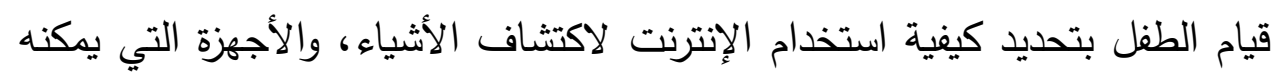

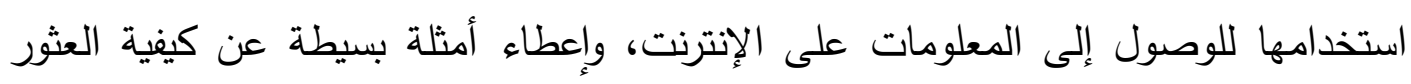

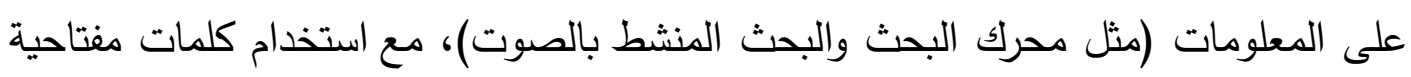

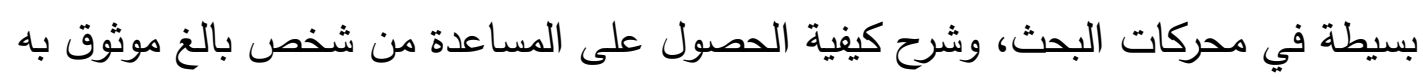

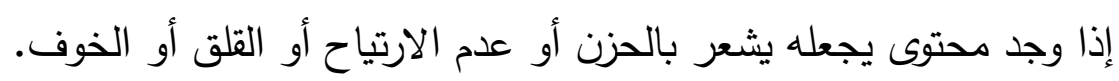

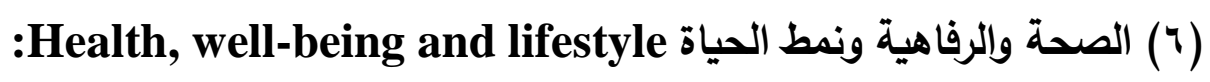
قيام الطفل بتحديد وشرح القواعد التي تساعد في الحفاظ على سلامتنا وصحتنا داخل المنزل وخارجه عند استخدام التكنولوجيا، مع إعطاء أمثلة بسيطة.

\section{: Privacy and security الخصوصية والأمن (V)}

قيام الطفل بتحديد بعض الأمثلة البسيطة لمعلوماته الثخصية (مثل الاسم والعنوان

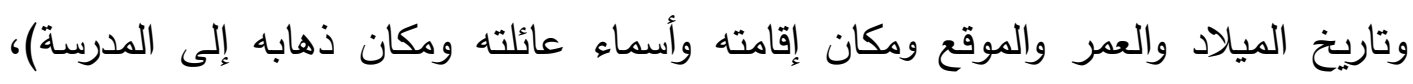

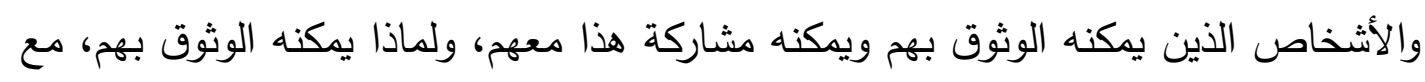


شرح كيفية استخدام كلمات المرور لحماية المعلومات والأجهزة، ولماذا يجب عليه دائماً أن يسأل شخصاً بالغاً موثوقاً به قبل أن يشارك أي معلومات عن نفسه عبر الإنترنت.

\section{:Copyright and ownership حقوق النشر والملكية (^)}

قيام الطفل بتوضيح مفهوم ملكية محتوى /عمل رقمي قام بإنشائه (كيف ولماذا يمتلك العمل الرقمي الذي قام بإنشائه)، وأهمية تسميه عمله الرقمي، وطرق تسمية الملفات لمساعدته في العثور عليها لاحقاً، مع قيامه بتسمية عمله الرقمي وحفظه حتى يعرف الآخرون أنه يخصه/ملك له.

ثانياً: تحديد قائمة مؤشرات ونواتج التعلم المرتبطة بالتعليم من أجل عالم متصل في منهج رياض الأطفال (·,r)، لكل مستوى برياض الأطفال، وهو ما سيتم تتاوله تفصيلياً في الخطوة

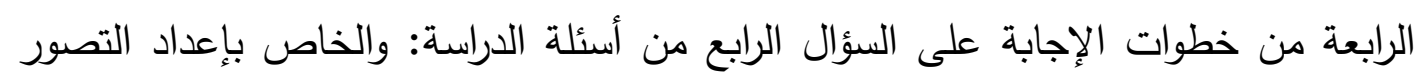
المقترح.

ثالثأ-تحديد استراتيجيات التعليم والتعلم والموارد الرقمية وغير الرقمية الملائمة: بحيث اشتملت

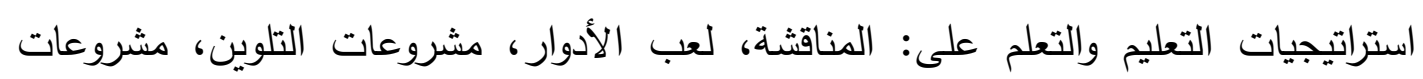
التصميم، العروض العملية، استخدام الرسوم المتحركة، استخدام القصص المصورة، استخدام السيناريوهات المصورة. كما تم تحديد مجموعة من الموارد الملائمة، التي توفرها البرامج والمشروعات السابق عرضها، والتي يمكن استخدامها بما يتناسب مع نواتج التعلم المستهدفة، تورهي بالمستويين الأول والثاني.

رابعاً: تصميم خريطة التدري/التعليم الخاصة بالتعليم من أجل عالم متصل في كل فصل من فصول محاور المحتوى متعدد التخصصات بمنهج رياض الأطفال (·, (r)، بحيث اشتملت على: نواتج التعلم الخاصة بالأبعاد المستهدفة للتعليم من أجل عالم متصل في كل نشاط، الموارد بشكل تم فيه توضيح استراتيجيات التعليم والتعلم المستخدمة، روابط الموارد الرقمية. 
خامساً: تصميم أنشطة التعليم من أجل عالم متصل، بحيث تمت إضافة عناصر للنشاط-إلى جانب عناصر النشاط المحددة بدليل المحتوى متعدد التخصصات(') -اشتملت على: أسئلة مفتاحية، ومهام/تكليفات منزلية.

سادساً: تحديد الأنشطة والممارسات الملائمة في إشراك أولياء أمور الأطفال، وهو ما تم

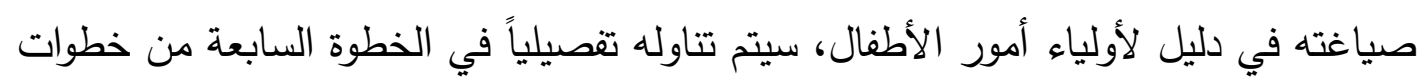
الإجابة على السؤال الرابع من أسئلة الدراسة، والخاص بإعداد التصور المقترح.

\section{وللإجابة على السؤال الرابع من أسئلة الدراسة:}

قامت الباحثة بإعداد التصور المقترح، وفقاً للخطوات التالية:

1 - تحديد الهذف العام للتصور المقترح

وتمثل في تفعيل التعليم من أجل عالم متصل في منهج رياض الأطفال ( •,؟). ץ-تحديد أسس بناء التصور المقترح، واشتملت على:

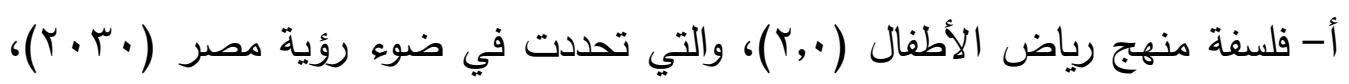
والخطة الاستراتيجية لوزارة التربية والتعليم، وخطة التمية المستدامة (•r.ب)، وتضمنت رؤية واضحة واستراتيجية بناءة للجمع بين الهوية الوطنية واحترام الخصوصية الثقافية، والأخذ بالاتجاهات العالمية في أساليب الجودة التعليمية، والتوفيق بين الإتاحة المجانية ومتطلبات الجودة، والتوازن بين تحديث المناهج واحياء

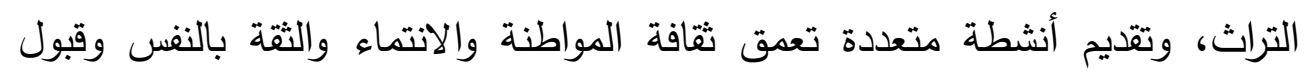

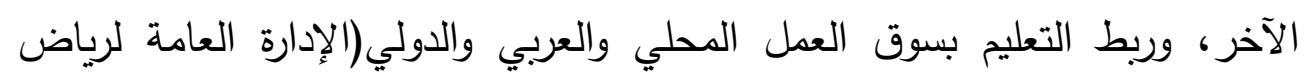

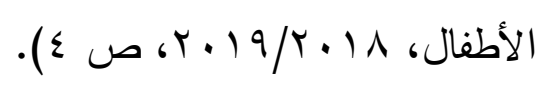

(1) تضضمن: نواتج التعلم، المفردات الأساسية، المواد، الإرشادات/ إجراءات كل درس، موضحاً بها ما تقوم به المعلمة وما يقوم به الأطفال. 


$$
\text { ج-الإطار العام لمنهج رياض الأطفال (·. ب). }
$$

د -مفهوم وأبعاد وخصائص وأهداف التعليم من أجل عالم متصل في مرحلة رياض

الأطفال.

هـ -فلسفة التعليم من أجل عالم متصل في مرحلة رياض الأطفال. و -خصائص طفل الروضة وحاجاته، والمظاهر المبكرة لاستعداده للتعلم من أجل عالم

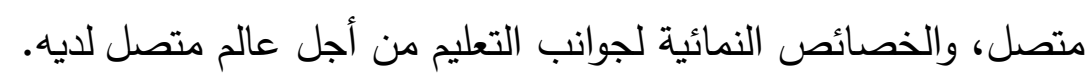
ز -الإتفاقيات والمواثيق العالمية في مجالات: حقوق الطفل، وحماية الأطفال من العنف، وتعزيز التعليم الثامل والمنصف والتعلّم مدى الحياة للأطفال، وأمان /سلامة الأطفال على الخط /الإنترنت، وتحقيق التوصيلية الثاملة/الرقمية. ح-التوجهات التربوية المعاصرة في مجال تفعيل أبعاد التعليم من أجل عالم متصل في منهج رياض الأطفال.

r- تحديد الفلسفة التي يستند إليها التصور المقترح

$$
\text { وتحددت في النقاط التالية: }
$$

أ-التعليم مـن أجل عـالم متصـل في مرحلـة ريـاض الأطفال إطسار عمل يجمـع المشهـد

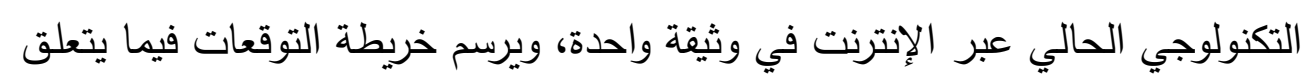

$$
\text { بالسلوك عبر الانترنت، في مقابل العمر . }
$$

ب-التعليم من أجل عالم متصل في مرحلة رياض الأطفال يدعم الأطفال للعيش بمعرفة

$$
\text { في العالم الرقمي. }
$$

جـمنهج رياض الأطفال الذي يُفعل التعليم من أجل عـالم متصل، منهج ثري وفعـال وتنموي، يدعم الأطفال 


\section{ليكونوا آمنين، وصحيين، ومزدهرين، عبر الإنترنت.}

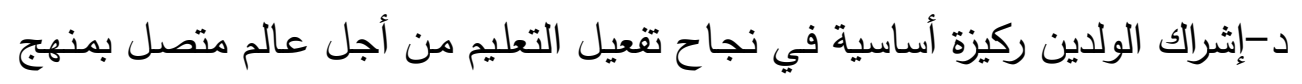

$$
\text { رياض الأطفال. }
$$

ء - إعداد قائمة بأبعاد ومؤشرات ونواتج تعلم التعليم من أجل متصل في منهج رياض

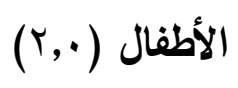

تم إعداد قائمـة بأبعاد ومؤشرات ونواتج تعلم التعليم من أجل متصل في منهج ريـاض الأطفال (·, (r)، وفقاً للخطوات التالية: ( ع - (1) تحديد الهدف من القائمة: وتمثل في تحديد أبعاد ومؤشرات ونواتج تعلم التعليم من أجل متصل، للمستوين الأول والثاني، والتي يمكن تكاملها في منهج رياض

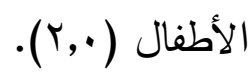

(Y- (Y) تحديد مصادر اشتقاق القائمة: تم اشتقاق القائمة بالرجوع لعدد من المصادر تمثلت في: (أ) إصدار مجلس السلامة على الإنترنت بالمملكة المتحدة (UKCIS) العمرية دن (ع-V) سنوات، (ب)الخبرات والتجارب العالمية/ البرامج والمشروعات العالمية المعاصرة التي تتاولت تفعيل كافة أو بعض أبعاد التعليم من أجل عالم متصل في منهج رياض الأطفال، (ج) المحتوى متعدد التخصصات بمنهج رياض الأطفال(·.ب)-مجال تكنولوجيا المعلومات والاتصالات، وما تضمنه من مؤشرات ذات علاقة بالتعليم من أجل عالم متصل.

$$
\text { ( ع - (r) وضع القائمة في صورتها المبدئية. }
$$

(ع - §) تضمين الصورة المبدئية للقائمة في استبيان: تم تضمين محتويات القائمة

$$
\text { المبدئية في استبيان، بهدف استطلاع الرأي حول الآتي: }
$$

أ- - أبعاد التعليم من أجل عالم متصل، من حيث: دقة التعريفات الإجرائية. 


\section{كلية التربية للطفولة المبكرة- جامعة بني سويف}

ب-مؤشرات تعلم أبعاد التعليم من أجل عالم متصل، لكل مستوى برياض الأطفال،

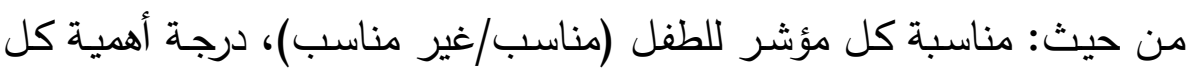
مؤشر بالنسبة للطفل (مهم/متوسط الأهمية/ غير مهم)، ارتباطه بالبعد المحدد (مرتبط/غيـر مـرتبط)، دقـة الصـياغة العلميـة واللغويـة (دقيقـة/غير دقيقـة)، والمؤشرات التي يمكن إضافتها.

ج- نواتج التعلم المرتبطة بمؤشرات أبعاد التعليم من أجل عالم متصل، لكل مستوى بريـاض الأطفـال، مـن حيـث: مناسـبة كـل نـاتج تعلـم للطفـل (مناسـبـ/غير مناسب)، درجة أهمية كل ناتج تعلم بالنسبة للطفل (مهم/متوسط الأهمية/ غير مهم)، ارتباطه بمؤشر التعلم المحدد (مرتبط/غير مرتبط)، دقة الصياغة العلمية واللغوية (دقيقة/غير دقيقة)، والنواتج التي يمكن إضافتها.

(ع-0) عرض الاستبيان على مجموعة من المحكمين للتحقق من صدق القائمة: تم عرض الاستبيان على مجموعة من المحكمين في مجال المناهج، وتكنولوجيا التعليم،

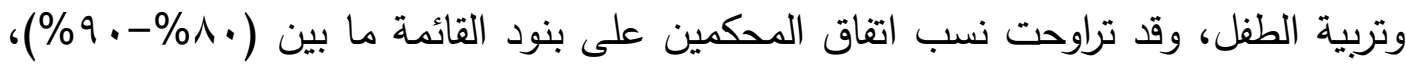
وتم إجراء التعديلات التي أشار لها السادة المحكمون، والتي تلخصت في إعادة صياغة بعض برون تعريفات الأبعاد وبعض مؤشرات ونواتج التعلم.

$$
\text { ( (-7) وضع القائمة في صورتها النهائية. }
$$

ه- وضع خطة تكامل/دمج أبعاد التعليم من أجل عالم متصل، في محاور المحتوى متعدد التخصصات بمنهج رياض الأطفال ( •. ( )

نظراً لطبيعة وآليات تنظيم المحتوى متعدد التخصصات(1)، والالتزام بخطة زمنية محدة لتتفيذ الدروس-محددة بدليل المعلمة- على مدار كل فصل دراسي، فلم يتم اللجوء إلى لي

(1) تضم نافذة المحتوى متعدد التخصصات، محورين لكل فصل دراسي، كل محور مقسم إلى فصول تطابق عناوين لمشاريع أو موضوعات، ويحتوي كل مشروع على أنثطة فردية وجماعية مبنية على نلى نشاط الطفل وفعاليته، ومرتبطة تماماً بالمحور وأهدافه، وبحيث يقسم كل فصل إلى ثلاثة مكونات لكل 
إضافة وحدات أو أنشطة مستقلة خاصة بأبعاد التعليم من أجل عالم متصل، وإنما تم الاعتماد على دمج الأنشطة المقترحة في سياق ذو معنى بدروس المنهج الفعلي، وعلى ذلك

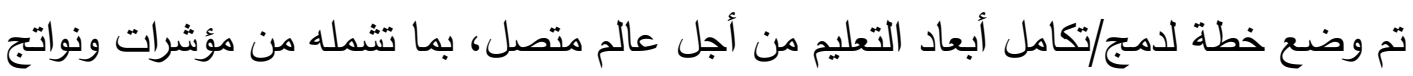

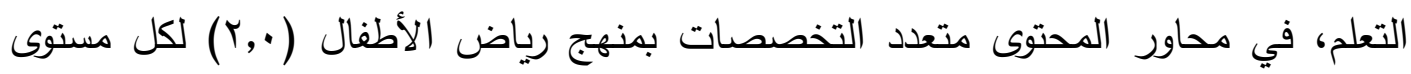
بكل فصل دراسي، وتم ذلك في جدول يوضح: أبعاد التعليم من أجل عالم متصل، مؤشرات التعلم المرتبطة، نواتج التعلم المرتبطة، عنوان المحور بالمحتوى متعدد التخصصات، عنوان الفصل، الدرس الذي سيتم فيه الدمج/التكامل، عنوان وموجز النشاط الخاص بالتعليم من أجل عالم متصل.

צ- تصميم أنثطة التعليم من أجل عالم متصل في كل محور من محاور المحتوى متعدد

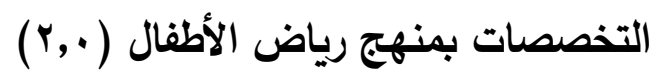

تم تصميم الأنشطة في أجزاء، يحمل كل جزء منها عنوان: أنشطة التعليم من أجل عالم متصل بمحور (إسم المحور)، وتم تفسيم كل جزء وفقاً لفصول المحور المحدد، بحيث تضمنت مقدمة أنشطة كل فصل: أولاً: نظرة عامة، تضمنت: أوصف كل مكون (اكتثِف، تعلم، شارك) وعدد الأنشطة المرتبطة به، ب-الربط بالقضايا، ج-المهارات الحياتية التي تتم

تغطيتها.

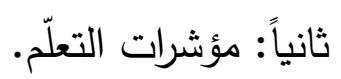
ثالثاً: الخريطة الزمنية للتدريس. تؤن

منها عدد من الدروس، والمكونات هي: اكتثِف(يتم فيه تعريف الأطفال بالمشروع الأساسي الذي يتتاوله

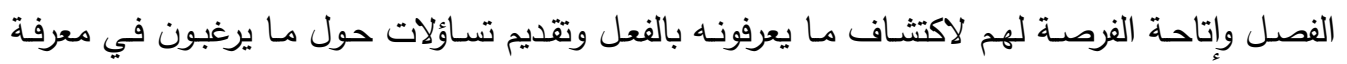
المزيد عنه)، تعلَّم ( يتم فيه التركيز بشكل خاص على المحتوى والمهارات التي سيستخدها الأطفال

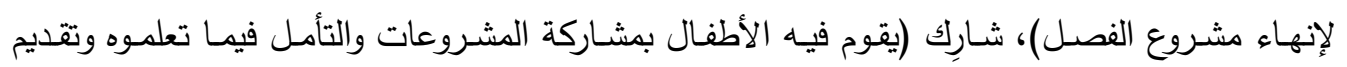
ملاحظاتهم وتعليقاتهم إلى زملائهم وتلقي الملاحظات والتعليقات منهم) (وزارة التربية والتعليم والتعليم

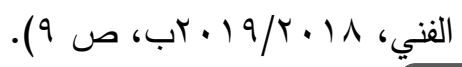


ثم تم عرض الأنشطة، بحيث تضمن كل نشاط العناصر الآتية: ترتيب الدرس (الأول/الثاني/الثالث.......) الذي سيتم دمج النشاط المقترح في سياقه وأرقام صفحاته بدليل المعلمة، نواتج التعلم، المفردات الأساسية، المواد والأدوات، الموارد الرقمية، أسئلة مفتاحية، الإشادات/ الإجراءات بشكل تم فيه توضيح آلية التكامل في سياق الدرس المحدد، والمهام/التكليفات المنزلية.

- إعداد وثائق التصور المقترح لتفعيل التعليم من أجل عالم متصل بمنهج رياض

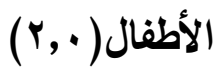

$$
\text { تمت صياغة التصور المقترح في شكل عدد من الوثائق كالتالي: }
$$

( ) ( - ( ) وثائق تكامل التعليم من أجل عالم متصل بالمحتوى متعدد التخصصات

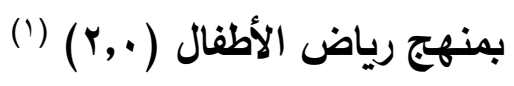

تم إعداد (7) وثائق تستخدم لتكامل التعليم من أجل عالم متصل بالمحتوى متعدد

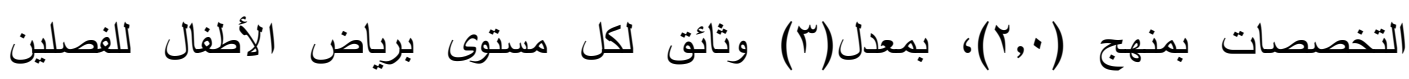
الدراسيين، تضمنت: دليل المعلمة "إكتشف عالمك المتصل"، كتاب الطفل"إكتشف عالمك المتصل"، دليل الوالدين "ساعد طفلك على اكتشاف عالمه المتصل"، وتم عرضها على مجموعة المحكمين السابق الإشارة إليهه، وإجراء التعديلات في ضوه مقترحاتهم، وفيما يلي وصف لمحتويات كل وثيقة من الوثائق الثلاث:

أولاً: دليل المعلمة "اكتشف عالمك المتصل" واشتمل على: (أ) مقدمة الدليل. 
(ب) معلومات أساسية، وفيها تم توضيح الهدف العام للإطار المقترح، والفلسفة التي يستند إليها، مع توضيح الآلية المتبعة لتكامل التعليم من أجل متصل في المحتوى متعدد

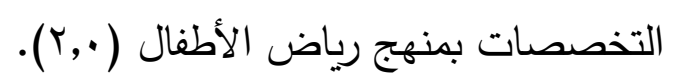

(ج) الأساس النظري، بما يشمله من: مفهوم، وفلسفة، وأبعاد، وخصائص التعليم من أجل

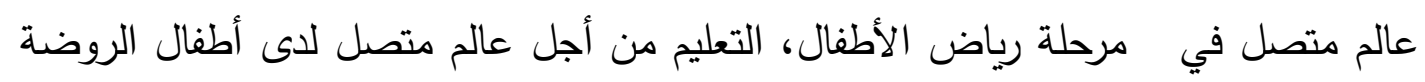
من منظور نمائي، أهداف التعليم من أجل عالم متصل في مرحلة رياض الأطفال، أهمية التعليم من أجل عالم متصل في منهج رياض الأطفال، نواتج التعلم المرتبطة بأبعاد التعليم من أجل عالم متصل في مناهج مرحلة الطفولة المبكرة.

(د) قائمة بأبعاد ومؤشرات ونواتج تعلم التعليم من أجل متصل في منهج رياض الأطفال

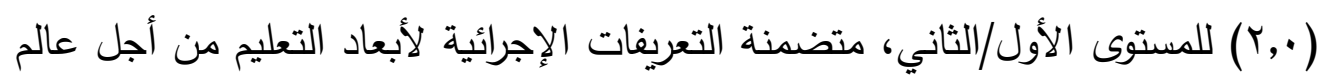

متصل.

$$
\begin{aligned}
& \text { (هـ) استراتيجيات التعليم والتعلم. } \\
& \text { (و) إرشادات استخدام الدليل. }
\end{aligned}
$$

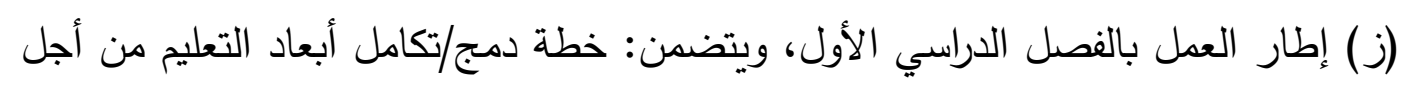
عالم متصل بمحوري الفصل الدراسي الأول، أنشطة التعليم من أجل عالم متصل التصل بمحور : من أكون، أنشطة التعليم من أجل عالم متصل بمحور : العالم من حولي. (ح) إطار العمل بالفصل الدراسي الثاني، ويتضمن: خطة دمج/تكامل أبعاد التعليم من أجل

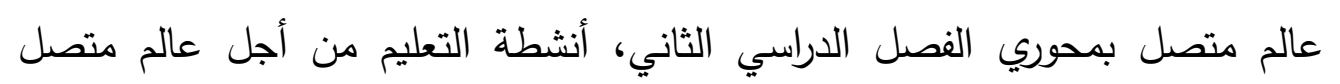
بمحور : كيف يعمل العالم، أنشطة التعليم من أجل عالم متصل بمحور : التواصل. (ط) مراجع ومواقع انترنت يمكن الرجوع إليها. 
ثانياً: كتاب الطفل"إكتثف عالمك المتصل"

وتضمن مجموعة من أوراق العمل ومشروعات التلوين المرتبطة بالأنشطة، والتي

يقوم الطفل بالأداء فيها سواء مع المعلمة أثناء النشاط، أو في المنزل بمساعدة ولي الأمر، والكتاب مقسم إلى جزأين، للفصلين الدراسيين الأول والثاني، وكل جزء مقسم تبعاً للمحاور والفصول بكل فصل دراسي.

ثالثاً: دليل الوالدين "ساعد طفلك على اكتثاف عالمه المتصل" واشتمل على:

أ- مقدمة: توضح الهدف من الدليل وأهميته في مساعدة الوالدين في التعرف على

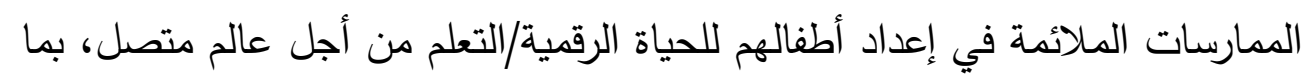
يشمله من المشاركة في تتفيذ أنشطة ذات علاقة في منهج رياض الأطفال (·, (ب)، وتوجيه نشاط أطفالهم على الإنترنت بشكل إيجابي وفاعل. ب-الفوائد والمخاطر في تعامل أطفال الروضة مع شبكة الإنترنت. ج-أبعاد التعليم من أجل عالم متصل في منهج رياض الأطفال (•,r): الجوانب المستهدف مشاركة الوالدين في تتميتها لدى الأطفال في هذا الدليل.

د- الممارسات الوالدية الملائمة في تدعيم تعلم طفل الروضة من أجل عالم متصل. هـ-إرشادات عامة لاستخدام الدليل.

و -الأنشطة المنزلية /المهام المنزلية الخاصة بالتعليم من أجل عالم متصل في منهج رياض الأطفال (·,r) للمستوى الأول/الثاني: وفيها تم عرض موجز لكل نشاط/مهمة

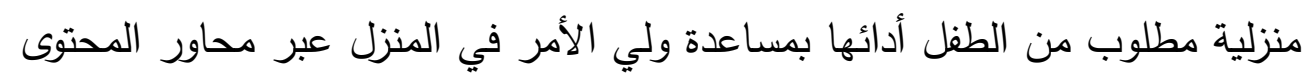

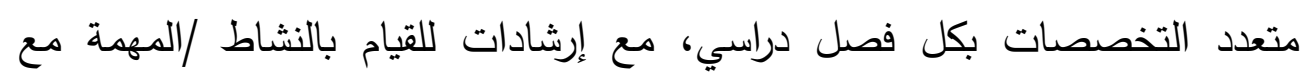
الطفل. 
ز-موارد إضافية مساندة، واشتمل هذا الجزء على روابط للآتي: موارد رقمية يمكن للوالدين استخدامها مع الأطفال (كأنشطة صيفية/في فترة الإجازة الصيفية) لدعم تعلمه من أجل عالم متصل، موارد رقمية توفر معلومات للوالدين عن السلامة

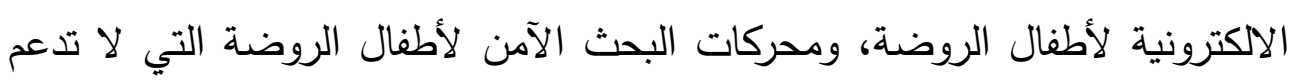

$$
\begin{aligned}
& \text { الإعلانات والتي تدعم الإعلانات. } \\
& \text { ح-مراجع الدليل. }
\end{aligned}
$$

(r-V)

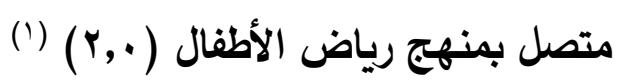

تم بناء الأداة المشار إليها استتاداً إلى أسلوب تقييم المتعلمين في نظام "تعليم •, ب"،

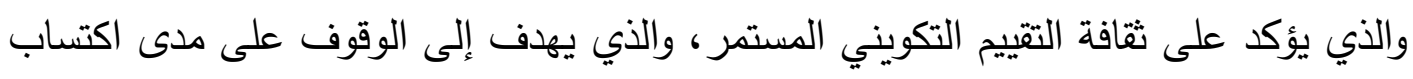

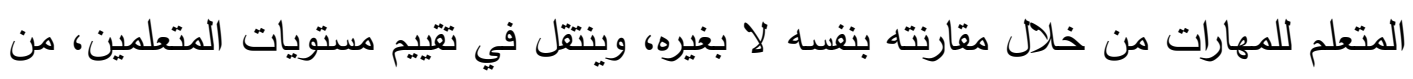
إصدار أحكام أو إعطاء درجات، إلى التقييم من خلال الألوان التي تعطي دلالات محددة

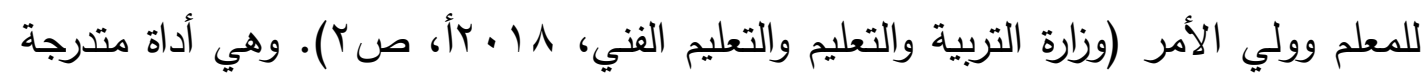
لتسجيل مستوى أداء طفل الروضة، توفر أمثلة ملموسة عن تطور تعلم الأطفال من أجل عالم متصل، وهي منظمة على أساس أبعاد ومؤشرات تعلم التعليم من أجل عالم متصل في منهج

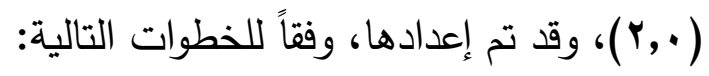

$$
\text { تحديد الهذف من الأداة (1- }-\mathrm{r}-\mathrm{V})
$$

هدفت الأداة إلى تحديد/تسجيل تقدم أداء الطفل تراكمياً، فيما يتعلق بمجال التعليم من أجل عالم متصل في منهج ( •.r)، بالمستويين الأول والثاني برياض الأطفال.

(1) يمكن إضافة هذه الأداة كملحق/مرفق بدليل معلمة الروضـة لتقييم طفل الروضة (وزارة التربية والتعليم

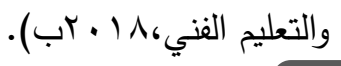


تحديد الجوانب الأساسية للتقييم ( $(r-V)$

وهي تشمل أبعاد التعليم من أجل عالم متصل، بما تشمله من مؤشرات

للمستويين الأول والثاني برياض الأطفال.

$$
\text { صياغة مفردات الأداة (r-v) }
$$

تمت صياغة مفردات الأداة في ضوء مؤشرات أبعاد التعليم من أجل عالم متصل، وتمت الصياغة في عبارات سلوكية بسيطة، يمكن ملاحظتها وقياسها، تصف مؤشرات أداء الطفل عبر أربع مستويات، يرمز لكل منها بلون معين، كالتالي:

أ- أقل من التوقعات" ويرمز له باللون الأحمر: يعني أن الطفل لم يتمكن من اكتساب

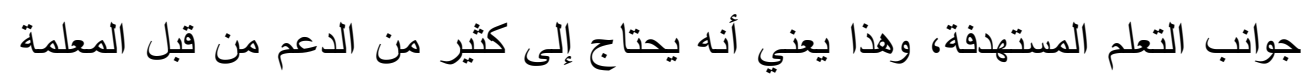

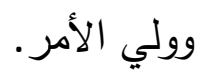

ب- " "يلبي التوقعات أحياناً" ويرمز له باللون الأصفر : يعني أن الطفل اكتسب بعضاً من أن أنساً

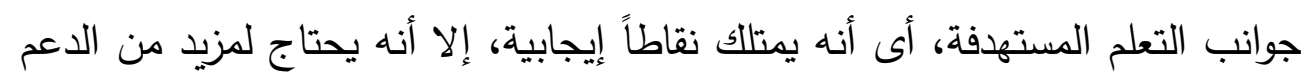
للتغلب على النقاط السلبية. ج- "يلبي التوقعات" ويرمز له باللون الأخضر : يعني أن الطفل اكتسب جميع جوانب التعلم المستهدفة.

د- "يفوق التوقعات" ويرمز له باللون الأزرق: يعني أن الطفل وظف ماكتسبه من جوانب

$$
\text { التعلم في إظهار نواتج إبداعية. }
$$

مع الوضع في الاعتبار إمكانية قيام المعلمات بكتابة عبارات تصف مستوى الطفل، من تعبيراتهم ومفرداتهم الخاصة، دون التقيد تماماً بما ورد في نموذج التقييم المدرج بالأداة، وعند مله الاستمارة النهائية للتثييم، يتم تلخيص جميع العبارات الوصفية الخاصة بمجال التعليم من أجل عالم متصل في عبارة عامة واحدة تصف مستوى الطفل، وتعكس أحد ألوان التقييم الأربعة. 
( صياغة تعليمات الأداة ( -

تمت صياغة تعليمات الأداة في عبارات بسيطة وواضحة، بما يضمن سهولة ودقة استخدام القائم بالتطبيق للأداة، وتضمنت التعليمات العناصر الآتية: الهدف من الأداة متضمناً التعريفات الإجرائية لأبعاد التعليم من أجل عالم متصل المستهدف تسجيل تقدم أداء الطفل

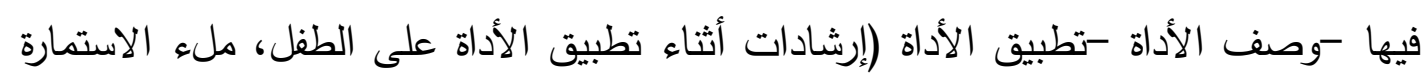
النهائية للتقييم).

\section{(التحقق من صدق الأداة (- - (- - )}

تم التحقق من صدق محتوى الأداة، من خلال عرضها في صورتها المبدئية، على مجموعة من المتخصصين في مجال المناهج، وتكنولوجيا التعليم، وتربية الطفل، لإبداء الرأي فيما يتعلق بالآتي:

تعليمات الأداة، من حيث: مدى وضوح ودقة التعليمات، الصياغة السليمة للتعليمات، شمول التعليمات لكل ما يحقق سهولة ودقة استخدام القائم بالتطبيق للأداة.

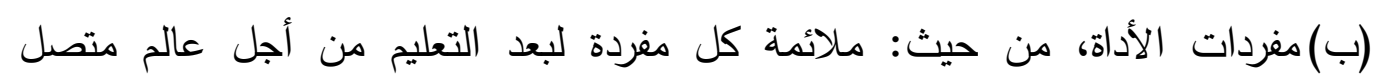
المستهدف، ملائمة كل مفردة لطفل الروضة، ملائمة كل مفردة لمستوى التقييم المحدد، مدى قابلية كل مغردة للملاحظة من قبل المعلمة، الصياغة السليمة للمفردة. وذلك إلى جانب إضافة ما يرونه مناسباً من تعديلات أو مقترحات، فيما يتعلق بكل

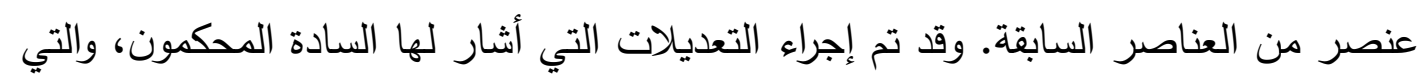
تلخصت في إعادة صياغة بعض المفردات. وفي ضوء ما سبق تم وضع الأداة في صورتها النهائية، كوثيقة لتقييم الطفل في إطار التصور المقترح. 
في ضوء ما تقدم، توصي الدراسة الحالية بالآتي:

Education for a Connected (1) (1ضع إطار قومي للتعليم من أجل عالم متصل من مرحلة رياض الأطفال وحتى المرحلة الثانوية.

Education for a تخطيط ومتابعة وتقويم عمليات تفعيل التعليم من أجل عالم متصلى (Y)

$$
\text { Connected World في منهج رياض الأطفال (·, (r). }
$$

(ץ) توفير موارد رقمية، متاحة على بنك المعرفة المصري، للمساعدة في تفعيل التعليم من أجل

$$
\text { عالم متصل في منهج رياض الأطفال (·, (Y). }
$$

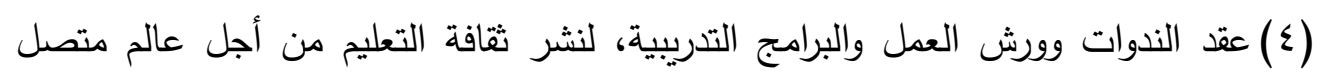
Education for a Connected World

(0) تشجيع وتوجيه ودعم وتقويم الجهود المبذولة في مجال تفعيل التعليم من اجل عالم متصل Education for a Connected World

(T) إجراء الأبحاث والدراسات في مجال تفعيل التعليم من أجل عالم متصل Education for a Connected World

تعزيز الشراكة بين مؤسسات رياض الأطفال ومؤسسات المجتمع المدني، في مجال تفعيل

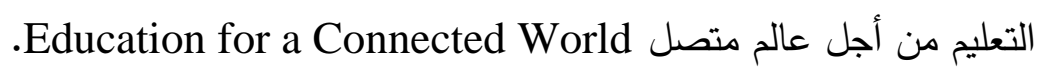

$$
\text { (^) التعاون وتبادل الخبرات مع المؤسسات العالمية ذات العلاقة. }
$$

(9) الاهتمام بتدريب معلمات الروضة قبل وأثناء الخدمة على تفعيل التعليم من أجل عالم متصل Education for a Connected World في منهج رياض الأطفال ( •,r).

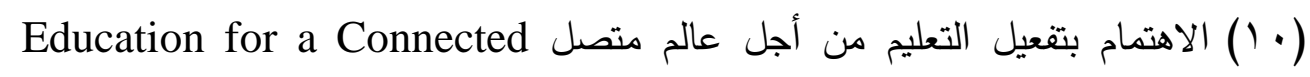
World

$$
\text { مؤسسات رياض الأطفال. }
$$




$$
\begin{aligned}
& \text { المراجع } \\
& \text { أولاً: المراجع العربية } \\
& \text { الإتحاد الدولي للاتصالات ( · · · ). على الخط مع سانغو. جنيف. }
\end{aligned}
$$

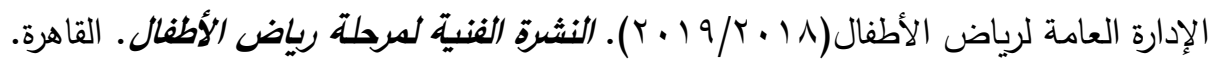

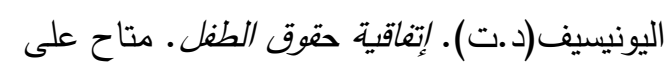

www.unicef.org/arabic/crc/files/crc_arabic.pdf

رضوان، صفاء وقاسم، منال(Yr ·r). تصور مقترح لتفعيل أدوار معلمة رياض الأطفال في التربية الرقمية

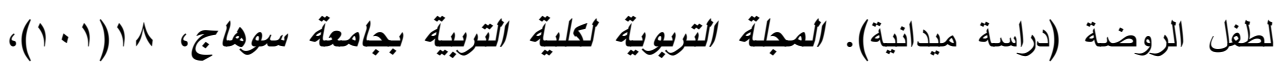

$$
\text { roq-rVI }
$$

عبد السيد، منال (9 (ب). برنامج قائم على التربية الأمانية لتتمية الوعي التكنولوجي بمخاطر الألعاب

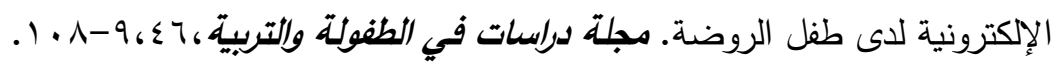

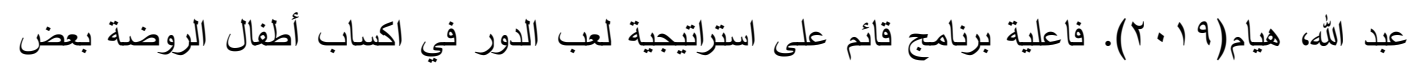

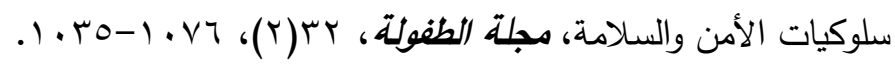

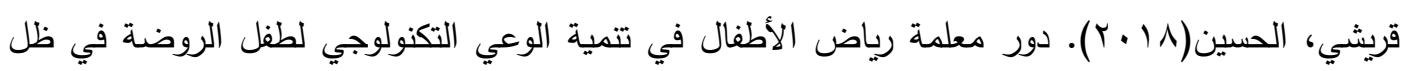

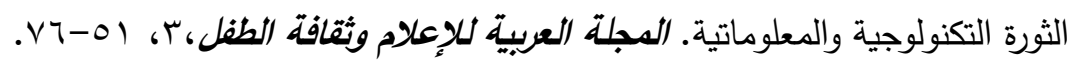

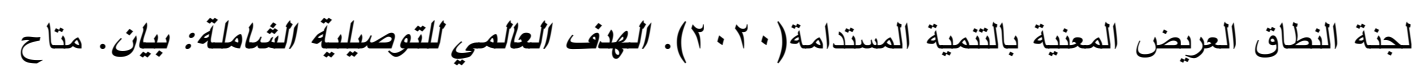

$$
\text { على }
$$

https://www.broadbandcommission.org/Documents/BroadbandCommission_ma nifesto_AR.pdf

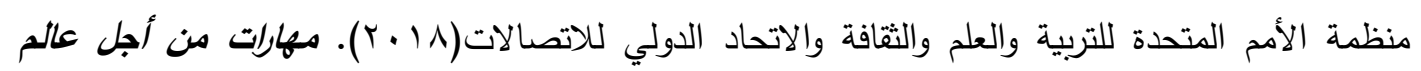

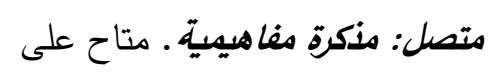

http://lists.esn.org.za/pipermail/oer-

forum/attachments/20180119/f8af3bca/attachment-0012.pdf

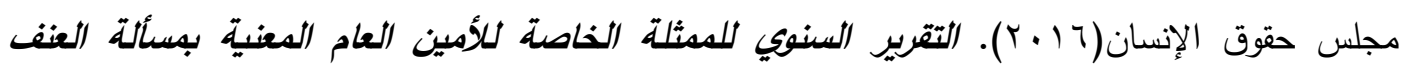

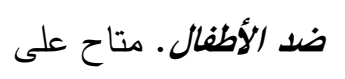


https://www.ohchr.org/EN/HRBodies/HRC/RegularSessions/Session31/Docume nts/A_HRC_31_20_A.doc.

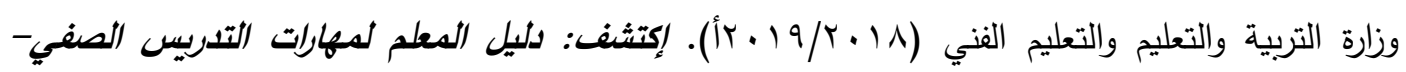
المستوى الأول -الفصل الدراسي الأول .القاهرة.

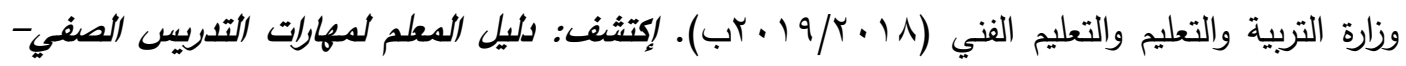
المستوى الأول -الفصل الدراسي الثاني.القاهرة.

وزارة التربية والتعليم والتعليم الفني (1) •ـأ). دليل المعلم لتعبئة استعارة التقييم للصف الأول الابتدائسي.القاهرة.

وزارة التربية والتعليم والتعليم الفني (1 ( • باب). دليل معلمة الروضة لتقييم طفل الروضة .القاهرة.

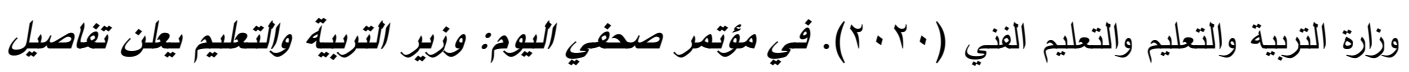

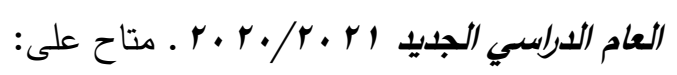

http://portal.moe.gov.eg/Pages/single-news-view.aspx?NewsID=4646

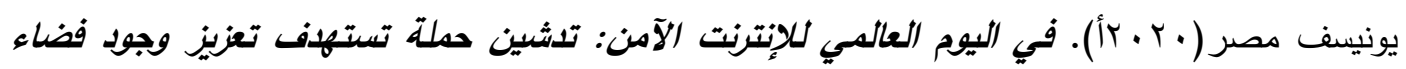

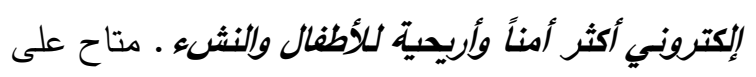

https://www.unicef.org/egypt/ar/protecting-children-cyberbullying-internet-safety يونيسف مصر(·r.r.ب). إطلاق حملة لتعزيز الاستخدام الآمن للإنترنت للأطفال في اليوم العالمي للطفلة. متاح على مانى

https://www.unicef.org/egypt/ar/press-releases/campaign-promoting-safer-internetuse-children-launches-international-day-girl-child

\section{ثانياً: المراجع الأجنبية}

Broadband Commission for Sustainable Development (2019). Child Online Safety Universal Declaration: Child safety is everyone's business. Retrieved from https://broadbandcommission.org/Documents/workinggroups/ChildOnlineSafety_Declaration.pdf

Broadband Commission for Sustainable Development (2021). Who we are. Retrieved from https://www.broadbandcommission.org/about-us/

Child Rights Connect (2020). Our Organisation. Retrieved from https://www.childrightsconnect.org/organisation/ 
Creative Commons (2020). What we do. Retrieved from https://creativecommons.org/about/

DQ Institute (2020).DQ (Digital Intelligence): World's first global standard on digital literacy, digital skills, and digital readiness (IEEE 3527.1 Standard). Retrieved from

https://www.dqinstitute.org/global-standards/\#contentblock1

ECPAT International (2016). A global network with one goal. Retrieved from https://www.ecpat.org/

eSafety Commissioner (2019a). Hector's World: About this resource. Australia: Author.

eSafety Commissioner (2019b). Hector's World lesson plans: Teacher guide. Australia: Author.

Haber, E.(2020). The internet of children: Protecting children's privacy in a hyperconnected world. University of Illinois Law Review, 4, 1209-1248.

International Telecommunication Union (ITU) (2020). Guidelines for parents and educators on Child Online Protection. Geneva: Author.

International Telecommunication Union (ITU) (2021). About the Child Online Protection Initiative. Retrieved from https://www.itu.int/en/cop/Pages/about_cop.aspx

LERNPRIVACY (2020). Secrets Are Allowed: A teaching aid on the topic of data privacy for cycle 1. Switzerland: Author.

London School of Economics and Political Science (2019). Children's data and privacy online: Growing up in a digital age. Research findings. London: Author.

OpenView Education (2020).The Internet Owl: Be Kind Online (EYFS/KS1).UK: Author.

Power of Zero (2018). The Power of Kindness program. USA: SCHOLASTIC.

National Online Safety (NOS) (2019a). Lesson Plans Bundle for Early Years (Age 0-4).UK: Author.

National Online Safety (NOS) (2019b). Lesson Plans Bundle for Key Stage 1 (Age 5-7) .UK: Author.

Purple Mash (2019). Education for a connected world with Purple Mash. UK: Author.

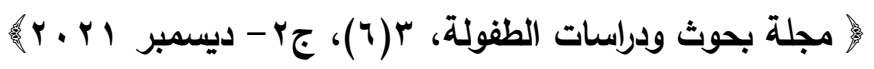




\section{كلية التربية للطقولة المبكرة- جامعة بني سويف}

South West Grid (SWGfL) (2020).PROJECT EVOLVE Toolkit. UK: Author.

Safer Internet Day (SID) (2021). About Safer Internet Day. Retrieved from https://www.saferinternetday.org/about

Thinkuknow (2020). Jessie \& Friends: online safety education for 4-7s.UK: CEOP.

UK Council for Child Internet Safety (UKCCIS) (2018). Education for a Connected World: A framework to equip children and young people for digital life. UK: Author.

UK Council for Internet Safety (UKCIS) (2020). Education for a Connected World - 2020 edition: A framework to equip children and young people for digital life. UK: Author.

UK Safer Internet Centre (2018). UK Government launches new Education Framework for a Connected World. UK: Author.

United Nations Children's Fund (UNICEF) (2019).Growing up in a connected world. Paris: Author. 